INSTITUTO DE PESQUISAS ENERGÉTICAS E NUCLEARES

Autarquia Associada à Universidade de São Paulo

\title{
ESTUDO DA DISTRIBUIÇÃO DE ÍONS E METAIS EM SANGUE VIA METODOLOGIA NUCLEAR
}

Laura Cristina de Oliveira

Tese apresentada como parte dos requisitos para obtenção do Grau de Doutor em Ciências na Área de Tecnologia Nuclear - Aplicações.

Orientadora:

Dra. Cibele Bugno Zamboni

São Paulo 2008 
"O prazer do trabalho aperfeiçoa a obra"

(Aristóteles)

Dedico com carinho este trabalho à minha filha Melissa 


\section{Agradecimentos}

Diversas pessoas contribuíram direta e indiretamente para que este trabalho fosse viável. Em especial gostaria de agradecer:

À Dra. Cibele Bugno Zamboni, pela orientação, incentivo e apoio, indispensáveis para a realização deste trabalho.

Aos colegas do LEER, Agostinho, Ilca, Fred, Guilherme, Luciana, Rodrigo, Tatiana e Wagner pela amizade e auxílio no desenvolvimento deste trabalho.

Aos colegas Cláudio e Fábio pela colaboração e amizade.

Ao corpo técnico do reator IEA-R1m e Proteção Radiológica pelo pronto atendimento nas irradiações.

Ao pessoal da CPG pela colaboração.

Ao IPEN/CNEN por possibilitar a realização deste trabalho.

Ao CNPq pelo apoio financeiro.

À equipe técnica do Banco de Sangue Paulista - SP e a Fundação HEMOPE - PE pelo auxílio na coleta das amostras.

À Melissa, que é a minha luz, que veio ao mundo no meio desta ventura e me deu muita força e razão para continuar.

Aos meus pais e irmãos pelo carinho e apoio em todos os momentos.

Ao Marco pelo companheirismo.

E a todos que a minha memória não conseguiu incluir nesta lista, mas que merecem um carinhoso reconhecimento. 


\section{ESTUDO DA DISTRIBUIÇÃO DE ÍONS E METAIS EM SANGUE VIA METODOLOGIA NUCLEAR}

\section{Laura Cristina de Oliveira}

\section{RESUMO}

O presente estudo consiste na utilização de ferramentas nucleares com o intuito de fornecer um procedimento alternativo para realização de análises bioquímicas em sangue que possam auxiliar no diagnóstico de patologias diversas.

O objetivo é medir a ocorrência de metais e íons em sangue total de humanos, via ativação neutrônica, disponibilizando os limites de normalidade bem como as correlações entre eles. Para realização deste estudo 283 amostras de sangue total foram analisadas (doadas de indivíduos selecionados em bancos de sangue) obtendo-se os limites de normalidade para: $\operatorname{Br}\left(0,0067-0,0263 \mathrm{gl}^{-1}\right), \mathrm{Cl}\left(2,54-3,50 \mathrm{gl}^{-1}\right), \mathrm{K}\left(1,33-1,89 \mathrm{gl}^{-1}\right)$ e $\mathrm{Na}\left(1,48-2,06 \mathrm{gl}^{-1}\right)$. Esses dados constituem as primeiras estimativas realistas para valor de referência em sangue total da população brasileira. Esses limites foram avaliados em função do sexo e idade permitindo salientar as diferenças biológicas.

Os limites obtidos para $\mathrm{Br}, \mathrm{Cl}, \mathrm{K}$ e $\mathrm{Na}$ foram avaliados também entre diferentes populações, isto é, para duas regiões distintas: Sudeste (coleta realizada na cidade de São Paulo) e Nordeste (coleta realizada na cidade de Recife), locais escolhidos em função das similaridades (cidades de grande porte e industrializadas). Adicionalmente, foi realizado um estudo sistemático desses limites, no período de 4 (quatro) anos, na cidade de São Paulo; para esta finalidade a coleta foi realizada em função do tempo, dada a necessidade de atualização desses dados, pois esses elementos atuam como monitores ambientais.

Estimativas para $\mathrm{Ca}$ e $\mathrm{Fe}$ foram também propostas para um conjunto de 22 amostras de sangue total. 


\title{
STUDY OF THE DISTRIBUTION OF IONS AND METALS IN BLOOD USING NUCLEAR METHODOLOGY
}

\section{Laura Cristina de Oliveira}

\begin{abstract}
The present study consists of using nuclear tools aiming to establish an alternative procedure to perform biochemistry analyses in whole blood to help the diagnosis of diverses pathologies.

The aim is to determine the íons and metals concentrations in whole blood of human beings (specifically: $\mathrm{Br}, \mathrm{Cl}, \mathrm{K}$ e $\mathrm{Na}$ ), using neutron activation analysis, providing the limits of normality, as well as, the matrix of the correlation for these elements. To perform this study, 283 samples of whole blood had been analyzed (of healthy volunteers selected from blood banks), resulting in the limits of normality for $\mathrm{Br}\left(0.0067-0.0263 \mathrm{gl}^{-1}\right), \mathrm{Cl}(2.54-3.50$ $\left.\mathrm{gl}^{-1}\right), \mathrm{K}\left(1.33-1.89 \mathrm{gl}^{-1}\right)$ and $\mathrm{Na}\left(1.48-2.06 \mathrm{gl}^{-1}\right)$. These data are the first estimates for reference values in whole blood of the Brazilian population. These limits were evaluated in function of the sex and age for checking the biological differences.

The behavior of these limits was also evaluated for different populations, i.e., in two distinct regions: Southeast (blood collection carried out in São Paulo city) and Northeast (blood collection carried out in Recife city). These places were chosen in function of the similarities (cities with high concentration people and industrialized). Futhermorer, a systematic study of these limits was also evaluated, in the period of 4 (four) years, in São Paulo city. This analysis was elaborated in function of time due the necessity to update these data, therefore they act as monitorial ambient.

The estimation for $\mathrm{Ca}$ and $\mathrm{Fe}$ were also proposal for a set of 22 samples of whole blood.
\end{abstract}




\section{SUMÁRIO}

Página

INTRODUÇÃO

MOTIVAÇÕES RELACIONADAS À PROPOSIÇÃO DO ESTUDO 2

Capítulo 1: Aspectos Biológicos Fundamentais Para Avaliação Clínica Do

ORGANISMO 6

1.1 Composição e importância dos elementos presentes no organismo $\quad 6$

$1.2 \mathrm{O}$ papel dos minerais no organismo 9

1.3 Variações dos minerais no organismo \& Disfunções associadas

1.3.1 Distúrbios do equilíbrio hidroeletrolítico 12

1.3.2 Distúrbios associados ao ferro 15

1.3.3 Distúrbios associados ao bromo 15

CAPÍTULO 2: DESCRIÇÃo DA METODOLOGIA NUCLEAR 16

2.1 Procedimento semi-paramétrico de Análise por Ativação com Nêutrons $\quad 16$

2.2 Instrumentação nuclear

2.3 População de estudo $\quad 21$

2.4 Coleta e preparo das amostras 22

2.5 Procedimento experimental

2.6 Análise de dados 28

CAPÍTULO 3: MATERIAL DE REFERÊNCIA

3.1. Análise dos materiais de referência 29

CAPÍTULO 4: RESULTADOS 33

4.1 População em geral 33

4.2 Análise do elemento bromo em sangue 35

4.3 Análise do elemento cloro em sangue 39

4.4 Análise do elemento potássio em sangue $\ldots \ldots \ldots$

4.5 Análise do elemento sódio em sangue _ 47

4.6 Comparação entre regiões e gênero

4.7 Análise das correlações 55 
4.8 Análise dos elementos $\mathrm{Ca}$ e $\mathrm{Fe}$

CAPITULO 5: DisCUSSÃO

5.1 Vantagens do uso da AAN em bioquímica clínica $\quad 59$

5.2 Estudo do comportamento dos elementos medidos via AAN em sangue total $\quad 60$

5.2.1 Comportamento do elemento bromo em função do gênero, idade e localização geográfica

5.2.2 Comportamento do elemento cloro em função do gênero, idade e localização geográfica

5.2.3 Comportamento do elemento potássio em função do gênero, idade e localização geográfica

5.2.4 Comportamento do elemento sódio em função do gênero, idade e localização geográfica 61

5.3 Comparação com outras estimativas 62

5.4 Comparação sangue e soro 63

CAPITULO 6: CONCLUSÕES 66

$\begin{array}{ll}\text { ANEXO } 1 & 67\end{array}$

ANEXO 2

$\begin{array}{ll}\text { ANEXO } 3 & 69\end{array}$

ANEXO 4

ANEXO $5 \quad 71$

ANEXO 6

ANEXO 7

ANEXO $8 \quad 74$

ANEXO 9

REFERÊNCIAS BIBLIOGRÁFICAS 76 


\section{LISTA DE FIGURAS}

Página

Figura 1: Tabela periódica 8

Figura 2: Vista superior do detetor HPGE de $198 \mathrm{~cm}^{3}(\mathrm{FWHM}=1,87 \mathrm{keV}) \ldots 18$

Figura 3: Vista frontal do detetor HPGE de $198 \mathrm{~cm}^{3}(\mathrm{FWHM}=1,87 \mathrm{keV}) \quad 19$

Figura 4: Diagrama de blocos da instrumentação nuclear utilizada para aquisição dos espectros de radiação gama 19

Figura 5: Curva de eficiência do espectrômetro- $\gamma \ldots 20$

Figura 6: Dimensões da amostra de sangue total em papel de filtro _ _ _ 23

Figura 7: Amostras de sangue total em papel de filtro acondicionadas em recipiente apropriado 23

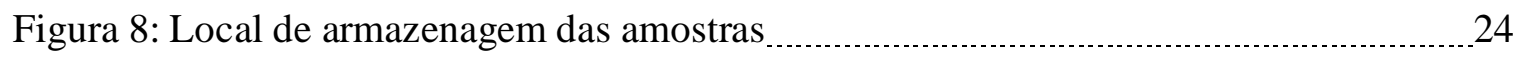

Figura 9: Cobertura de cádmio (em forma de disco); detetor de ativação (disco de ouro); Amostra de sangue total fixada em papel de filtro e cápsula de polietileno utilizada como dispositivo de irradiação

Figura 10a: Espectro- $\gamma$ (parcial) de sangue total irradiado por 3 minutos (fluxo $\sim 10^{11} \mathrm{n} . \mathrm{cm}^{-2} . \mathrm{s}^{-1}$ ), onde os picos não identificados em termos de energia correspondem ao $\mathrm{Bg}$ (radiação de fundo)

Figura 10b: Espectro- $\gamma$ (parcial) de sangue total irradiado por 2 horas

(fluxo de $\sim 10^{11}{ }^{n} \cdot \mathrm{cm}^{-2} \cdot \mathrm{s}^{-1}$ ), onde os picos não identificados em termos de energia correspondem ao Bg (radiação de fundo)

Figura 11: Concentração do elemento $\mathrm{Cl}$ nas amostras de padrão de sangue humano

(ICP-01B-03)

Figura 12: Concentração do elemento K nas amostras de padrão de sangue humano

(ICP-01B-03)

Figura 13: Concentração do elemento Na nas amostras de padrão de sangue humano (ICP-01B-03)

Figura 14: Representação via Box-plot para o elemento $\mathrm{Br}$ 36

Figura 15: Comportamento do $\mathrm{Br}$ em sangue total em função da faixa etária 37

Figura 16: Comportamento do $\mathrm{Br}$ em sangue total em função do sexo nas regiões 
monitoradas (Sudeste e Nordeste)

Figura 17: Monitoramento do $\mathrm{Br}$ em sangue total em função do tempo na cidade de São Paulo 38

Figura 18: Histograma e ajuste gaussiano da concentração de $\mathrm{Br}$. 38

Figura 19: Representação via Box-plot para o elemento $\mathrm{Cl}$ 40

Figura 20: Comportamento do $\mathrm{Cl}$ em sangue total em função da faixa etária 41

Figura 21: Comportamento do $\mathrm{Cl}$ em sangue total em função do sexo nas regiões monitoradas (Sudeste e Nordeste)

Figura 22: Monitoramento do $\mathrm{Cl}$ em sangue total em função do tempo na cidade de São Paulo

Figura 23: Histograma e ajuste gaussiano da concentração de $\mathrm{Cl}$ 42

Figura 24: Representação via Box-plot para o elemento K 44

Figura 25: Comportamento do K em sangue total em função da faixa etária 45

Figura 26: Comportamento do K em sangue total em função do sexo nas regiões monitoradas (Sudeste e Nordeste)

Figura 27: Monitoramento do K em sangue total em função do tempo na cidade de São Paulo 46

Figura 28: Histograma e ajuste gaussiano da concentração de K 46

Figura 29: Representação via Box-plot para $\mathrm{Na}$ 48

Figura 30: Comportamento do $\mathrm{Na}$ em sangue total em função da faixa etária 49

Figura 31: Comportamento do Na em sangue total em função do sexo nas regiões monitoradas (Sudeste e Nordeste)

Figura 32: Monitoramento do Na em sangue total em função do tempo na cidade de São Paulo 50

Figura 33: Histograma e ajuste gaussiano da concentração de $\mathrm{Na}$ 50

Figura 34: Comparação sangue total - soro para os elementos $\mathrm{Cl}, \mathrm{K}$ e $\mathrm{Na}$ 64 


\section{LISTA DE TABELAS}

Página

Tabela 1: Exames bioquímicos amplamente empregados para o acompanhamento das funções biológicas

Tabela 2: Valores de referência (normalidade) associados aos principais elementos presentes no organismo

Tabela 3: Análise do material de referência (ICP-04S-06) usando AAN 30

Tabela 4: Análise do material de referência (ICP-01B-03) usando AAN 30

Tabela 5: Resultados dos elementos $\mathrm{Br}, \mathrm{Cl}, \mathrm{K}$ e Na medidos em sangue total usando

AAN 34

Tabela 6: Tratamento estatístico para $\mathrm{Br}$ em sangue total dos dados obtidos via AAN 35

Tabela 7: Intervalo de referência para Br em sangue total usando AAN para a população brasileira e diferentes regiões do Brasil 36

Tabela 8: Tratamento estatístico para $\mathrm{Cl}$ em sangue total dos dados obtidos via AAN 39

Tabela 9: Intervalo de referência para $\mathrm{Cl}$ em sangue total usando AAN para a população brasileira e diferentes regiões do Brasil 40

Tabela 10: Tratamento estatístico para K em sangue total dos dados obtidos via AAN 43

Tabela 11: Intervalo de referência para K em sangue total usando AAN para a população brasileira e diferentes regiões do Brasil

Tabela 12: Tratamento estatístico para Na em sangue total dos dados obtidos via AAN $\quad 47$

Tabela 13: Intervalo de referência para $\mathrm{Na}$ em sangue total usando AAN para a população brasileira e diferentes regiões do Brasil......

Tabela 14: Resultados do Teste t para o elemento $\mathrm{Br}$ em sangue total em função do gênero

Tabela 15: Resultados do Teste t para o elemento $\mathrm{Br}$ em sangue total em função da região. 
Tabela 16: Resultados do Teste t para o elemento $\mathrm{Cl}$ em sangue total em função do gênero

Tabela 17: Resultados do Teste t para o elemento $\mathrm{Cl}$ em sangue total em função da região

Tabela 18: Resultados do Teste t para o elemento K em sangue total em função do gênero

Tabela 19: Resultados do Teste t para o elemento K em sangue total em função da região

Tabela 20: Resultados do Teste t para o elemento Na em sangue total em função do gênero

Tabela 21: Resultados do Teste t para o elemento Na em sangue total em função da região

Tabela 22: Matriz de correlação para $\mathrm{Br}, \mathrm{Cl}, \mathrm{K}$ e Na em sangue total para toda população de estudo

Tabela 23: Matriz de correlação para $\mathrm{Br}, \mathrm{Cl}, \mathrm{K}$ e Na em sangue total para o gênero feminino

Tabela 24: Matriz de correlação para $\mathrm{Br}, \mathrm{Cl}, \mathrm{K}$ e $\mathrm{Na}$ em sangue total para o gênero masculino

Tabela 25: Matriz de correlação para $\mathrm{Br}, \mathrm{Cl}, \mathrm{K}$ e $\mathrm{Na}$ em sangue total para a região Sudeste

Tabela 26: Matriz de correlação para $\mathrm{Br}, \mathrm{Cl}, \mathrm{K}$ e $\mathrm{Na}$ em sangue total para a região

Nordeste

Tabela 27: Concentração dos elementos Ca e Fe em sangue total usando AAN 58

Tabela 28: Sumário dos dados relacionados ao valor de referência em sangue total 63

Tabela 29: Comparação dos resultados das análises bioquímicas em soro e sangue para a população brasileira pela técnica de AAN 


\section{INTRODUÇÃO}

A presença de metais no corpo humano pode ser aferida em análises laboratoriais convencionais de sangue, urina e em análises invasivas como as biópsias [13], sendo que a acurácia de cada método de análise varia de elemento para elemento. Entretanto, desde o início da década de 60, outras técnicas como a Análise por Ativação com Nêutrons (AAN), Proton Induced X-Ray Emission (PIXE), Fluorescência de Raios X e outros métodos atômicos têm sido empregados em pesquisas na área médica para detectar metais com a finalidade de relacioná-los a possíveis disfunções. Estas pesquisas têm se complementado fazendo uso de outras ferramentas, como o tratamento estatístico de dados, que permitem correlacionar o comportamento dos metais em organismos saudáveis e debilitados, na tentativa de associar disfunções a variações desses elementos [4-13].

Dentre os estudos realizados utilizando a técnica AAN dois estudos recentes apresentam resultados de relevância em clínica [12,13]. Mihai e outros [12] calcularam as matrizes de correlação para elementos traços em sangue total de indivíduos "sadios" e com "diabetes". As correlações obtidas neste estudo indicam que as concentrações dos elementos medidos no sangue podem ser um marcador da anomalia em questão. Outro estudo utilizando AAN foi realizado por Popescu e outros [13] no qual é feita uma análise da relação entre as covariâncias dos elementos traços $\mathrm{Mn} / \mathrm{Se}$ no estudo de anomalias no pâncreas e no nervo ciático entre indivíduos saudáveis e anêmicos.

Têm-se também resultados importantes com o emprego de outros métodos analíticos. Um estudo realizado por Mousavi-Yeganeh [14] utilizando a técnica PIXE apresenta as comparações entre os elementos medidos em indivíduos "normais" e "dependentes" (usuários de drogas) em sangue total, mostrando que essa avaliação fornece também subsídios para realização de diagnóstico. Da mesma forma, Hasegawa e outros [15] utilizando as técnicas Inductively Coupled Plasma Atomic Emission Spectroscopy (ICP-AES) e Inductively Coupled Plasma Mass Spectrometry (ICP-MS), para análise de elementos traços majoritários em soro de pacientes saudáveis e com Linfoma 
Non-Hodgkin viabilizaram um diagnóstico baseado nas correlações multielementares entre os elementos medidos.

Portanto, investigações em bioquímica clínica envolvendo metodologias alternativas vêm sendo realizadas, principalmente em soro e sangue, com o intuito de avaliar e/ou implantar outros métodos analíticos, bem como o emprego de tratamento estatístico, permitindo aprimorar e/ou complementar seu diagnóstico.

\section{Motivações relacionadas à proposição do estudo}

O diagnóstico tradicional de certas disfunções que afetam significativamente a população brasileira, como por exemplo, anemia, distúrbios renais e parasitoses, podem demandar dias para obtenção do resultado final, sendo para boa parte da população um processo oneroso. No caso das análises convencionais, como os exames bioquímicos apresentados na TAB. 1, nota-se que a execução dessas análises requer o processamento da amostra biológica, isto é, uso de anticoagulantes, separação soro-plasma, refrigeração, quantidades de material biológico (soro/plasma) da ordem de $5 \mathrm{ml}$ ou mais (em função do número de exames a serem realizados), além de demandar dias para obtenção dos resultados [2-3]. Portanto, a busca por processos para a realização de análises bioquímicas que possam minimizar interferentes pré-analíticos (transporte, separação soro/plasma, armazenamento, etc) e com isso permitir um diagnóstico mais rápido e de baixo custo, em prática clínica, fundamental em pesquisas na área médica. 
TABELA 1 - Exames bioquímicos amplamente empregados para o acompanhamento das funções biológicas.

\begin{tabular}{|c|c|c|c|c|}
\hline $\begin{array}{l}\text { Exame } \\
\text { Clínico }\end{array}$ & $\begin{array}{c}\text { Material Biológico/ } \\
\text { quantidade }\end{array}$ & Diagnóstico & $\begin{array}{c}\text { Elemento medido/ } \\
\text { Método [2-3] }\end{array}$ & $\begin{array}{c}\text { Tempo execução } \\
\text { (dias) / } \\
\text { Custo*(R\$) }\end{array}$ \\
\hline Brometo & sangue total / 4,0 ml & $\begin{array}{l}\text { Avaliação de toxicidade } \\
\text { em decorrência de } \\
\text { ingestão. }\end{array}$ & $\begin{array}{c}\mathrm{Br} / \\
\text { Colorimétrico }\end{array}$ & $15 / 265,08$ \\
\hline Cálcio & soro / 0,5 ml & $\begin{array}{l}\text { Útil no diagnóstico de } \\
\text { distúrbios do } \\
\text { metabolismo de } \mathrm{Ca} \text {, } \\
\text { como doenças ósseas e } \\
\text { do rim. }\end{array}$ & $\begin{array}{l}\text { Ca / } \\
\text { Colorimétrico, } \\
\text { Química seca }\end{array}$ & $1 / 45,00$ \\
\hline Cloro & soro / 0,5 ml & $\begin{array}{l}\text { Avaliação do equilíbrio } \\
\text { hídrico, eletrolítico e } \\
\text { ácido básico. }\end{array}$ & $\begin{array}{c}\mathrm{Cl} / \\
\text { Potenciométrico, } \\
\text { Química seca }\end{array}$ & $1 / 50,50$ \\
\hline Potássio & soro / $1,0 \mathrm{ml}$ & $\begin{array}{l}\text { Avaliação do equilíbrio } \\
\text { hídrico, eletrolítico e } \\
\text { ácido básico, também em } \\
\text { nefropatias como } \\
\text { insuficiência renal. }\end{array}$ & $\begin{array}{c}\text { K/ } \\
\text { Potenciométrico, } \\
\text { Química seca }\end{array}$ & $1 / 46,23$ \\
\hline Ferro & soro / $1,0 \mathrm{ml}$ & $\begin{array}{c}\text { Útil na avaliação de } \\
\text { anemias }\end{array}$ & $\begin{array}{c}\mathrm{Fe} / \\
\text { Química seca }\end{array}$ & $1 / 48,00$ \\
\hline Sódio & Soro ou plasma / 3,0 ml & $\begin{array}{l}\text { Avaliação do equilíbrio } \\
\text { hídrico e eletrolítico. }\end{array}$ & $\begin{array}{c}\mathrm{Na} / \\
\text { Potenciométrico, } \\
\text { Química seca }\end{array}$ & $1 / 43,22$ \\
\hline
\end{tabular}

(* Preços praticados pelo Laboratório Fleury, atualizado em 12/10/2007) 
Nos últimos anos o Laboratório de Espectroscopia e Espectrometria das Radiações - IPEN (LEER) também tem se dedicado a realizar pesquisa aplicada em Física Nuclear junto à área Médica [4,16-33], visando um maior conhecimento sobre os processos de desenvolvimento de patologias bem como a obtenção de diagnósticos mais rápidos e sensíveis. Um dos trabalhos relevantes nesta área está relacionado ao desenvolvimento de metodologia nuclear para realização de análises bioquímicas em amostras de sangue [26].

O bom desempenho do método nuclear aplicado no estudo de problemas de saúde pública no Brasil como, por exemplo, a ocorrência de anemias [31,32] e a elevada taxa de indivíduos portadores de disfunção renal [28] motivaram a continuidade dessas aplicações.

Com base nisto, no presente estudo é utilizado um método nuclear, especificamente o procedimento semi-paramétrico de Análise por Ativação com Nêutrons, com o objetivo de estabelecer os valores de referência (VR) em sangue total para população brasileira, para posterior uso desses indicadores na realização de análise bioquímica utilizando sangue total. Em decorrência, torna-se possível estudar em mais detalhes os valores de referência de deficiências comuns da população brasileira aprimorando seu diagnóstico.

A necessidade de realizar medida referente ao intervalo de normalidade (valores de referência) em sangue total esta relacionada ao fato de que a maioria das análises convencionais na área de bioquímica clínica é realizada principalmente em soro e/ou plasma (TAB. 1), não sendo, portanto, conhecido o limite de normalidade em sangue total da população brasileira.

Este estudo faz parte de um projeto multidisciplinar denominado "Aplicação de Metodologia Nuclear para realização de Análises Clínicas em Materiais Biológicos de interesse na Área da Saúde: pré-diagnóstico e Medicina Preventiva". Participam do projeto a Universidade de Santo Amaro (UNISA), o Centro Regional de Ciências Nucleares (CRCN), o Banco de Sangue Paulista em São Paulo - SP, o Hemocentro de Recife - PE (HEMOPE), Instituto Butantan, Laboratório PIXE do IFUSP e a Universidade de Berkeley (USA). 
O objetivo do trabalho consiste em medir a ocorrência de metais e íons em sangue total, via AAN, em organismos saudáveis e estabelecer os valores de referência, isto é, "Limites de Normalidade em Sangue Total" para cada elemento medido e a partir desses dados obter as correlações existentes entre esses elementos.

Os elementos $\mathrm{Br}, \mathrm{Ca}, \mathrm{Cl}, \mathrm{Fe}, \mathrm{K}$ e $\mathrm{Na}$ foram selecionados para este estudo, pois são de grande relevância na prática clínica.

O estudo divide-se em duas etapas: espectrometria gama de amostras de sangue total de organismos saudáveis para obtenção dos valores de referência (limites de normalidade) e elaboração das matrizes de correlação.

A abordagem do texto é feita em 6 capítulos. No capítulo 1 são apresentados os aspectos biológicos que mostram a relevância dos elementos selecionados para análise em sangue total. No capítulo 2 é feita a descrição da metodologia nuclear aplicada e a descrição do experimento: população de estudo, coleta e preparo das amostras, detalhes do arranjo experimental e a análise de dados. No capítulo 3 são apresentadas as medidas que permitem checar o desempenho do aparato experimental, bem como a validação do método utilizando materiais de referência (padrões biológicos de sangue e soro humano). No capítulo 4 são apresentados os resultados. No capítulo 5 é feita a discussão dos resultados e no capítulo 6 são apresentadas as conclusões. Na seqüência são apresentados os anexos e as referências. 


\section{CAPITULO 1. ASPECTOS BIOLÓGICOS FUNDAMENTAIS PARA AVALIAÇÃO CLÍNICA DO ORGANISMO}

\subsection{Composição e importância dos elementos presentes no organismo}

A água e a matéria orgânica responsável pela estrutura do corpo como proteínas, ácidos nucléicos, gorduras e carboidratos, contêm a maior parte do oxigênio, hidrogênio, carbono e nitrogênio e em menor parte enxofre e fósforo. Já os compostos minerais do esqueleto, junto com íons dissolvidos, constituem a pequena porcentagem restante. Assim, os elementos, oxigênio, carbono, hidrogênio e nitrogênio, constituem 96\% do peso corpóreo total de um mamífero, enquanto que os elementos cálcio, fósforo, potássio, enxofre, sódio, cloro e magnésio, nesta ordem, constituem quase que os $4 \%$ restantes. Embora esses elementos sejam necessários para a manutenção saudável do organismo, a quantidade total desses elementos no corpo dos mamíferos é de menos de $0,01 \%$ de sua massa corpórea [34].

Os íons quantitativamente mais importantes nos organismos (animais) são sódio, potássio e cloro. O sódio é o principal cátion no sangue e nos fluídos extracelulares, enquanto o potássio é o cátion dominante no espaço intracelular. O cloro, na forma de cloretos, formado nos fluídos corpóreos (principalmente os cloretos de sódio e de potássio), apresenta-se normalmente mais elevado no meio extracelular e pode variar em função dos níveis de sódio e potássio no organismo $(\mathrm{NaCl}$ e $\mathrm{KCl})$. Em decorrência, a manutenção das concentrações normais de íons sódio e cloro é necessária para o equilíbrio osmótico dos organismos enquanto que a manutenção de concentrações normais de íons potássio e cloro é necessária para o equilíbrio eletrolítico.

A relevância dos íons de cálcio, magnésio e fósforo no organismo está diretamente relacionada aos processos fisiológicos e, conseqüentemente, variações em suas concentrações podem ser deletérias ou até fatais. 
Pode-se avaliar a normalidade, isto é, a condição de saudável dos organismos, a partir da monitoração dos níveis desses elementos em fluidos corpóreos, usualmente urina e soro na prática clinica. Esta verificação é realizada a partir de análises bioquímicas onde os limites de normalidade para os seres humanos são bem estabelecidos [2-3].

Há também os chamados microelementos, que se encontram em quantidades tão pequenas que alguns métodos analíticos no passado não eram suficientemente acurados para uma análise precisa. Hoje, com a disponibilidade de novas tecnologias, existem métodos de maior sensibilidade. Em particular, com o auxílio dos radioisótopos, tornou-se possível determinar microelementos de forma mais acurada, esclarecendo seus papéis fisiológicos e bioquímicos [34]. Entretanto, alguns microelementos são necessários em quantidades muito pequenas tornando-se difícil planejar uma dieta balanceada.

Os microelementos podem ser divididos em 3 grupos:

- Os essenciais;

- $\quad$ Os com efeitos metabólicos, mas não indispensáveis;

- E os que se encontram amplamente distribuídos nos organismos vivos, mas que parecem ser apenas contaminantes.

Todos esses elementos são considerados essenciais tanto para a vida humana como para os demais organismos. Mas, para que se considere um elemento químico essencial este deve cumprir quatro condições [34]:

- A ingestão insuficiente do elemento provoca deficiências funcionais, reversíveis se o elemento retornar para os valores das concentrações adequadas;

- $\quad$ Sem o elemento, o organismo não cresce e nem completa o seu ciclo vital;

- $\quad$ O elemento influi diretamente no organismo e está envolvido em seus processos metabólicos;

- $\quad$ O mesmo efeito no organismo não pode ser conseguido por nenhum outro elemento.

A maioria dos elementos que compõe os seres vivos são denominados elementos organógenos ou bioelementos. Geralmente são classificados segundo a sua abundância em majoritários, traços e microtraços, sendo esses dois últimos também denominados oligoelementos [34]. 
- Majoritários: oxigênio, carbono, hidrogênio, nitrogênio, cálcio, fósforo, enxofre, potássio, sódio, cloro e magnésio.

- Traços: ferro, zinco, cobre, flúor, bromo e selênio.

- Microtraços (ultratraços): iodo, manganês, vanádio, silício, arsênio, boro, níquel, cromo, molibdênio e cobalto.

Há também elementos como lítio, cádmio e estanho sem uma essencialidade muito clara. Outro aspecto relevante a ser considerado é que nem todos os seres vivos têm os mesmos elementos essenciais no seu organismo.

Na FIG. 1 a seguir estão destacados os elementos essenciais aos animais, assim como alguns outros cuja essencialidade está sendo discutida [34].

$\underline{\mathrm{Li}} \mathrm{Be}$

$\underline{\mathrm{Na}} \quad \underline{\mathrm{Mg}}$
$\underline{B} \quad \underline{C} \quad \underline{N} \quad \underline{O} \quad \underline{F} \quad \mathrm{Ne}$

Al $\quad \underline{\mathrm{Si}} \quad \underline{\mathrm{P}} \underline{\mathrm{S}} \quad \underline{\mathrm{Cl}} \mathrm{Ar}$

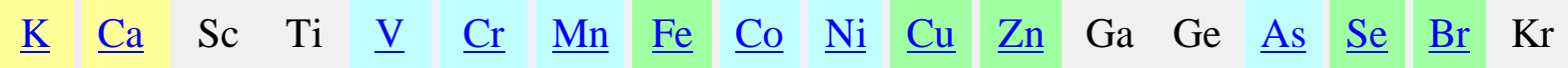
$\begin{array}{llllllllllllllllll}\mathrm{Rb} & \mathrm{Sr} & \mathrm{Y} & \mathrm{Zr} & \mathrm{Nb} & \underline{\mathrm{Mo}} & \mathrm{Tc} & \mathrm{Ru} & \mathrm{Rh} & \mathrm{Pd} & \mathrm{Ag} & \underline{\mathrm{Cd}} & \mathrm{In} & \underline{\mathrm{Sn}} & \mathrm{Sb} & \mathrm{Te} & \underline{\mathrm{I}} & \mathrm{Xe}\end{array}$

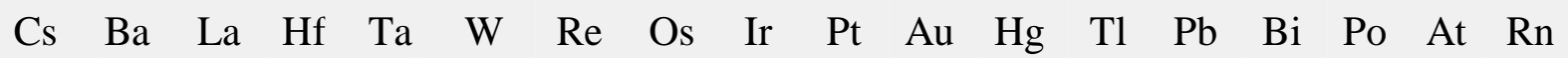
Fr $\quad$ Ra Ac

\begin{tabular}{c|c|c|c} 
Elemento & Elemento & $\begin{array}{c}\text { Elemento } \\
\text { majoritário }\end{array}$ & $\begin{array}{c}\text { Essencialidade } \\
\text { traço }\end{array}$ \\
microtraço & discutida
\end{tabular}

FIGURA 1 - Tabela periódica.

Qualquer elemento, essencial ou não, pode ser tóxico a partir de determinadas concentrações. Por isso, para cada elemento químico essencial existe uma faixa de concentração considerada ótima para um organismo. Nesta faixa de concentração o organismo consegue desenvolver corretamente as funções que dependem deste elemento. Desta forma o elemento não pode estar em concentração excessivamente alta para que não 
produza efeitos tóxicos e nem abaixo, pois sua deficiência pode ter como consequência efeitos patológicos. Portanto, tanto acima como abaixo desta faixa ótima os organismos ficam sujeitos a efeitos patológicos que podem levar à morte.

Num organismo os níveis ótimos de um elemento se mantêm mediante "mecanismos homeostáticos", o que possibilita o controle de absorção, armazenamento e excreção dos elementos. Entretanto, a deficiência ou excesso de um elemento, devido principalmente a dieta, pode gerar problemas nos mecanismos de absorção ou outras anomalias no organismo.

\subsection{O papel dos minerais no organismo}

Minerais são elementos químicos, que participam na formação e na regulação das funções do organismo. A suplementação medicamentosa de minerais, assim como a de vitaminas, deve ser evitada, pois a dieta equilibrada com variação dos alimentos contém todos os minerais necessários ao organismo em quantidades suficientes.

Dada a importância desses íons no organismo, é importante conhecer as funções a que se destinam. Particularmente, neste estudo serão enfocados os elementos selecionados para a análise.

\section{Bromo}

Sua avaliação pode ser útil no monitoramento nutricional, pois está diretamente relacionado aos hábitos alimentares. Embora esteja em concentrações muito baixas nos organismos (TAB. 2), níveis acima do limite de normalidade são relacionados principalmente a ingestão de antidepressivos e soníferos (brometos são empregado na fabricação de drogas medicinais) cada vez mais utilizados pela população.

Excesso: intoxicação

Fonte: frutos do mar 


\section{Cálcio}

Função: construção dos ossos e dentes, manutenção dos ossos, contração muscular, manutenção das membranas das células, coagulação do sangue, absorção da vitamina B2, ativação de enzimas.

Deficiência: raquitismo nas crianças, osteoporose e maior risco de fraturas nos adultos. Excesso: tontura, letargia, redução da absorção de ferro, zinco e manganês, acúmulo de cálcio nos tecidos do organismo.

Fonte: leite e derivados (iogurtes e queijos), peixes enlatados com os ossos (sardinha, salmão), mandioca, mostarda em folha, salsinha, brócolis e feijão.

\section{Cloro}

Função: regulação do líquido extracelular, manutenção do equilíbrio ácido-básico, formação do ácido clorídrico $(\mathrm{HCl})$ do estômago, que tem papel importante na digestão dos alimentos, entre outros.

Excesso: destrói a vitamina E, e reduz o Iodo; vômitos.

Fonte: sal, vegetais e alimentos industrializados.

\section{$\underline{\text { Ferro }}$}

Função: formação da hemoglobina (célula vermelha do sangue) que carrega o oxigênio no organismo e da mioglobina (célula do músculo), formação de enzimas e proteínas. Deficiência: anemia com fadiga, fraqueza, descoramento, respiração difícil. Excesso: náusea, vômito, diarréia, taquicardia, tontura, confusão.

Fonte: fígado, gema de ovo, nozes, ostra, feijão, carne, aveia e aspargo. 


\section{Potássio}

Função: manutenção do líquido intracelular e balanço eletrolítico nas células, integridade celular, contração muscular, transmissão de impulsos nervosos.

Deficiência: fraqueza muscular, paralisia, letargia.

Excesso: fraqueza muscular, vômito, ritmo cardíaco desregulado.

Fonte: espinafre, feijão, melancia, beterraba, brócolis, abobrinha, banana, couve-flor, leite, salsinha, tomate e cenoura.

\section{Sódio}

Função: regulação do líquido extracelular, manutenção do equilíbrio ácido-básico, transmissão nervosa, contração muscular.

Deficiência: câimbra, apatia mental, perda de apetite.

Excesso: edema, hipertensão aguda.

Fonte: sal, vegetais e alimentos industrializados.

Em um organismo sadio os elementos constituintes encontram-se dentro dos limites de normalidade apresentados na TAB. 2. Esta tabela contém informações a respeito do elemento e do material biológico (primeira coluna); do isótopo que pode ser quantificado via AAN (segunda coluna) e dos valores de normalidade (terceira coluna). 
TABELA 2 - Valores de referência (normalidade) associados aos principais elementos presentes no organismo.

\begin{tabular}{|c|c|c|}
\hline $\begin{array}{c}\text { Elemento/ } \\
\text { material biológico }\end{array}$ & $\begin{array}{l}\text { Características dos } \\
\text { radionuclídeos } \\
{\left[\mathrm{T}_{1 / 2}\right] ; \mathrm{E}_{\gamma}(\mathrm{keV})[35]}\end{array}$ & Limites de normalidade [2-3] \\
\hline $\begin{array}{c}\text { Bromo (brometos) / } \\
\text { sangue }\end{array}$ & ${ }^{80} \mathrm{Br}(17,68 \mathrm{~min}) ; 616$ & $\begin{array}{c}1-2 \mathrm{mg} / \mathrm{ml} \\
\text { (níveis terapêuticos) }\end{array}$ \\
\hline Cálcio / soro & ${ }^{49} \mathrm{Ca}(8,7 \mathrm{~min}) ; 3084$ & $8,4-10,2 \mathrm{mg} / \mathrm{dl}$ \\
\hline Cloro / soro & ${ }^{38} \mathrm{Cl}$ (37min); 1642 & $97-106 \mathrm{mEq} / 1$ \\
\hline Ferro / soro & ${ }^{59} \mathrm{Fe}(44 \mathrm{~d}) ; 1099$ & $\begin{array}{l}\mathrm{F}: 37-170 \mathrm{mg} / \mathrm{dl} \\
\mathrm{M}: 49-181 \mathrm{mg} / \mathrm{dl}\end{array}$ \\
\hline Potássio / soro & ${ }^{42} \mathrm{~K}(12,2 \mathrm{~h}) ; 1525$ & $3,6-5,0 \mathrm{mEq} / 1$ \\
\hline Sódio / soro & ${ }^{24} \mathrm{Na}(15 \mathrm{~h}) ; 1368$ & $137-145 \mathrm{mEq} / \mathrm{l}$ \\
\hline
\end{tabular}

F: feminino

M: masculino

\subsection{Variações dos minerais no organismo \& Disfunções associadas}

\subsubsection{Distúrbios do equilíbrio hidroeletrolítico}

Um aspecto importante relacionado a um organismo sadio diz respeito a manutenção do equilíbrio hídrico, que requer $2 / 3$ da água do corpo no interior das células e $1 / 3$ restante fora. Este balanço de líquidos no organismo permite a eliminação de até 2400 $\mathrm{ml}$ de água por dia, sendo da ordem de $1500 \mathrm{ml}$ sob a forma de urina, $~ 800 \mathrm{ml}$ através dos pulmões e superfície da pele e o restante $(\sim 100 \mathrm{ml})$ pelas fezes e sua reposição via 
alimentos e bebidas. Entretanto, quando as perdas excedem a reposição, desenvolve-se a desidratação.

$\mathrm{Na}$ área de Patologia Clínica, vários estudos destinam-se a determinar íons e/ou metais em fluídos biológicos diversos como: sangue, soro, plasma e urina, na tentativa de elucidar o metabolismo destes componentes nos organismos vivos, pois quase sempre, as suas variações (excesso ou deficiência) estão associadas a algum tipo de patologia em curso.

Como o $\mathrm{Na}$ e o $\mathrm{K}$ são os principais íons dos meios extra e intracelular, respectivamente, pequenas variações em suas concentrações podem levar a distúrbios diversos. Prioritariamente, a alteração de $\mathrm{Na}$ (hiponatremia e hipernatremia) e/ou de $\mathrm{K}$ (hipopotassemia e hiperpotassemia) no organismo leva a desordens no balanço da água.

O sódio é o íon mais importante no meio extracelular e sua manutenção sérica se dá em níveis restritos (136 a $145 \mathrm{mEq} / \mathrm{l})$. Como existe uma estreita relação entre a água e o sódio, pequenas alterações podem causar inúmeras disfunções no organismo. Dentre os sintomas que podem ser observados, tanto na hiponatremia como na hipernatremia, destacam-se os neurológicos.

A hiponatremia é definida como a concentração de sódio abaixo de seu limiar $(<136 \mathrm{mEq} / \mathrm{l})$. É associada a diferentes patologias e quase sempre é devida a retenção hídrica, como no caso da insuficiência renal crônica. Em casos de hiponatremia acentuada, onde ocorre rapidez na variação da concentração (diminuição em horas), pode haver a entrada de água para dentro das células levando ao edema cerebral.

A hipernatremia ocorre quando a concentração de sódio ultrapassa $145 \mathrm{mEq} / \mathrm{l}$. É comum em pacientes que apresentam dificuldade ou restrição para ingerir líquidos levando a desidratação. Em geral a hipernatremia, na vigência de insuficiência renal e a sobrecarga de volume, necessita do procedimento de diálise.

Os distúrbios relacionados ao potássio são, em geral, mais freqüentes do que ao sódio. Por ser um íon predominantemente intracelular sua concentração varia de 140 a 150 $\mathrm{mEq} / \mathrm{l}$, sendo no tecido muscular seu maior depósito, enquanto apenas $2 \%$ (3,5 a 5,0 
$\mathrm{mEq} / \mathrm{l}$ ) do potássio corporal encontra-se no espaço extracelular. Conseqüentemente, por ser mais abundante no meio intracelular, pequenas e rápidas variações transcelulares podem levar a significativas alterações no ritmo cardíaco e na função cardiovascular, pondo em risco a vida do paciente.

Os termos hipopotassemia ou hipocalemia são empregados quando a concentração de $\mathrm{K}$ é inferior a 3,5 $\mathrm{mEq} / \mathrm{l}$. Esse déficit resulta em perdas renais e gastrointestinais que podem levar a distúrbios em múltiplos órgãos e sistemas. Como agravante, os sinais e sintomas não aparecem habitualmente, até que a deficiência seja significativa. A hiperpotassemia ou hipercalemia é definida quando a concentração plasmática de potássio ultrapassa seu limite superior (> 5,0 $\mathrm{mEq} / \mathrm{l}$ ); do ponto de vista clínico pode manifestar-se desde a ausência de qualquer sintoma até parada cardíaca. É, freqüentemente, causada pelo aumento de potássio que sai das células ou pela diminuição de sua excreção pelo rim. As causas mais comuns são: insuficiência renal em fase final de evolução e o uso de medicamentos que retêm potássio (alguns diuréticos, suplementos de potássio, inibidores da enzima de conversão, e outros).

Em complementação, os distúrbios de cálcio (hipercalcemia e hipocalcemia), embora sejam menos danosos ao equilíbrio hidroeletrolítico podem levar também, em menor escala, a anomalias no rim, no tecido ósseo e no trato gastrointestinal, mas quando presente associam-se a elevado índice de morbi-mortalidade. A hipercalcemia é definida como concentração de cálcio acima de $10,5 \mathrm{mg} / \mathrm{dl}$ e, na maioria dos casos, corresponde a saída de $\mathrm{Ca}$ do osso e a absorção intestinal, comprometendo a liberação renal. A hipocalcemia é identificada quando os níveis séricos de cálcio encontram-se abaixo de 8,5 $\mathrm{mg} / \mathrm{dl}$ e, embora pouco freqüente, pode resultar em síndrome de choque térmico, em tumores e ainda em anormalidades nos níveis de magnésio e potássio, pois a troca de cálcio $\left(\mathrm{Ca}^{++}\right)$depende da concentração de $\mathrm{K} \mathrm{e} \mathrm{Mg}$.

Finalmente, outro íon de relevância, embora pouco utilizado na avaliação de distúrbios eletrolíticos, é o Cloro. Como normalmente está presente no sangue em forma de cloretos, sua monitoração é também útil, pois variações em sua concentração denominam, indiretamente, oscilações nos níveis de $\mathrm{Na}$ e/ou K e/ou Ca. 


\subsubsection{Distúrbios associados ao ferro}

O ferro é absorvido através da dieta e não possui via fisiológica de excreção. Em casos de carência de ferro (abaixo de $37 \mathrm{mg} / \mathrm{dl}$ ), desenvolve-se a anemia ferropriva. Por outro lado, qualquer falha no complexo mecanismo regulador da absorção do ferro ou de seu transporte orgânico, ou situações como a de múltiplas transfusões sanguíneas, geram um acúmulo de ferro orgânico que é potencialmente danoso ao organismo já que se combina com outros elementos (radicais livres) e se acumula em órgãos-alvo, como o fígado, o coração e o baço, por exemplo, caracterizando a hemocromatose.

O controle do ferro no organismo é feito através da sua medida em soro e sua faixa de normalidade oscila entre 37 a $181 \mathrm{mg} / \mathrm{dl}$.

Particularmente no Brasil, considerando-se que a deficiência de ferro é um problema de saúde pública, pois da ordem de $60 \%$ da população (principalmente crianças de 4 a 24 meses de idade, adolescentes do sexo feminino, gestantes e nutrizes) são portadoras de anemia ferropriva [36], sua avaliação clínica é de fundamental importância em patologia clínica.

\subsubsection{Distúrbios associados ao bromo}

Os limites de normalidade do elemento Bromo em sangue são estabelecidos a níveis terapêuticos $(1-2 \mathrm{mg} / \mathrm{ml})$. Sua monitoração clinica é necessária em casos de intoxicação, pois o excesso no organismo pode estar está relacionado à ingestão de antidepressivos e soníferos (medicamentos que contém brometos em sua formulação). Não apresenta limites de normalidade. 


\section{CAPITULO 2. DESCRIÇÃO DA METODOLOGIA NUCLEAR}

\subsection{Procedimento semi - paramétrico de Análise por Ativação com Nêutrons}

A indução de radioatividade em materiais utilizando nêutrons como feixe incidente é denominada ativação neutrônica [37,38]. Através deste procedimento pode-se obter informações da composição do material ativado.

Na prática, a técnica de Análise por Ativação com Nêutrons (AAN), consiste em irradiar um material com nêutrons e analisar a radiação $\gamma$ induzida após a ativação nuclear. $O$ material irradiado torna seus elementos constituintes radioativos, conseqüentemente, cada elemento radioativo formado emitirá radiação $\gamma$ característica, com energia de emissão bem estabelecida [35].

A partir do conhecimento da energia de emissão dessas radiações $\gamma$ e de sua respectiva meia-vida $\left(T_{1 / 2}\right)$ [35], isto é, o tempo necessário para que a radiação $\gamma$ reduza-se a metade, pode-se identificar o elemento radioativo presente. A etapa seguinte é sua quantificação utilizando outras propriedades associadas ao raio gama emitido como sua intensidade e eficiência.

O uso da técnica de ativação com nêutrons fornece informações qualitativas quantitativas dos materiais ativados. Mas, para a utilização deste método de análise é necessário o conhecimento do fluxo de nêutrons. Particularmente, para determinação de fluxo de nêutrons em reator térmico emprega-se a técnica da Razão de Cádmio [37-39]. A utilização deste procedimento permite a determinação do fluxo pela expressão: 
$\phi \mathbf{n}=\mathbf{A}^{\mathrm{au}} \cdot \mathbf{M}\left(\mathbf{1}-\mathbf{F}_{\mathrm{cd}} / \mathbf{R}_{\mathrm{cd}}\right) / \mathbf{m} \cdot \mathbf{N}_{\mathrm{A}} \cdot \sigma \cdot \mathbf{k t}$

onde:

$\phi$ n: fluxo de nêutrons

$\mathrm{A}^{\mathrm{Au}}$ : atividade de saturação do detetor de ativação (folha de Ouro)

M: peso atômico do ouro $(\mathrm{Au})$

$\mathrm{N}_{\mathrm{A}}$ : número de Avogadro

m: massa da amostra de ouro

$\mathrm{F}_{\mathrm{cd}}$ : fator de Cádmio, tabelado na referência [40]

$\mathrm{R}_{\mathrm{cd}}$ : a razão obtida experimentalmente pela irradiação das folhas de ouro (nua e coberta com Cádmio)

б: seção de choque de ativação (tabelado) [41]

$\mathrm{k}_{\mathrm{t}}$ : fator de perturbação do fluxo (tabelado) [42]

A medida da atividade pode ser obtida por um sistema de contagem conhecendo-se e eficiência de detecção da transição $\gamma$ de interesse usando a expressão:

$\mathbf{A}=\mathbf{C}_{\gamma} \cdot \lambda / \varepsilon_{\gamma} \cdot \mathbf{I}_{\gamma} \cdot\left(\mathbf{1}-\mathbf{e}^{-\lambda T i}\right) \cdot \mathbf{e}^{-\lambda T e} \cdot\left(1-\mathbf{e}^{-\lambda T c}\right)$

onde:

A: atividade do isótopo

$\mathrm{C}_{\gamma}$ : área da transição gama discriminada, obtida pelo programa de ajuste IDF [43]

$\lambda$ : constante de desintegração (tabelado) [35]

$\varepsilon_{\gamma}$ : eficiência de detecção na energia da transição gama discriminada

(medida experimentalmente)

$\mathrm{I}_{\gamma:}$ intensidade da transição gama discriminada (tabelada) [44]

Ti: tempo de irradiação (estabelecido)

Te: tempo de espera (intervalo de tempo que decorre entre o final da irradiação e o início da contagem)

Tc: tempo de contagem (estabelecido).

Desta forma, obtém-se a concentração dos elementos ativados, nas amostras biológicas em questão. 


\subsection{Instrumentação nuclear}

A instrumentação nuclear utilizada na aquisição dos espectros em energia da radiação - gama constitui-se de um espectrômetro - $\gamma$, um sistema eletrônico e um sistema de aquisição de dados descritos a seguir.

O espectrômetro- $\gamma$ mostrado nas FIG. 2 e 3 é constituído por um detetor de HPGE de $198 \mathrm{~cm}^{3}$ (FWHM = 1,87keV em $\left.1332 \mathrm{keV}\right)$, montado no interior de uma blindagem de chumbo. Este tipo de blindagem é necessário para minimizar a radiação de fundo do laboratório. Um suporte circular de lucite, centralizado sobre a face do detetor, sustenta a fonte a uma distância que atenua efeitos secundários de detecção como soma e empilhamento, causados pelas transições-gama mais intensas. Entre a fonte e o detetor não há nenhum tipo de absorvedor, o que minimiza os efeitos de absorção e espalhamento.

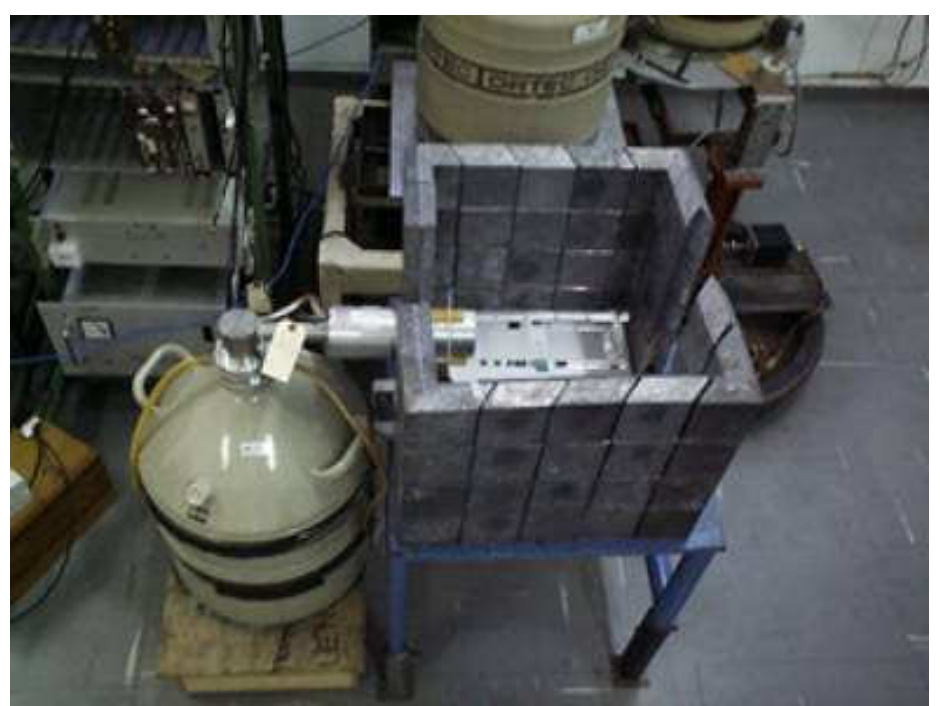

FIGURA 2 - Vista superior do detetor HPGE de $198 \mathrm{~cm}^{3}(\mathrm{FWHM}=1,87 \mathrm{keV})$. 


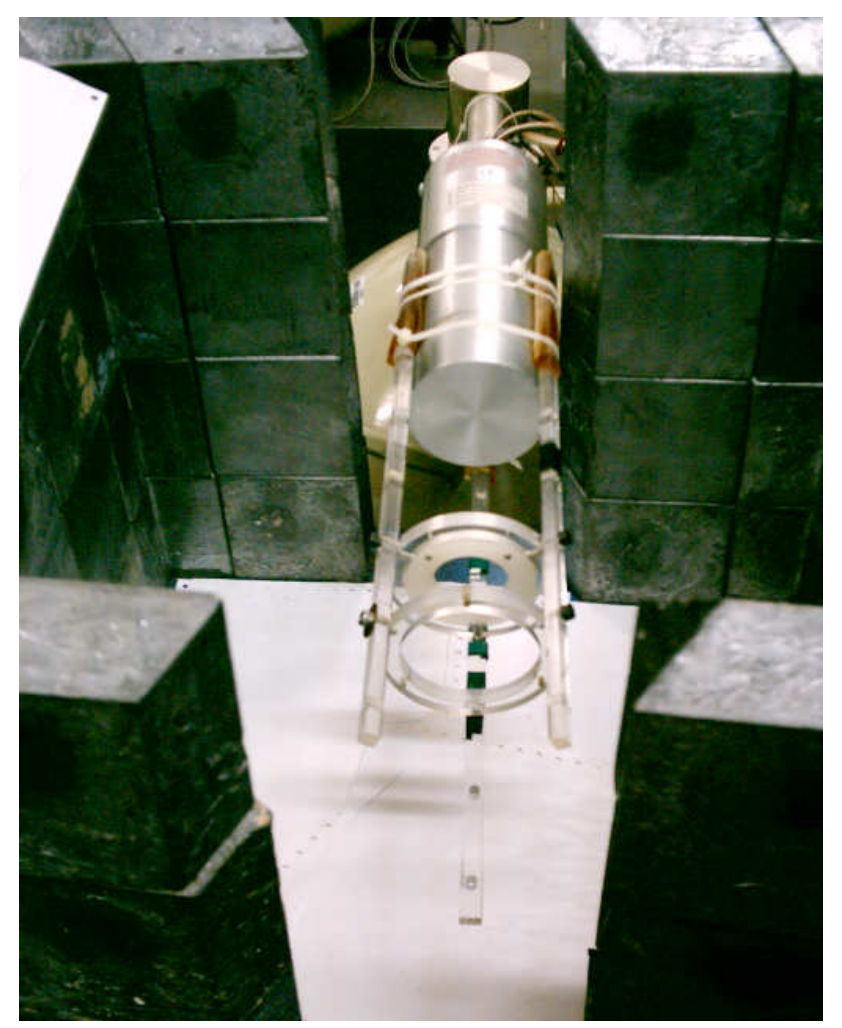

FIGURA 3 - Vista frontal do detetor HPGE de $198 \mathrm{~cm}^{3}(\mathrm{FWHM}=1,87 \mathrm{keV})$.

O sistema de aquisição de dados consiste de um multicanal ADCAM, (ORTEC-918-A) controlado por um microcomputador padrão PC-486. Um diagrama de blocos deste sistema eletrônico é apresentado na FIG. 4.

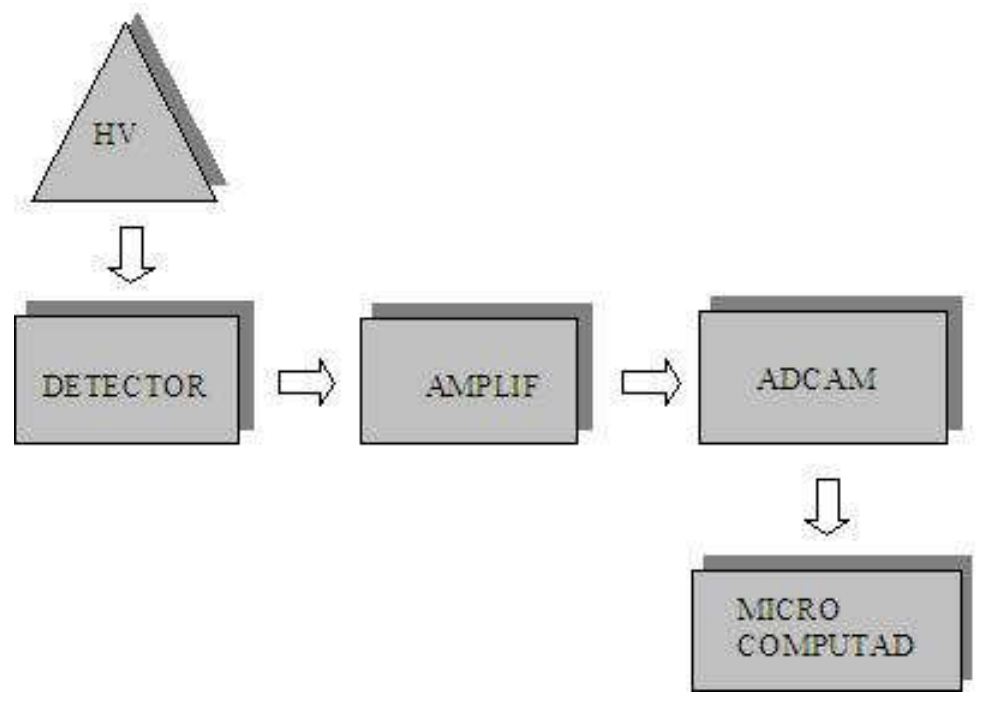

FIGURA 4 - Diagrama de blocos da instrumentação nuclear utilizada para aquisição dos espectros de radiação gama. 
Com a instrumentação descrita acima pode ser obtida a curva de calibração em energia do espectrômetro- $\gamma$ utilizando-se fontes padrão [44] de: ${ }^{60} \mathrm{Co},{ }^{109} \mathrm{Cd},{ }^{133} \mathrm{Ba},{ }^{137} \mathrm{Cs}$ e ${ }^{152} \mathrm{Eu}$, com a finalidade de associar a posição dos fotopicos dos espectros resultantes, ao longo dos 4096 canais, com suas respectivas energias.

A curva de eficiência do detetor, na geometria de detecção, pode ser obtida a partir de dados provenientes das fontes padrão de ${ }^{152} \mathrm{Eu}$ e ${ }^{56} \mathrm{Co}$, que possuem valores de intensidade de suas transições gama $\left(\mathrm{I}_{\gamma}\right)$ bem determinadas, obtidas na compilação da IAEA [44].

A curva obtida é apresentada na FIG. 5 e a função ajustada é dada por:

$$
E_{f}=P_{1} * \exp \left(P_{2} * E\right)+P_{3} * \exp \left(P_{4} * E\right)
$$

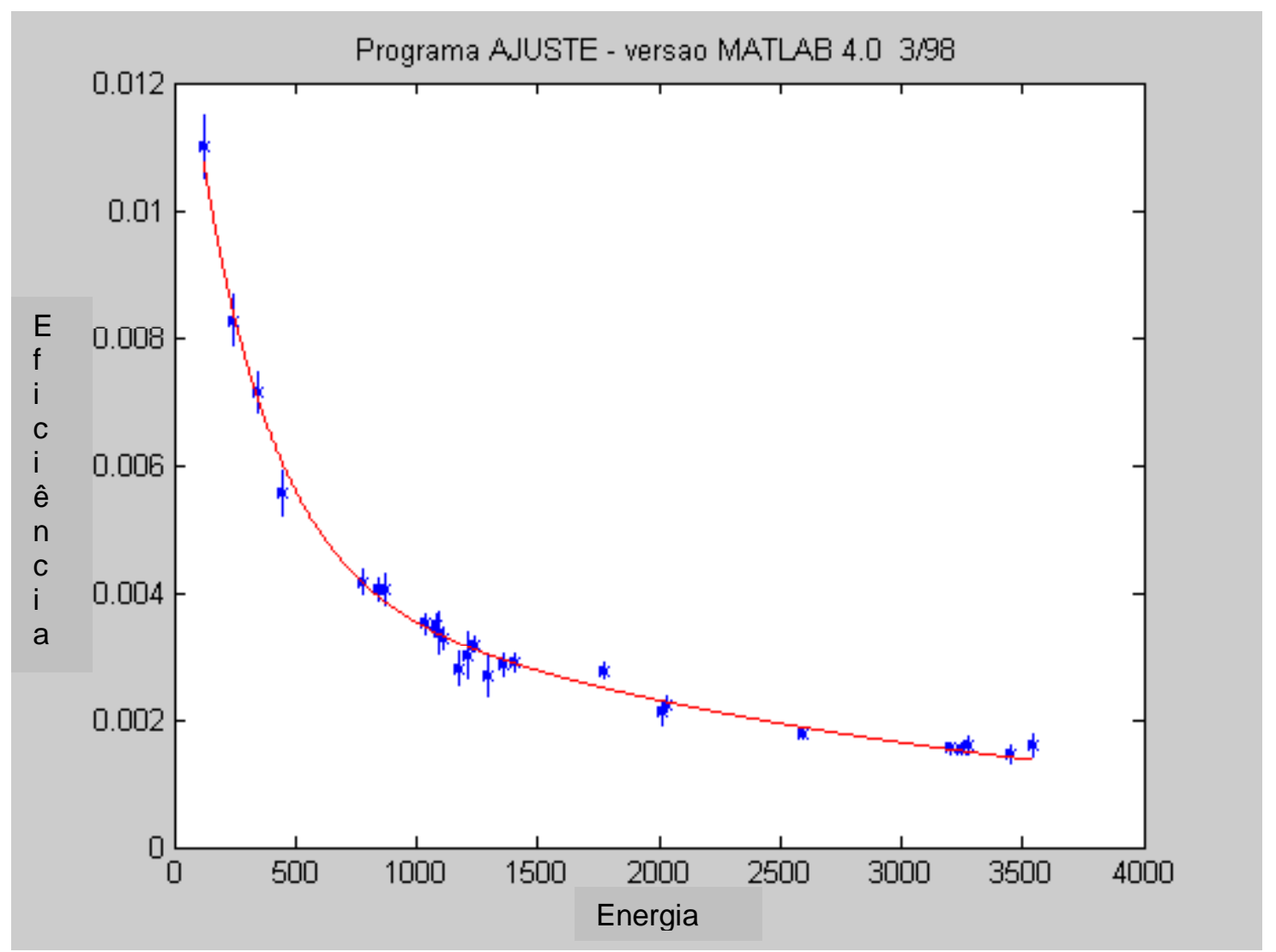

FIGURA 5 - Curva de eficiência do espectrômetro- $\gamma$. 


\subsection{População de estudo}

Foram coletadas 283 amostras de sangue total de doadores voluntários do Banco de Sangue Paulista da cidade de São Paulo e da Fundação HEMOPE da cidade de Recife, mediante autorização por escrito no Termo de Consentimento Livre e Esclarecido a respeito do trabalho em desenvolvimento, conforme padrões éticos para trabalho envolvendo seres humanos (Anexo 1).

As cidades de São Paulo e Recife foram selecionadas porque apresentam algumas similaridades, como alta densidade populacional em área industrializada com populações urbanas e suburbanas, sugerindo que estes voluntários têm um histórico similar em termos de exposição ocupacional.

Essas amostras foram fornecidas por Laboratórios e Bancos de Sangue devidamente credenciados para manuseio, armazenamento, gerenciamento e utilização desse material, e, portanto trata-se de materiais devidamente coletados, isto é, dentro das especificações exigidas por lei e com autorização para fins de pesquisa.

A população escolhida para o estudo foi a de doadores de sangue, cujo perfil atende ao padrão previsto em legislação própria, com faixa etária definida, bem como valores de hemoglobina, pressão arterial, ausência de febre e sorologias negativas, buscando evitar prejuízos à saúde do doador e do receptor do sangue. Esses fatores foram considerados importantes numa tentativa de minimizar situações como processos infecciosos ou doenças crônicas, que interferem nos valores de referência dos elementos estabelecidos.

Os elementos estudados em sangue total foram avaliados em função do gênero, da localização geográfica e da faixa etária. Outro fator levado em consideração neste estudo está relacionado à correlação que existe entre os valores de referência com o meio ambiente. Nesse contexto foi monitorada a concentração dos elementos $\mathrm{Br}, \mathrm{Cl}, \mathrm{K}$ e $\mathrm{Na}$ em sangue na cidade de São Paulo por um período de 4 (quatro) anos e para isso foram selecionadas 20 amostras por ano. 
Foi utilizado o Test t para comparação dos parâmetros estudados em função da localização geográfica e gênero.

A análise das correlações entre os elementos medidos foi feita através da elaboração das matrizes de correlação considerando localização geográfica e gênero.

\subsection{Coleta e preparo das amostras}

As amostras foram obtidas de indivíduos saudáveis (homens e mulheres doadores de sangue), idade entre 18 e 60 anos e acima de $50 \mathrm{~kg}$, seguindo o procedimento convencionalmente estabelecido para doação de sangue.

Essas amostras foram irradiadas no reator IEA-R1 do IPEN/CNEN-SP, seguindo as exigências estabelecidas pela CNEN.

Para a realização do método foram coletados dos doadores, através de punção venosa, cerca de $2 \mathrm{ml}$ de sangue total em tubo seco (sem anticoagulante). Imediatamente após a coleta, antes da coagulação, alíquotas pré-estabelecidas de $100 \mu \mathrm{l}$ de sangue (em duplicata) [26] foram pipetadas e desprezadas em papel de filtro (FIG. 6) e em seguida expostas à luz infravermelha por alguns minutos para secagem. Outras alíquotas de $500 \mu \mathrm{l}$ (em duplicata) foram acondicionadas em cilindros plásticos e expostas à luz infravermelha para secagem por 10 minutos [31]. Posteriormente as amostras em papel de filtro foram armazenadas em recipiente apropriado (FIG. 7). Tanto as amostras em papel de filtro como as do cilindro plástico não necessitam ficar sob refrigeração e podem ser armazenadas (FIG. 8) por longos períodos (anos), dependendo da durabilidade do papel ou do cilindro plástico.

O material restante foi centrifugado e o soro mantido no Banco de Sangue para realização da sorologia para doenças infectocontagiosas. 


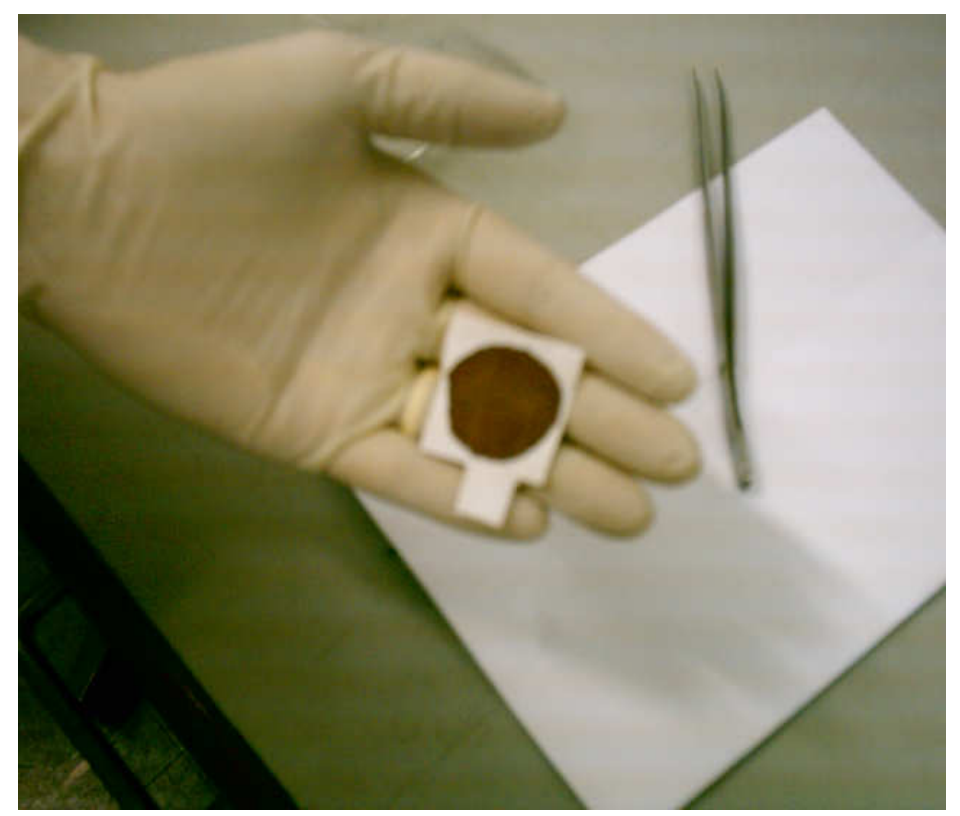

FIGURA 6 - Dimensões da amostra de sangue total em papel de filtro.

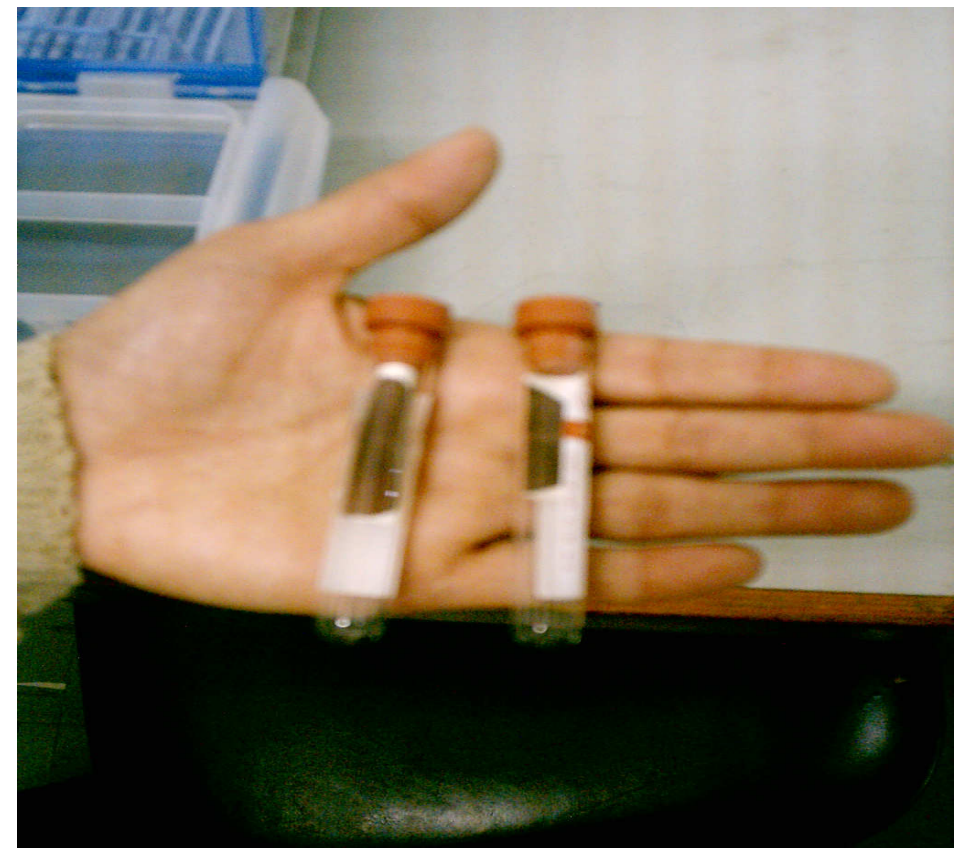

FIGURA 7 - Amostras de sangue total em papel de filtro acondicionadas em recipiente apropriado. 


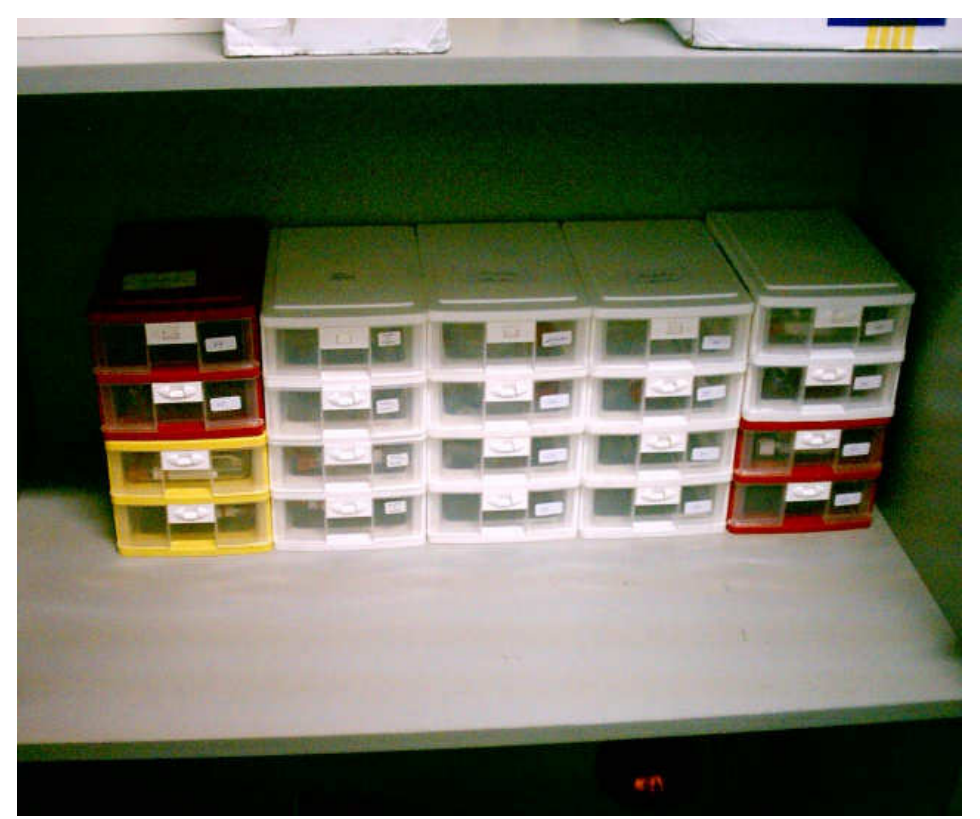

FIGURA 8 - Local de armazenagem das amostras.

\subsection{Procedimento experimental}

Para determinar simultaneamente a concentração dos elementos $\mathrm{Br}, \mathrm{Cl}, \mathrm{K}$ e $\mathrm{Na}$ cada amostra de sangue $(100 \mu \mathrm{l})$ foi acondicionada em cápsula de polietileno, junto com detetores de ativação (duas folhas metálicas de $\mathrm{Au}$ de $\leq 1 \mathrm{mg}$ nua e coberta com $\mathrm{Cd}$ ), mostrados na FIG. 9, usados para medida do fluxo de nêutrons [26] e irradiados por 3 minutos no reator nuclear (IEA-R1, 2-4MW) num fluxo de $\sim 10{ }^{11} \mathrm{n} . \mathrm{cm}^{-2} . \mathrm{s}^{-1}$, permitindo a ativação simultânea desses materiais. Usando esse procedimento a atividade dos raios gama induzida na amostra de sangue e nos detectores de Au é obtida sob as mesmas condições de irradiação. Procedimento análogo foi adotado para as alíquotas de $500 \mu 1$, para determinação da concentração do elemento $\mathrm{Fe}$, sendo o tempo de irradiação de 2 horas [31]. 


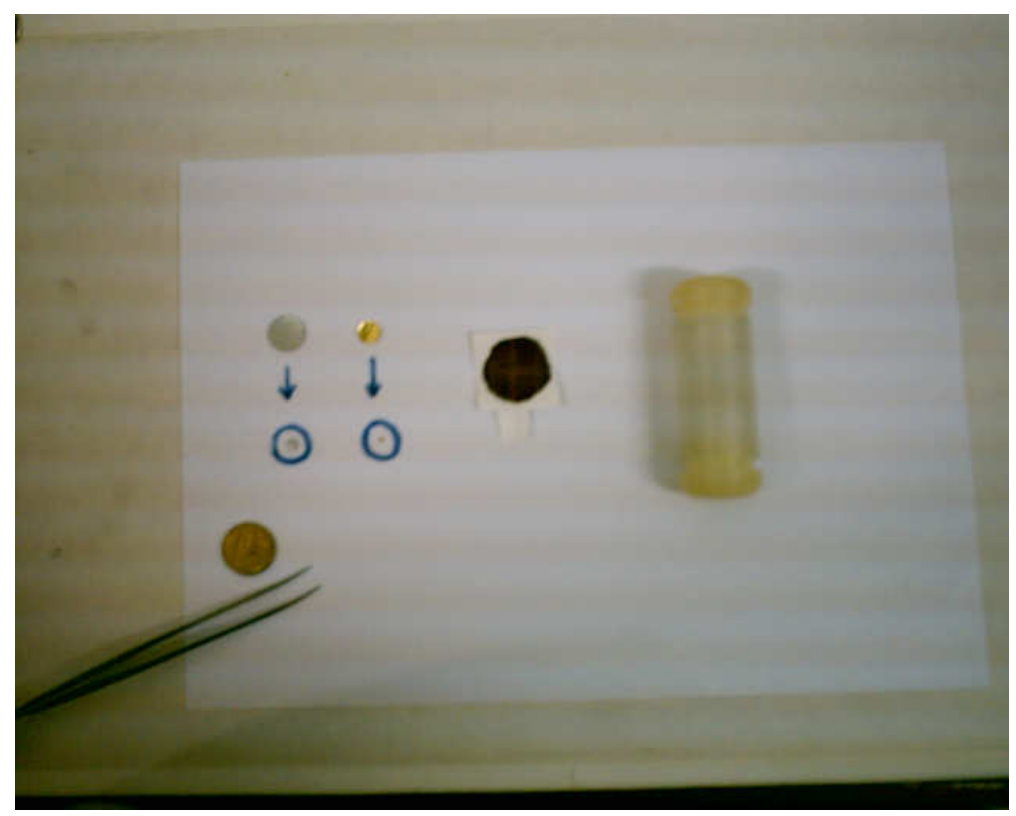

FIGURA 9 - Cobertura de cádmio (em forma de disco); detetor de ativação (disco de ouro); amostra de sangue total fixada em papel de filtro e cápsula de polietileno utilizada como dispositivo de irradiação (da esquerda para direita); tanto o disco de $\mathrm{Cd}$ como de $\mathrm{Au}$ estão representados em dimensão real e acima os discos em maior escala, para melhor visualização.

Para ilustrar, nas FIG. 10a e 10b são apresentados os espectros- $\gamma$ do sangue total ativado.

\footnotetext{
* dispositivo padrão de irradiação: diâmetro intemo $=2,5 \mathrm{~cm}$; diâmetro externo $=3,0 \mathrm{~cm}$; comprimento $=7,0 \mathrm{~cm}$
} 


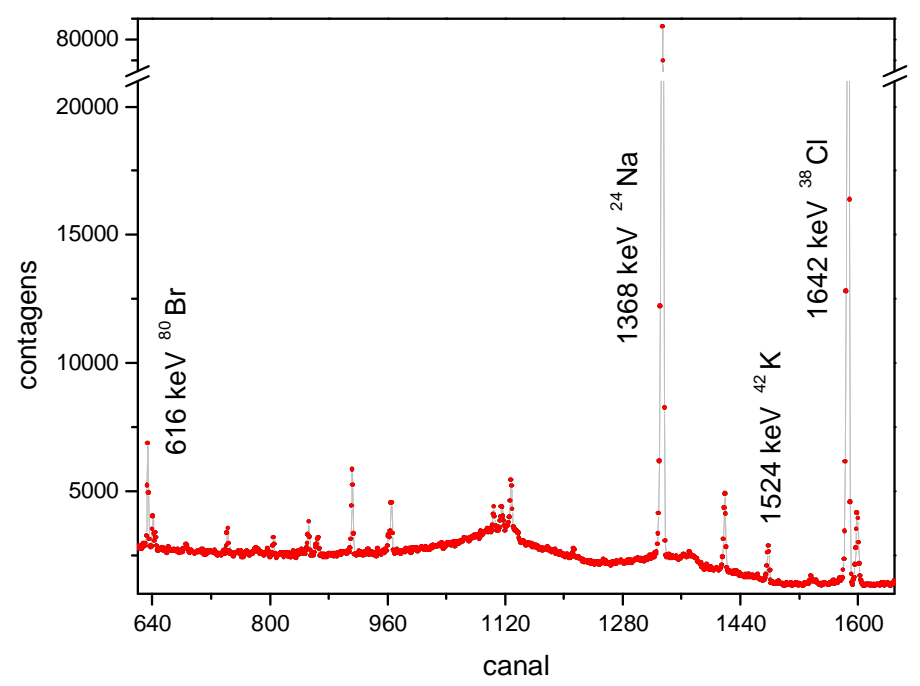

FIGURA 10a - Espectro- $\gamma$ (parcial) de sangue total irradiado por 3 minutos (fluxo $\sim 10$ $\left.{ }^{11} \mathrm{n} \cdot \mathrm{cm}^{-2} \cdot \mathrm{s}^{-1}\right)$, onde os picos não identificados em termos de energia correspondem ao $\mathrm{Bg}$ (radiação de fundo).

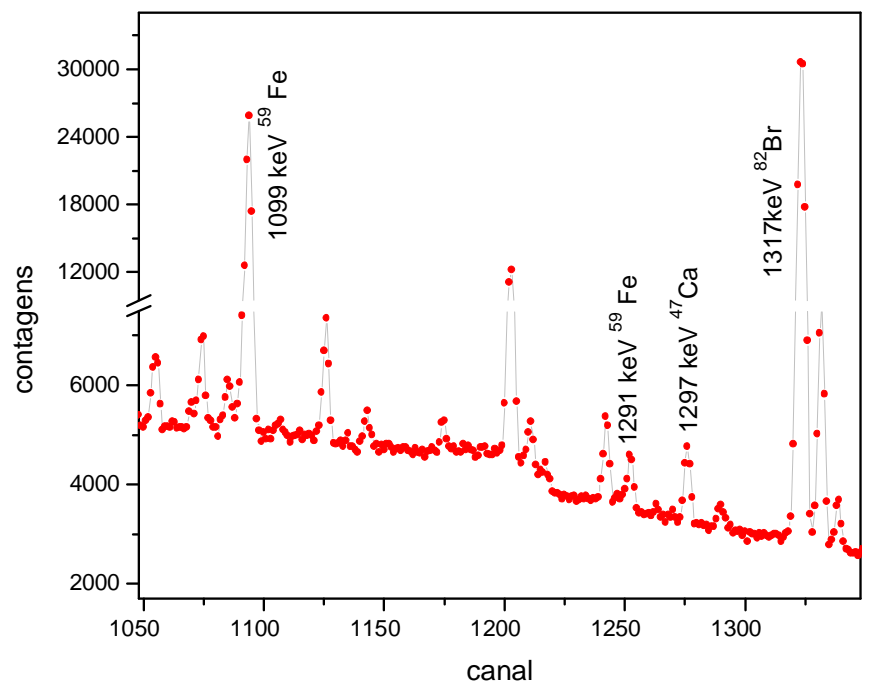

FIGURA 10b - Espectro- $\gamma$ (parcial) de sangue total irradiado por 2 horas (fluxo de $\sim 10$ $\left.{ }^{11} \mathrm{n} \cdot \mathrm{cm}^{-2} \cdot \mathrm{s}^{-1}\right)$, onde os picos não identificados em termos de energia correspondem ao Bg (radiação de fundo). 
No diagrama apresentado a seguir é mostrado o cronograma de execução da medida adotada no presente estudo.

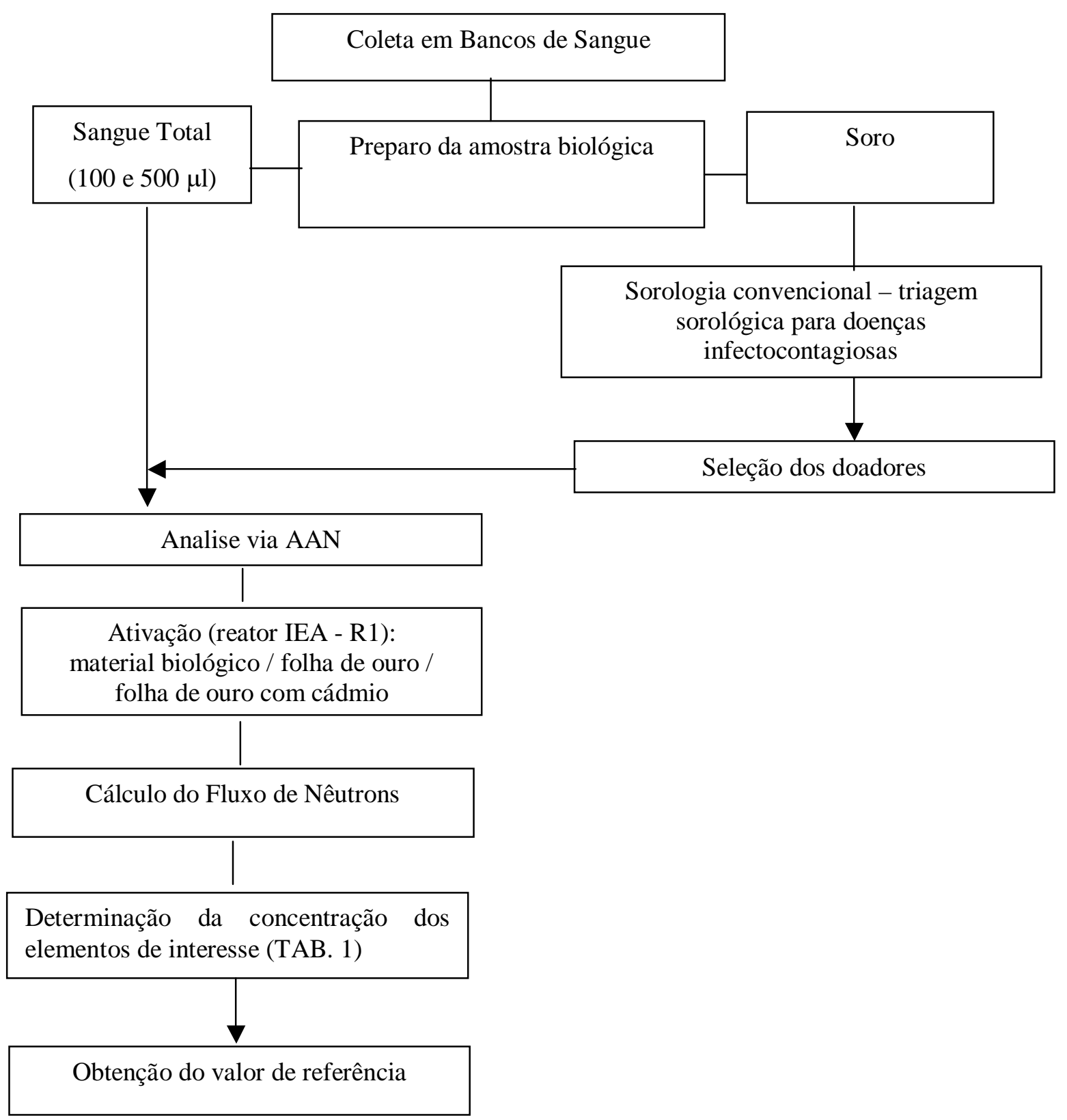




\subsection{Análise de dados}

Após a irradiação, a amostra de sangue e os detetores de Au são levados para contagem no espectrômetro gama. Os detetores de ativação são submetidos à contagem por 15 segundos e a amostra biológica por 10 minutos. Desta forma são gerados espectros de raios gama referentes aos elementos constituintes do sangue que foram ativados (FIG. 10a e 10b), bem como o espectro de ativação do Au, que é utilizado para a determinação do fluxo de nêutrons.

Para obtenção do cálculo das áreas referentes aos elementos ativados utiliza-se o software IDF [43] (Anexos 2 e 3).

De posse da curva de eficiência do espectrômetro- $\gamma$ e da área da transição $\gamma$ de interesse, obtém-se a concentração dos elementos nas amostras de sangue total utilizando o software ATIVAÇÃO [45] (Anexos 4, 5 e 6). 


\section{CAPÍTULO 3. MATERIAL DE REFERÊNCIA}

Os materiais de referência certificados servem basicamente para estabelecer rastreabilidade de medições a padrões nacionais ou internacionais e para auxiliar o processo de validação de métodos de medição.

De uma forma geral, os materiais de referência são utilizados para construir curvas de calibração, para verificar a variabilidade e os erros sistemáticos de métodos, para validar métodos, para checar procedimentos e aparatos experimentais, etc. As orientações básicas quanto ao uso de materiais de referência estão presentes em algumas normas internacionais e guias específicas da área.

Neste estudo as medidas utilizando padrões atendem tanto a validação do método como a verificação do bom funcionamento do aparato experimental.

A apresentação dos resultados encontra-se de acordo com o Guia para Expressão da Incerteza de Medição (ISO ${ }^{1}$ - GUM) que tem como objetivo estabelecer critérios e regras gerais, harmonizar métodos e procedimentos relacionados à expressão de incertezas associadas ao processo de medição.

\subsection{Análise dos materiais de referência}

Para verificar o desempenho do método nuclear foram realizadas primeiramente análises em materiais de referência (provenientes do National Institute of Public Health - Québec) de soro humano (ICP-04S-06) e de sangue humano (ICP-01B-03). As amostras foram preparadas em triplicata seguindo o mesmo procedimento descrito no Capítulo 2. Foram realizados sete medidas e o valor médio obtido para a concentração de $\mathrm{Cl}, \mathrm{K}$ e $\mathrm{Na}$ são apresentados nas TAB. 3 e 4, para soro e sangue total respectivamente.

\footnotetext{
${ }^{1}$ Organização Internacional para Padronização - Guia para Expressão de Incerteza de Medição.
} 
Para ilustrar nas FIG. 11, 12 e 13 pode-se avaliar a concentração desses elementos em sangue. Nessas FIG. e na TAB. 4 os limites de normalidade apresentados correspondem as estimativas extraídas do presente estudo.

TABELA 3 - Análise do material de referência (ICP-04S-06) usando AAN.

\begin{tabular}{c|c|c|c}
\hline $\begin{array}{c}\text { Material de } \\
\text { referência } \\
\left(\mathrm{gl}^{-1}\right)\end{array}$ & $\begin{array}{c}\mathrm{Cl} \\
\mathrm{N}\end{array}$ & $\mathrm{Na}$ & \\
\hline ICP-04S-06 & $3,42-3,72[p e]$ & $0,138-0,182[\mathrm{pe}]$ & $3,05-3,33[\mathrm{pe}]$ \\
\hline Soro (humano) & $3,38 \pm 0,16$ & $0,154 \pm 0,012$ & $3,10 \pm 0,17$ \\
\hline
\end{tabular}

[a]: dados da literatura - limites de normalidade [pe]: presente estudo - limites de normalidade

TABELA 4 - Análise do material de referência (ICP-01B-03) usando AAN.

\begin{tabular}{c|c|c|c}
\hline $\begin{array}{c}\text { Material de } \\
\text { referência } \\
\left(\mathrm{gl}^{-1}\right)\end{array}$ & $\mathrm{Cl}$ & $\mathrm{K}$ & $\mathrm{Na}$ \\
\hline $\begin{array}{c}\text { ICP-01B-03 } \\
\text { Sangue total } \\
\text { (humano) }\end{array}$ & $2,52 \pm 0,17$ & $1,82 \pm 0,11$ & $1,48-2,06[p e]$ \\
\hline
\end{tabular}

[pe]: presente estudo - limites de normalidade 


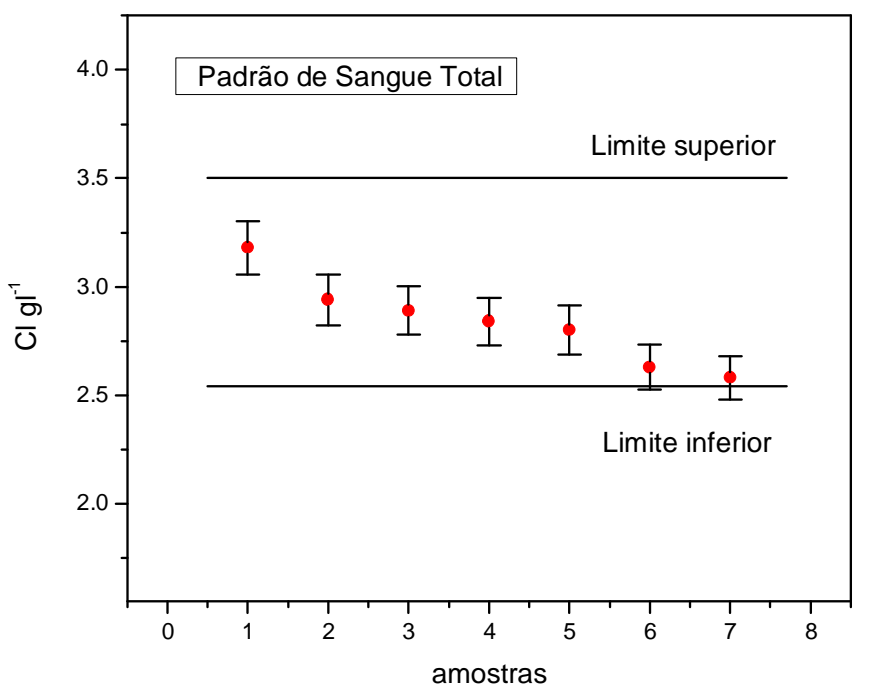

FIGURA 11 - Concentração do elemento $\mathrm{Cl}$ nas amostras de padrão de sangue humano (ICP-01B-03).

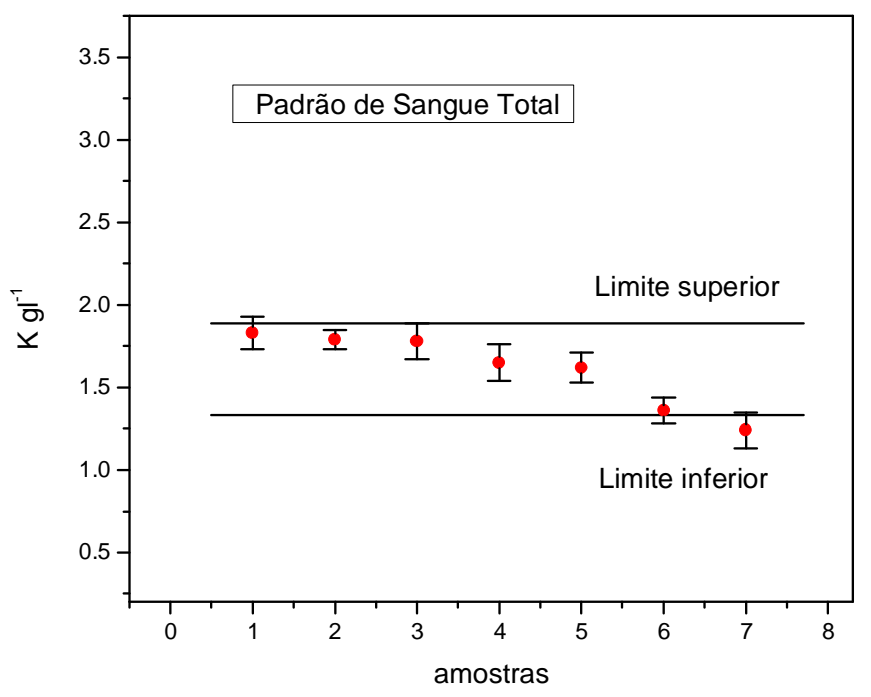

FIGURA 12 - Concentração do elemento $\mathrm{K}$ nas amostras de padrão de sangue humano (ICP-01B-03). 


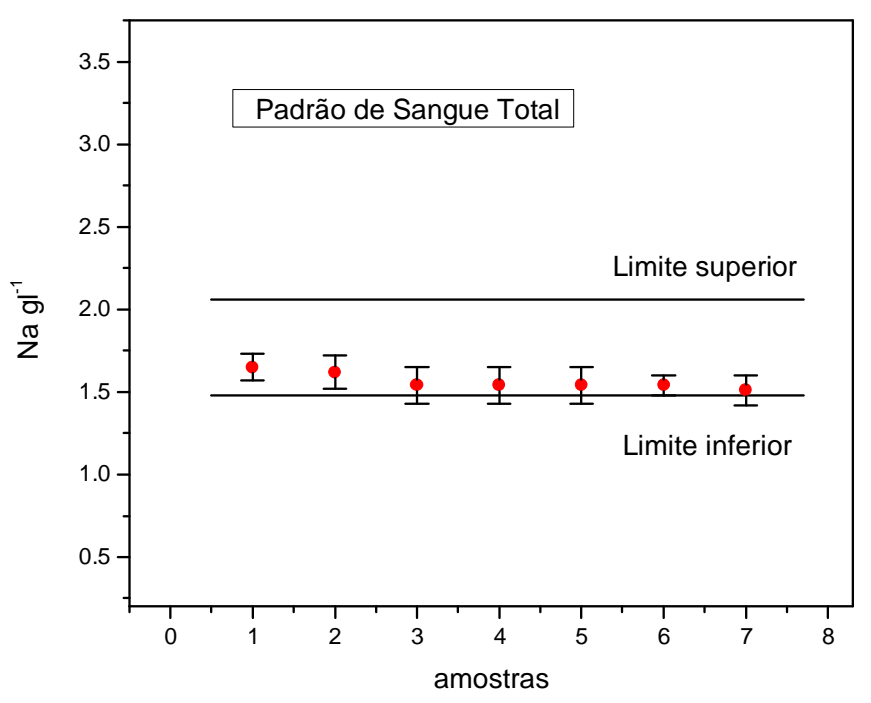

FIGURA 13 - Concentração do elemento Na nas amostras de padrão de sangue humano (ICP-01B-03).

Os resultados apresentados na TAB. 3 mostram a concordância dos dados via AAN com os valores estabelecidos para soro, validando o método de análise e o adequado funcionamento do aparato experimental.

Com relação as medidas em sangue total, embora o padrão utilizado não apresente valores certificados para $\mathrm{Cl}, \mathrm{K}$ e $\mathrm{Na}$, as estimativas dos valores médios obtidos para esses elementos (TAB. 4) estão dentro do intervalo de referência com confiabilidade de $68 \%$ (1 DP), extraídos do presente estudo. 


\section{CAPÍTULO 4. RESULTADOS}

\subsection{População em geral}

O tratamento estatístico aplicado aos resultados obtidos envolve a determinação da média aritmética (M), desvio padrão (DP), mediana, moda, valor mínimo (Vmin), valor máximo (Vmax), intervalo de referência, limite de detecção (LD), bem como a representação gráfica desses parâmetros pelo Box-plot. A apresentação desses resultados além de uniformizar o tratamento dos dados permite sua comparação com estimativas provenientes de outros estudos envolvendo diferentes técnicas e/ou localidades (cidades, países).

A apresentação dos resultados encontra-se de acordo com o Guia para Expressão da Incerteza de Medição (ISO ${ }^{1}$ - GUM) que tem como objetivo estabelecer critérios e regras gerais, harmonizar métodos e procedimentos relacionados à expressão de incertezas associadas ao processo de medição.

Desta forma, as concentrações obtidas para os elementos $\mathrm{Br}, \mathrm{Cl}, \mathrm{K}$ e $\mathrm{Na}$ em sangue total para a população de estudo são apresentados na TAB. 5. Todos os resultados foram obtidos pela análise das amostras em duplicata e o intervalo de referência proposto foi definido pelo uso da média aritmética com \pm 1 DP (Desvio Padrão).

\footnotetext{
${ }^{1}$ Organização Internacional para Padronização - Guia para Expressão de Incerteza de Medição.
} 
TABELA 5 - Resultados dos elementos $\mathrm{Br}, \mathrm{Cl}, \mathrm{K}$ e $\mathrm{Na}$ medidos em sangue total usando AAN.

\begin{tabular}{l|c|c|c|c|c|c|c|c}
\hline $\begin{array}{l}\text { Elementos } \\
\left(\mathrm{g} \mathrm{l}^{-1}\right) \\
\mathrm{n}=283\end{array}$ & $\mathrm{M}$ & $\mathrm{DP}$ & Mediana & Moda & $\begin{array}{c}\text { Intervalo } \\
\text { referência }\end{array}$ & Vmin & Vmax & LD \\
\hline $\mathrm{Br}$ & 0,0165 & 0,0098 & 0,0148 & 0,0133 & $0,0067-0,0263$ & 0,0028 & 0,0688 & 0,0002 \\
\hline $\mathrm{Cl}$ & 3,02 & 0,48 & 3,00 & 3,55 & $2,54-3,50$ & 2,00 & 4,52 & 0,0019 \\
\hline $\mathrm{K}$ & 1,61 & 0,28 & 1,61 & 1,71 & $1,33-1,89$ & 1,07 & 2,43 & 0,0333 \\
$\mathrm{Na}$ & 1,77 & 0,29 & 1,75 & 2,05 & $1,48-2,06$ & 1,21 & 2,54 & 0,0010 \\
\hline
\end{tabular}

n: número de amostras analisadas

* valores em mEq/1 são apresentados no Anexo 9 


\subsection{Análise do elemento bromo em sangue}

A TAB. 6 mostra o intervalo de referência em sangue total de $\mathrm{Br}$ para a população brasileira em geral e em função do sexo; na TAB. 7 é apresentada a comparação entre as duas regiões monitoradas (Sudeste e Nordeste).

A FIG. 14 ilustra a representação via Box-plot para Br; na FIG. 15 são apresentados os resultados das medidas em função da idade considerando diferentes faixas etárias (18-20, 21-30, 31-40, 41-50 e $\geq 51$ anos); a FIG. 16 ilustra o comportamento do $\mathrm{Br}$ em sangue total em função do sexo nas regiões monitoradas (Sudeste e Nordeste) e seu monitoramento em função do tempo (período de 3 anos), na cidade de São Paulo é apresentado na FIG. 17; na FIG. 18 é mostrada a distribuição de freqüências para o $\mathrm{Br}$ agrupados em classes de $0,005 \mathrm{gl}^{-1}$ e o ajuste da distribuição normal.

TABELA 6 - Tratamento estatístico para Br em sangue total dos dados obtidos via AAN.

\begin{tabular}{l|c|c|c|c|c|c|c}
\hline $\mathrm{Br}, \mathrm{gl}^{-1}$ & $\mathrm{M}$ & $\mathrm{DP}$ & Mediana & Moda & $\begin{array}{c}\text { Intervalo } \\
\text { referência }\end{array}$ & Vmin & Vmax \\
\hline $\begin{array}{l}\text { Total } \\
\mathrm{n}=283\end{array}$ & 0,0165 & 0,0098 & 0,0148 & 0,0133 & $0,0067-0,0263$ & 0,0028 & 0,0688 \\
\hline $\begin{array}{l}\text { Homem } \\
\mathrm{n}=150\end{array}$ & 0,0162 & 0,0095 & 0,0148 & 0,0133 & $0,0067-0,0257$ & 0,0035 & 0,0688 \\
\hline $\begin{array}{l}\text { Mulher } \\
\mathrm{n}=133\end{array}$ & 0,0180 & 0,0110 & 0,0158 & 0,0339 & $0,0070-0,0290$ & 0,0028 & 0,0563 \\
\hline
\end{tabular}

n: número de amostras analisadas 
TABELA 7 - Intervalo de referência para $\mathrm{Br}$ em sangue total usando AAN para a população brasileira e diferentes regiões do Brasil.

\begin{tabular}{l|c|c}
\hline Br, gl ${ }^{-1}$ & $\begin{array}{c}\text { São Paulo } \\
\text { (região Sudeste) }\end{array}$ & $\begin{array}{c}\text { Recife } \\
\text { (região Nordeste) }\end{array}$ \\
\hline Total & $0,0028-0,0176$ & $0,0087-0,0279$ \\
& $\mathrm{n}=141$ & $\mathrm{n}=142$ \\
\hline Homem & $0,0016-0,0166$ & $0,0089-0,0271$ \\
& $\mathrm{n}=74$ & $\mathrm{n}=76$ \\
Mulher & $0,0067-0,0197$ & $0,0083-0,0325$ \\
& $\mathrm{n}=67$ & $\mathrm{n}=66$ \\
\hline
\end{tabular}

n: número de amostras analisadas

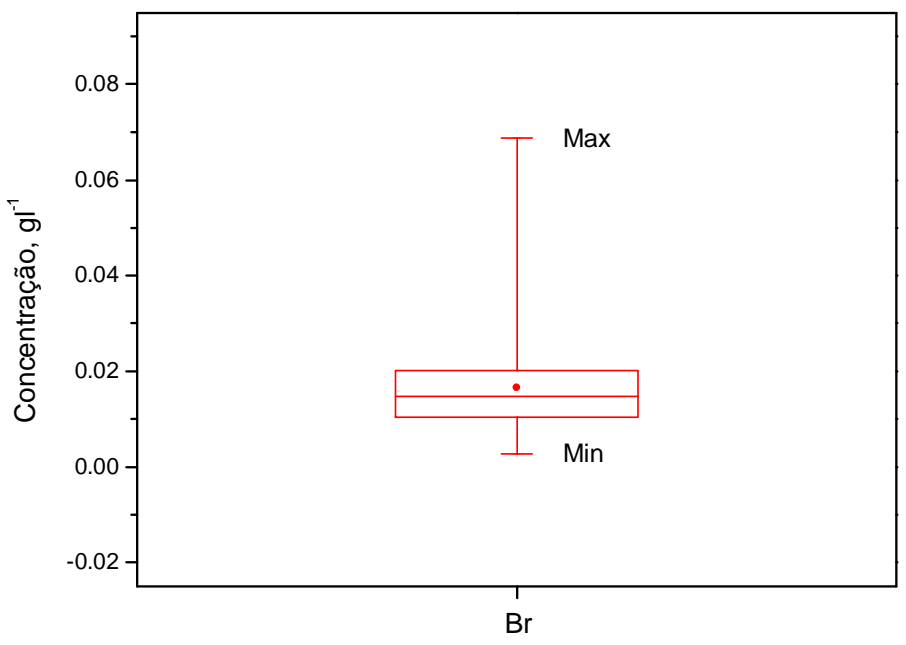

FIGURA 14 - Representação via Box-plot para o elemento Br 


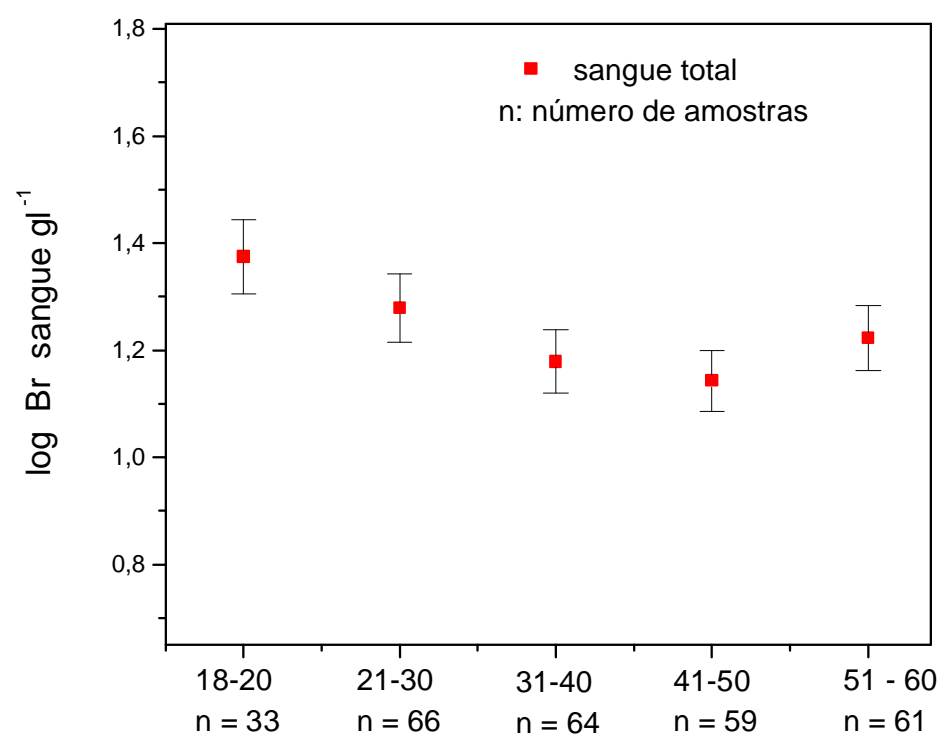

FIGURA 15 - Comportamento do Br em sangue total em função da faixa etária.

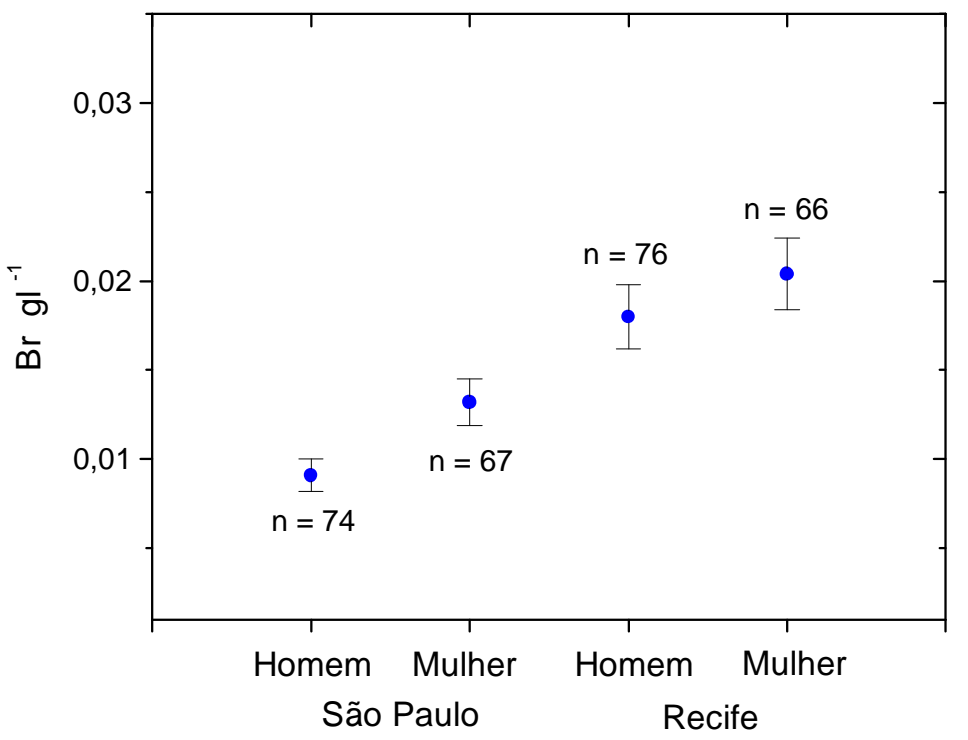

FIGURA 16 - Comportamento do $\mathrm{Br}$ em sangue total em função do sexo nas regiões monitoradas (Sudeste e Nordeste). 


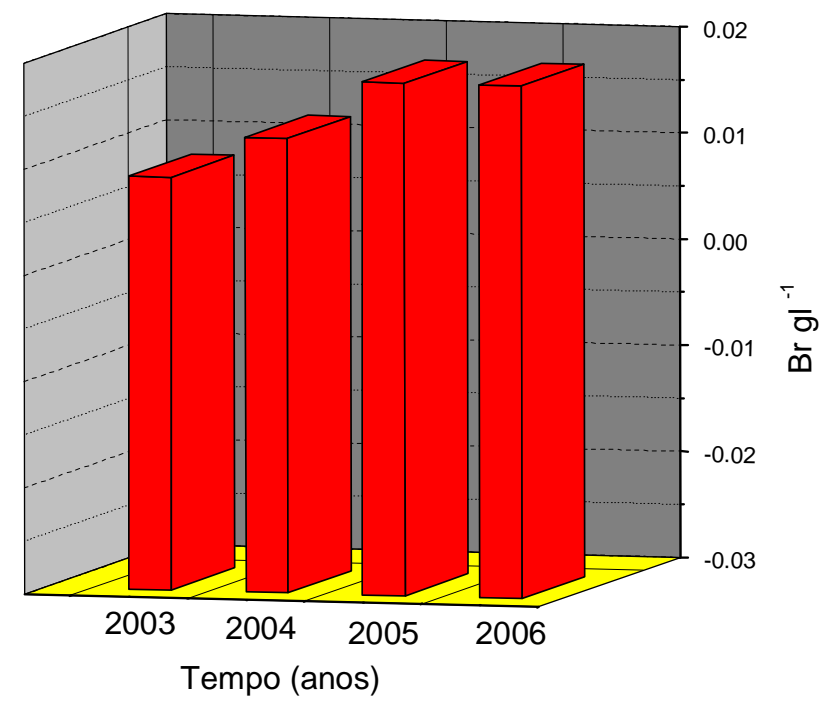

FIGURA 17 - Monitoramento do Br em sangue total em função do tempo na cidade de São Paulo.

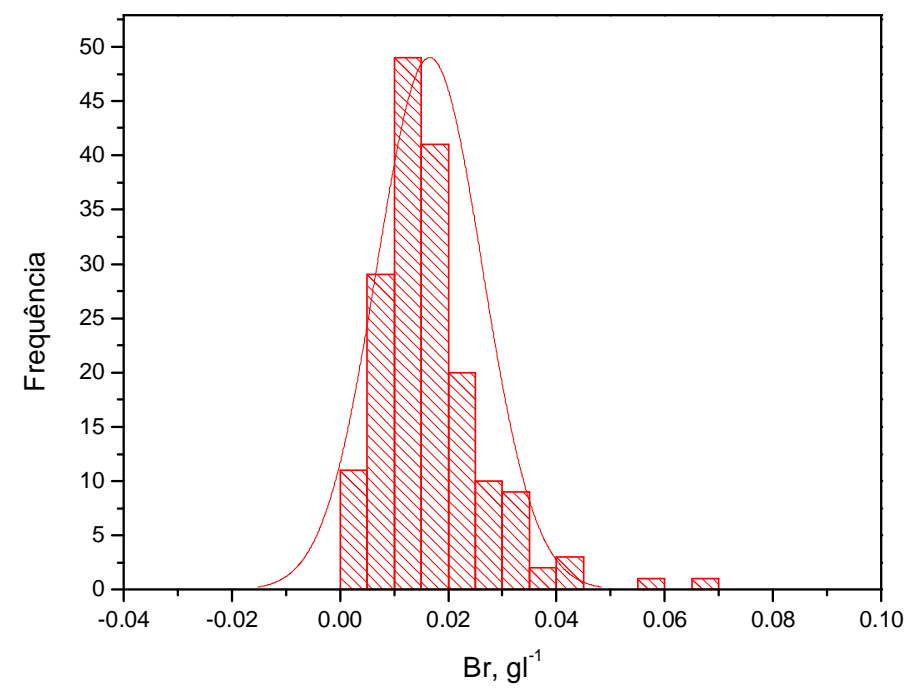

FIGURA 18 - Histograma e ajuste gaussiano da concentração de Br. 


\subsection{Análise do elemento cloro em sangue}

A TAB. 8 mostra o intervalo de referência em sangue total de $\mathrm{Cl}$ para a população brasileira em geral e em função do sexo; na TAB. 9 é apresentada a comparação entre as duas regiões monitoradas (Sudeste e Nordeste).

A FIG. 19 ilustra a representação via Box-plot para Cl; na FIG. 20 são apresentados os resultados das medidas em função da idade considerando diferentes faixas etárias (18-20, 21-30, 31-40, 41-50 e $\geq 51$ anos); a FIG. 21 ilustra o comportamento do Cl em sangue total em função do sexo nas regiões monitoradas (Sudeste e Nordeste) e na FIG. 22 seu monitoramento, em função do tempo, na cidade de São Paulo; na FIG. 23 é mostrada a distribuição de freqüências para o $\mathrm{Cl}$ agrupados em classes de $0,2 \mathrm{gl}^{-1}$ e o ajuste da distribuição normal.

TABELA 8 - Tratamento estatístico para Cl em sangue total dos dados obtidos via AAN.

\begin{tabular}{l|c|c|c|c|c|c|c}
\hline $\mathrm{Cl}, \mathrm{gl}^{-1}$ & $\mathrm{M}$ & $\mathrm{DP}$ & Mediana & Moda & $\begin{array}{c}\text { Intervalo } \\
\text { referência }\end{array}$ & Vmin & Vmax \\
\hline Total & 3,02 & 0,48 & 3,00 & 3,55 & $2,54-3,50$ & 2,00 & 4,52 \\
\hline Homem & 3,00 & 0,48 & 2,95 & 3,55 & $2,52-3,48$ & 2,00 & 4,52 \\
\hline Mulher & 3,12 & 0,50 & 3,12 & 3,31 & $2,62-3,62$ & 2,23 & 4,14 \\
\hline
\end{tabular}


TABELA 9 - Intervalo de referência para $\mathrm{Cl}$ em sangue total usando AAN para a população brasileira e diferentes regiões do Brasil.

\begin{tabular}{l|c|c}
\hline $\mathrm{Cl}, \mathrm{gl}^{-1}$ & $\begin{array}{c}\text { São Paulo } \\
\text { (região Sudeste) }\end{array}$ & $\begin{array}{c}\text { Recife } \\
\text { (região Nordeste) }\end{array}$ \\
\hline Total & $2,55-3,43$ & $2,53-3,53$ \\
& $\mathrm{n}=141$ & $\mathrm{n}=142$ \\
\hline Homem & $2,52-3,36$ & $2,53-3,51$ \\
& $\mathrm{n}=74$ & $\mathrm{n}=76$ \\
Mulher & $2,63-3,61$ & $2,59-3,65$ \\
& $\mathrm{n}=67$ & $\mathrm{n}=66$ \\
\hline
\end{tabular}

n: número de amostras analisadas

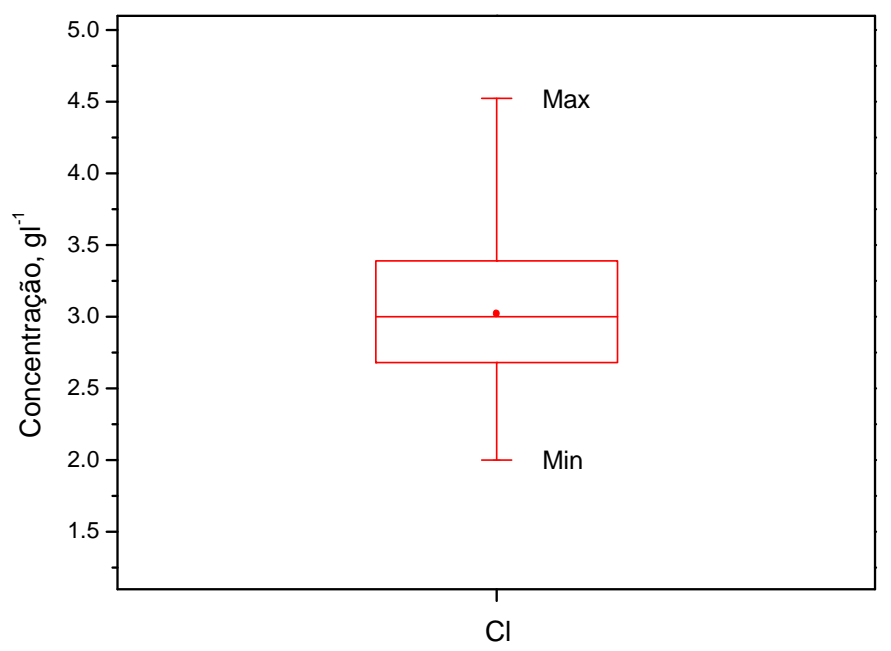

FIGURA 19 - Representação via Box-plot para o elemento Cl. 


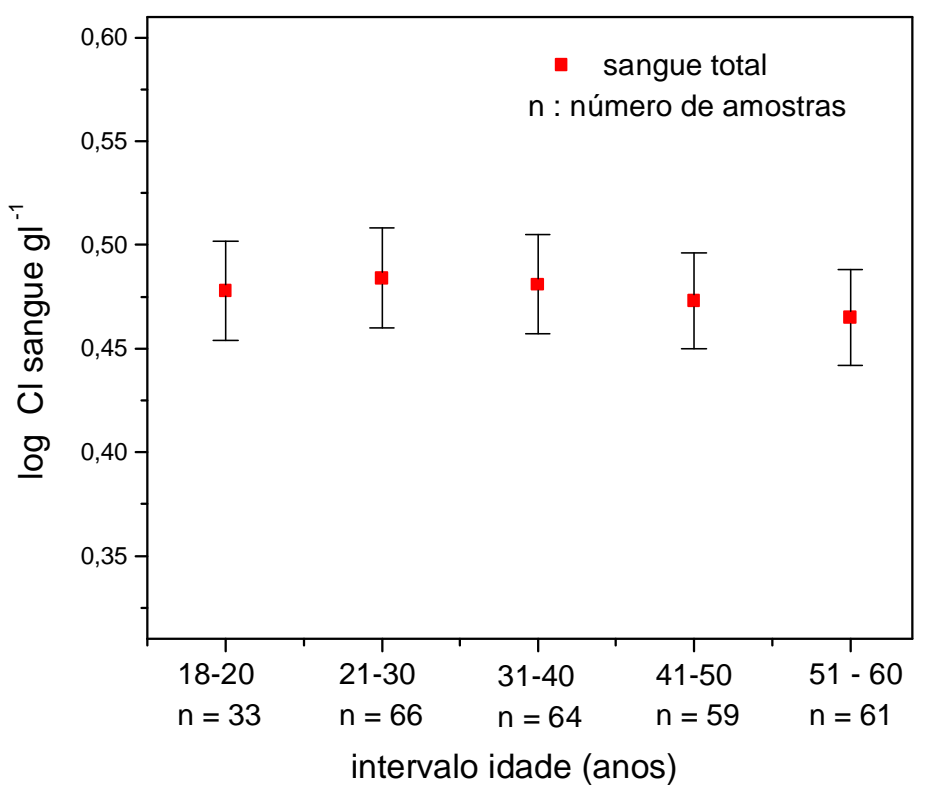

FIGURA 20 - Comportamento do $\mathrm{Cl}$ em sangue total em função da faixa etária.

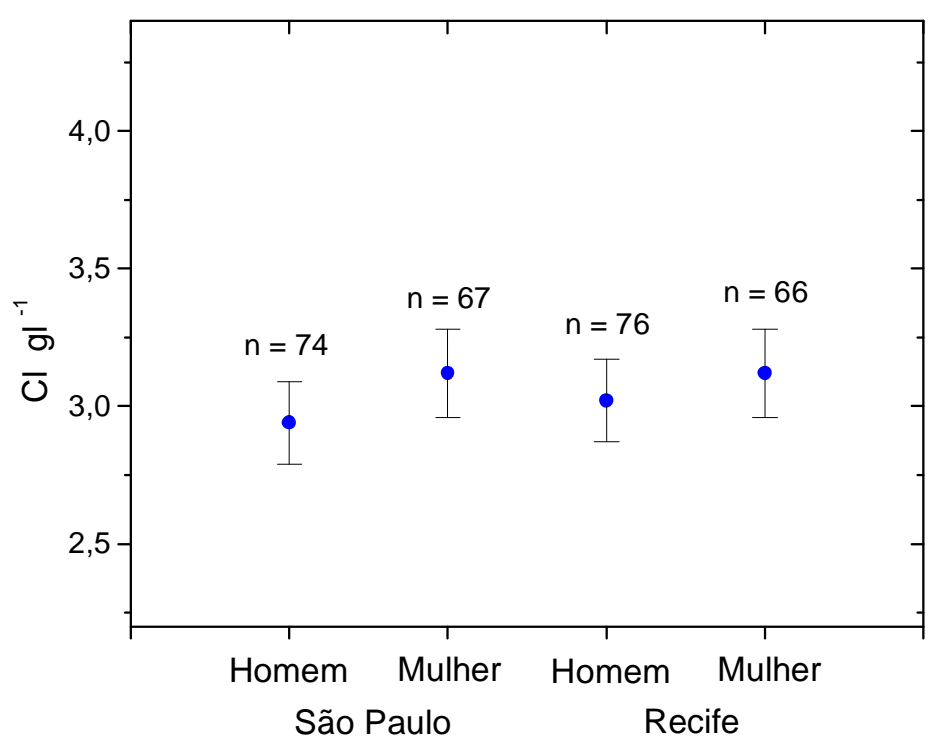

FIGURA 21 - Comportamento do $\mathrm{Cl}$ em sangue total em função do sexo nas regiões monitoradas (Sudeste e Nordeste). 


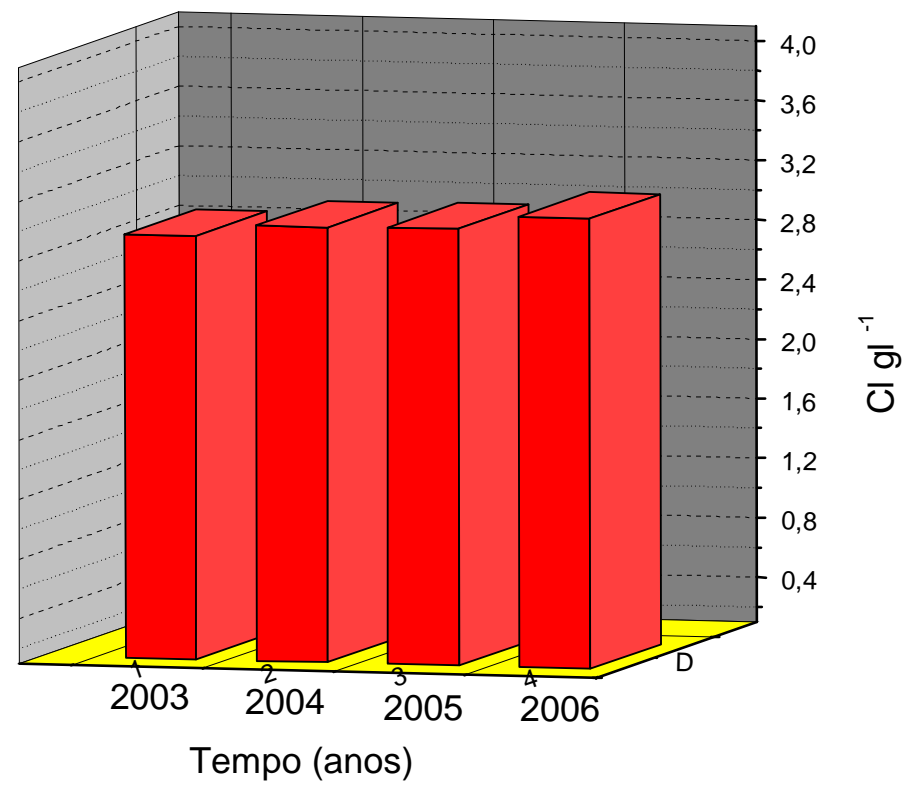

FIGURA 22 - Monitoramento do $\mathrm{Cl}$ em sangue total em função do tempo na cidade de São Paulo.

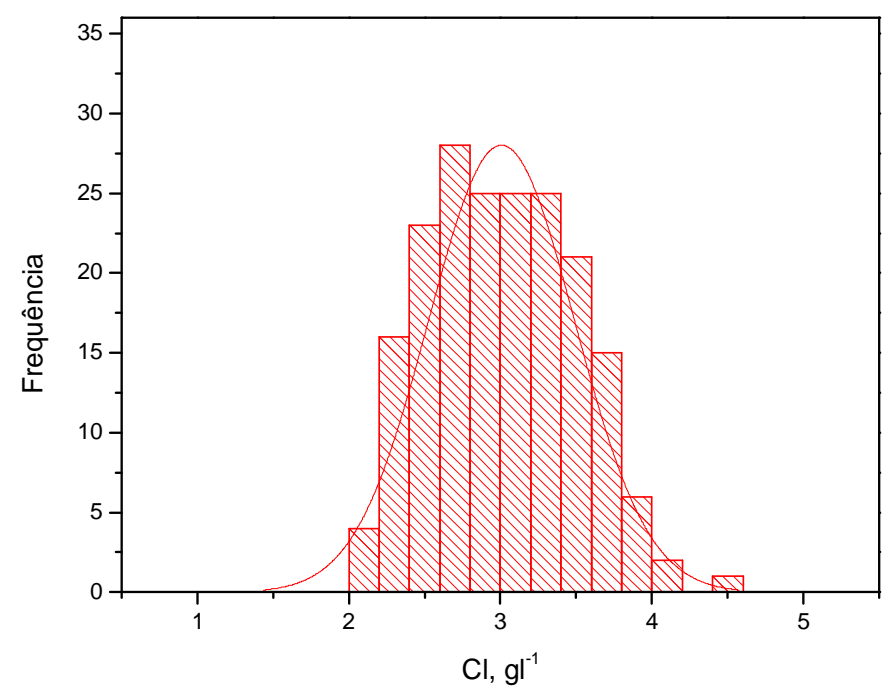

FIGURA 23 - Histograma e ajuste gaussiano da concentração de Cl. 


\subsection{Análise do elemento potássio em sangue}

A TAB. 10 mostra o intervalo de referência em sangue total de $\mathrm{K}$ para a população brasileira em geral e em função do sexo; na TAB. 11 é apresentada a comparação entre as duas regiões monitoradas (Sudeste e Nordeste).

A FIG. 24 ilustra a representação via Box-plot para K; na FIG. 25 são apresentados os resultados das medidas em função da idade considerando diferentes faixas etárias (18-20, 21-30, 31-40, 41-50 e $\geq 51$ anos); o comportamento do $\mathrm{K}$ em sangue total em função do sexo nas regiões monitoradas (Sudeste e Nordeste) é apresentado na FIG. 26 e seu monitoramento, em função do tempo, na cidade de São Paulo é apresentado na FIG. 27; na FIG. 28 é mostrada a distribuição de freqüências para o $\mathrm{K}$ agrupados em classes de $0,2 \mathrm{gl}^{-1}$ e o ajuste da distribuição normal.

TABELA 10 - Tratamento estatístico para K em sangue total dos dados obtidos via AAN.

\begin{tabular}{l|c|c|c|c|c|c|c}
\hline $\mathrm{K}, \mathrm{gl}^{-1}$ & $\mathrm{M}$ & $\mathrm{DP}$ & Mediana & Moda & $\begin{array}{c}\text { Intervalo } \\
\text { referência }\end{array}$ & Vmin & Vmax \\
\hline Total & 1,61 & 0,28 & 1,61 & 1,71 & $1,33-1,89$ & 1,07 & 2,43 \\
\hline Homem & 1,63 & 0,27 & 1,64 & 1,71 & $1,36-1,90$ & 1,10 & 2,33 \\
\hline Mulher & 1,50 & 0,27 & 1,49 & 1,47 & $1,23-1,77$ & 1,07 & 2,43 \\
\hline
\end{tabular}


TABELA 11 - Intervalo de referência para $\mathrm{K}$ em sangue total usando AAN para a população brasileira e diferentes regiões do Brasil.

\begin{tabular}{l|c|c}
\hline $\mathrm{K}, \mathrm{gl}^{-1}$ & $\begin{array}{c}\text { São Paulo } \\
\text { (região Sudeste) }\end{array}$ & $\begin{array}{c}\text { Recife } \\
\text { (região Nordeste) }\end{array}$ \\
\hline Total & $1,35-1,85$ & $1,32-1,90$ \\
$\mathrm{n}=141$ & $\mathrm{n}=142$ \\
\hline Homem & $1,37-1,91$ & $1,35-1,91$ \\
$\mathrm{n}=74$ & $\mathrm{n}=76$ \\
\hline Mulher & $1,33-1,71$ & $1,16-1,80$ \\
& $\mathrm{n}=67$ & $\mathrm{n}=66$ \\
\hline
\end{tabular}

n: número de amostras analisadas

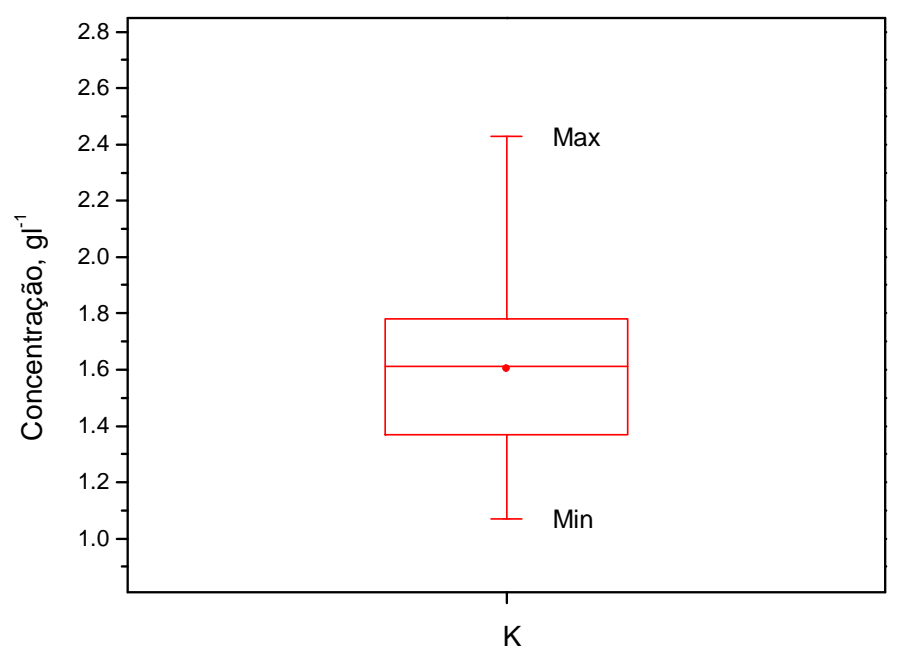

FIGURA 24 - Representação via Box-plot para o elemento K. 


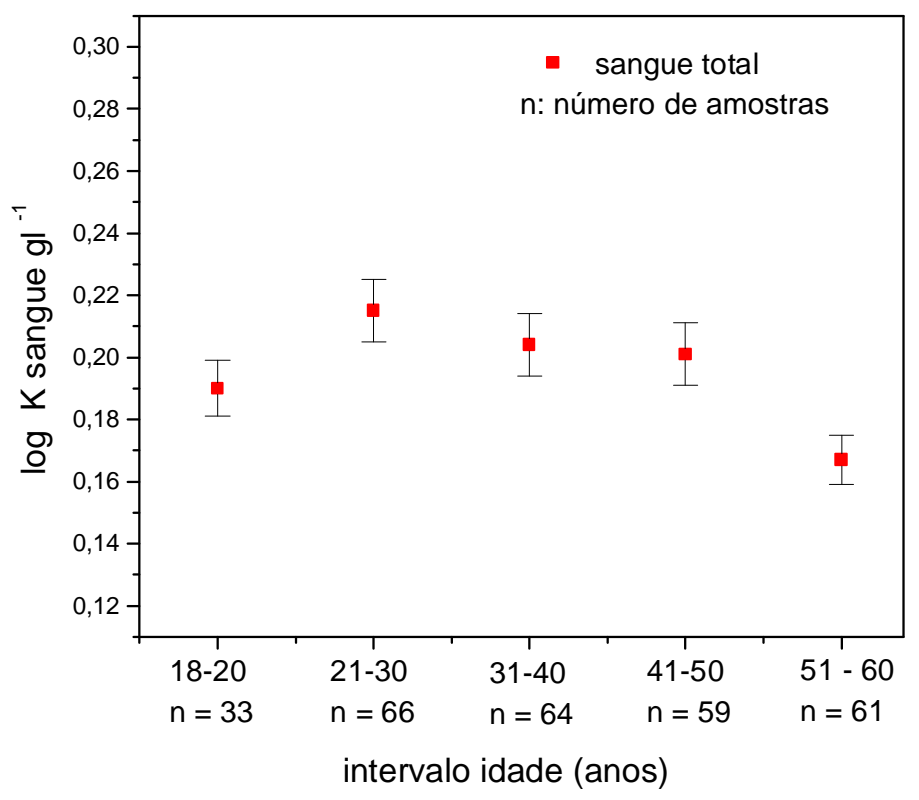

FIGURA 25 - Comportamento do K em sangue total em função da faixa etária.

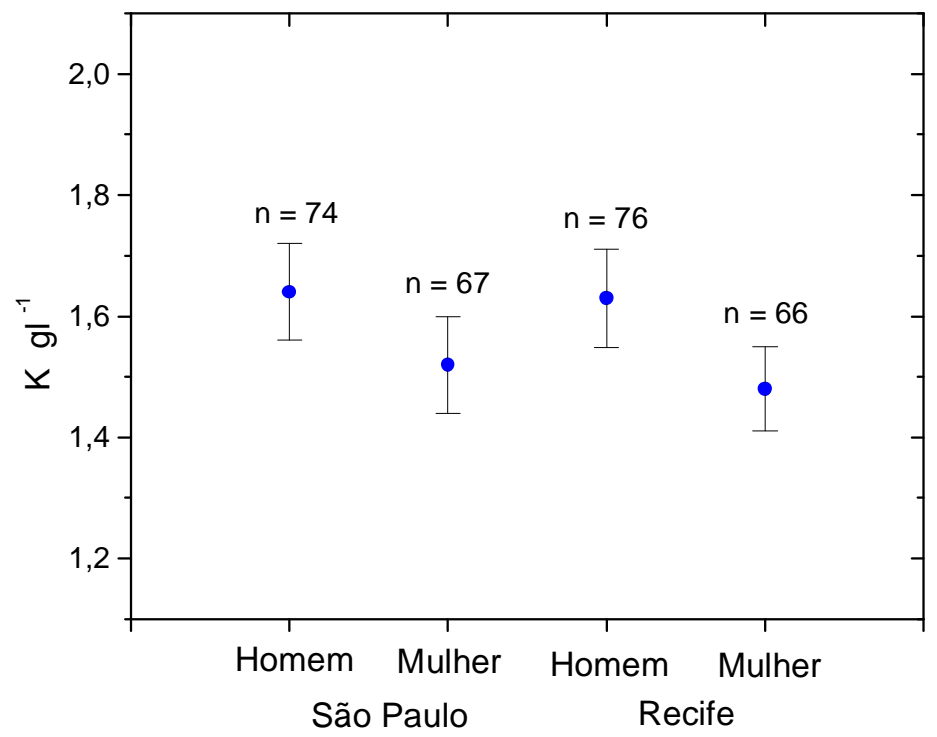

FIGURA 26 - Comportamento do $\mathrm{K}$ em sangue total em função do sexo nas regiões monitoradas (Sudeste e Nordeste). 


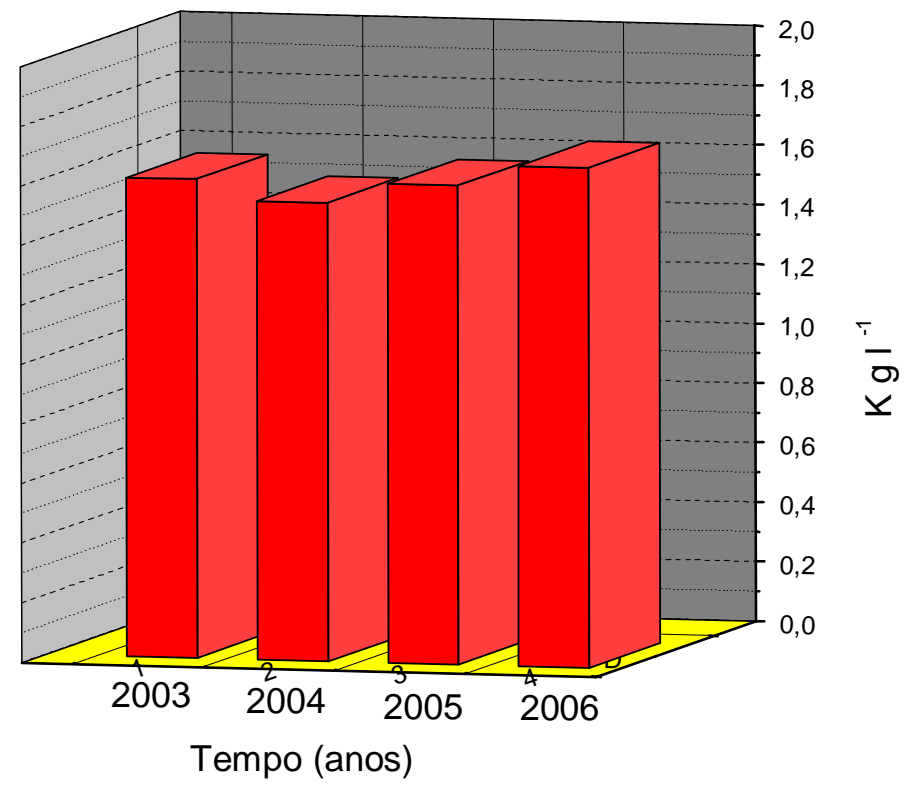

FIGURA 27 - Monitoramento do K em sangue total em função do tempo na cidade de São Paulo.

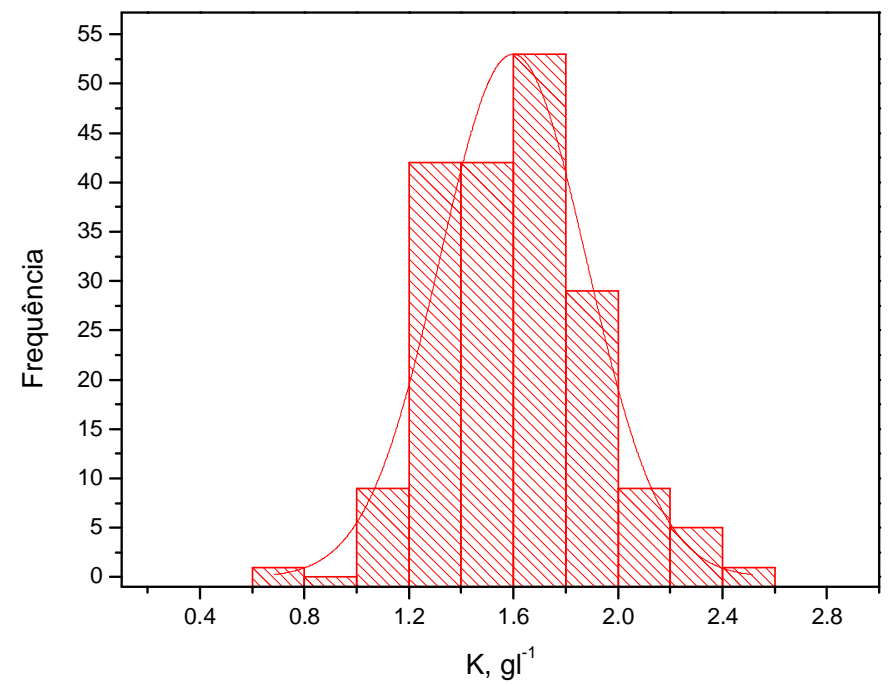

FIGURA 28 - Histograma e ajuste gaussiano da concentração de K. 


\subsection{Análise do elemento sódio em sangue}

A TAB. 12 mostra o intervalo de referência em sangue total de Na para a população brasileira em geral e em função do sexo; na TAB. 13 é apresentada a comparação entre as duas regiões monitoradas (Sudeste e Nordeste).

A FIG. 29 ilustra a representação via Box-plot para Na; na FIG. 30 são apresentados os resultados das medidas em função da idade considerando diferentes faixas etárias (18-20, 21-30, 31-40, 41-50 e $\geq 51$ anos); o comportamento do Na em sangue total em função do sexo nas regiões monitoradas (Sudeste e Nordeste) é apresentado na FIG. 31 e seu monitoramento, em função do tempo, na cidade de São Paulo é apresentado na FIG. 32; na FIG. 33 é mostrada a distribuição de freqüências para o Na agrupados em classes de $0,2 \mathrm{gl}^{-1}$ e o ajuste da distribuição normal.

TABELA 12 - Tratamento estatístico para Na em sangue total dos dados obtidos via AAN.

\begin{tabular}{l|c|c|c|c|c|c|c}
\hline $\mathrm{Na}, \mathrm{gl}^{-1}$ & $\mathrm{M}$ & $\mathrm{DP}$ & Mediana & Moda & $\begin{array}{c}\text { Intervalo } \\
\text { referência }\end{array}$ & Vmin & Vmax \\
\hline Total & 1,77 & 0,29 & 1,75 & 2,05 & $1,48-2,06$ & 1,21 & 2,54 \\
\hline Homem & 1,76 & 0,29 & 1,74 & 1,57 & $1,47-2,05$ & 1,21 & 2,54 \\
\hline Mulher & 1,80 & 0,27 & 1,79 & 2,05 & $1,53-2,07$ & 1,38 & 2,48 \\
\hline
\end{tabular}


TABELA 13 - Intervalo de referência para $\mathrm{Na}$ em sangue total usando AAN para a população brasileira e diferentes regiões do Brasil.

\begin{tabular}{l|c|c}
\hline Na, $\mathrm{gl}^{-1}$ & $\begin{array}{c}\text { São Paulo } \\
\text { (região Sudeste) }\end{array}$ & $\begin{array}{c}\text { Recife } \\
\text { (região Nordeste) }\end{array}$ \\
\hline Total & $1,48-1,90$ & $1,50-2,10$ \\
& $\mathrm{n}=141$ & $\mathrm{n}=142$ \\
\hline Homem & $1,45-1,89$ & $1,49-2,09$ \\
& $\mathrm{n}=74$ & $\mathrm{n}=76$ \\
Mulher & $1,56-1,92$ & $1,52-2,1$ \\
& $\mathrm{n}=67$ & $\mathrm{n}=66$ \\
\hline
\end{tabular}

n: número de amostras analisadas

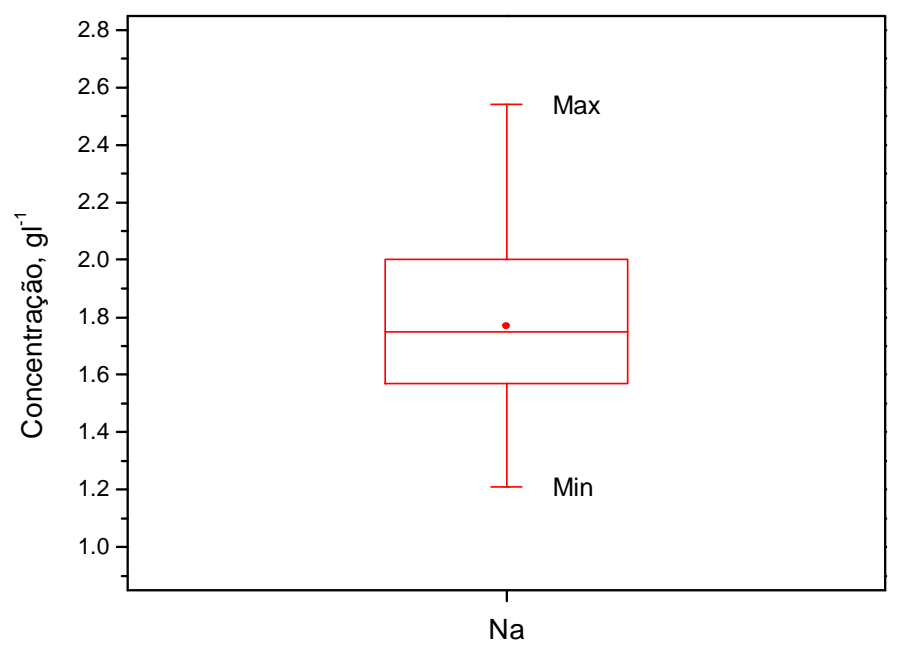

FIGURA 29 - Representação via Box-plot para Na. 


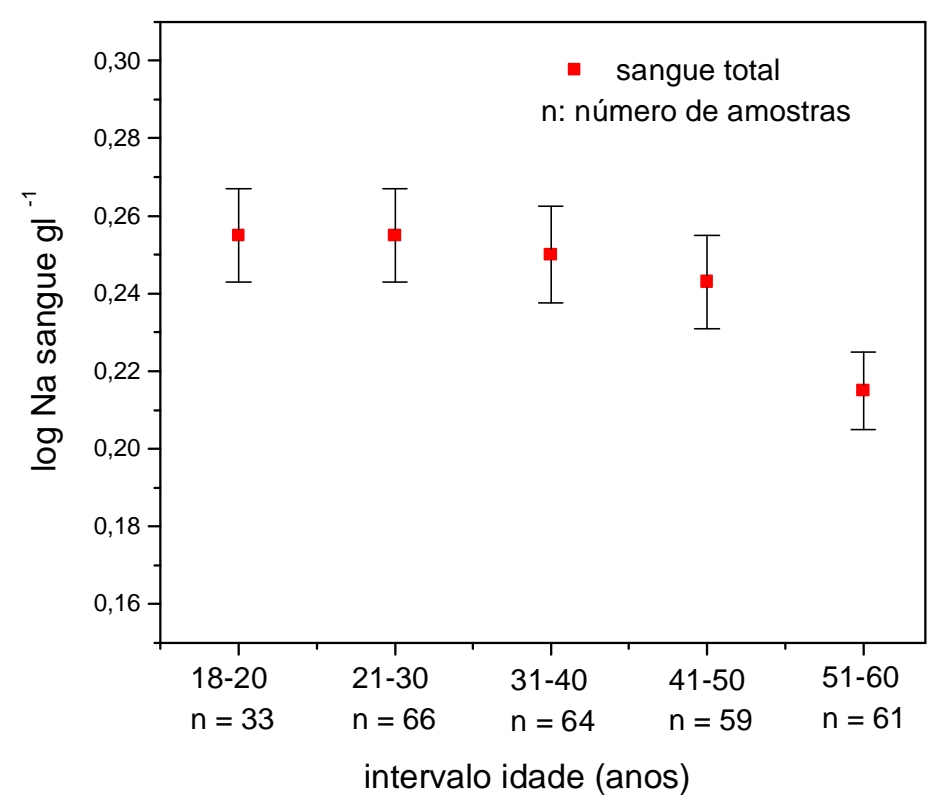

FIGURA 30 - Comportamento do Na em sangue total em função da faixa etária.

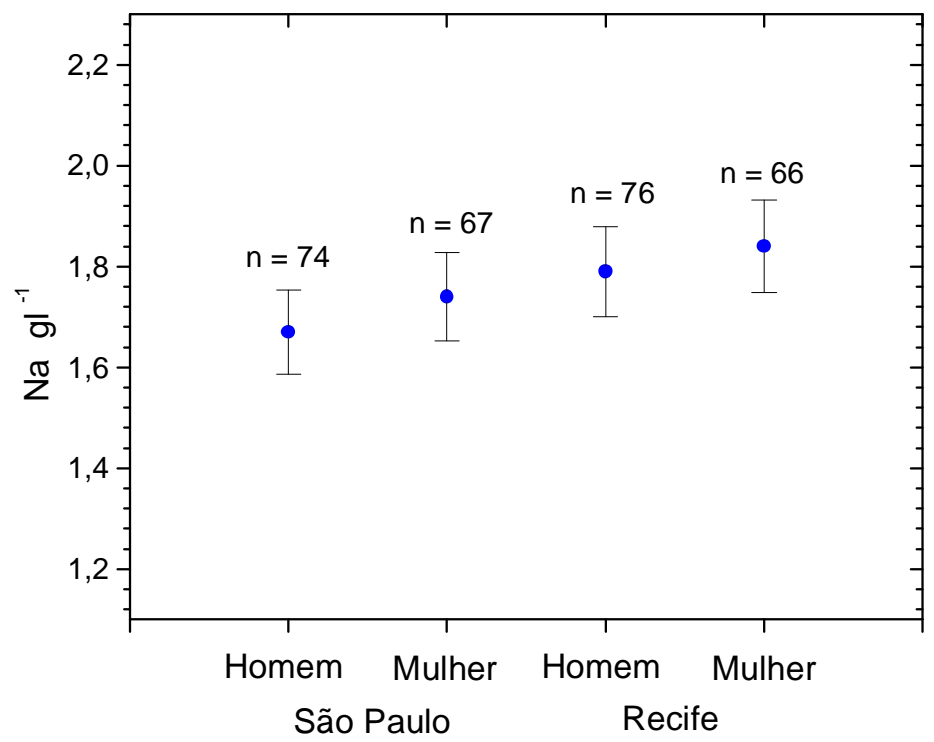

FIGURA 31 - Comportamento do $\mathrm{Na}$ em sangue total em função do sexo nas regiões monitoradas (Sudeste e Nordeste). 


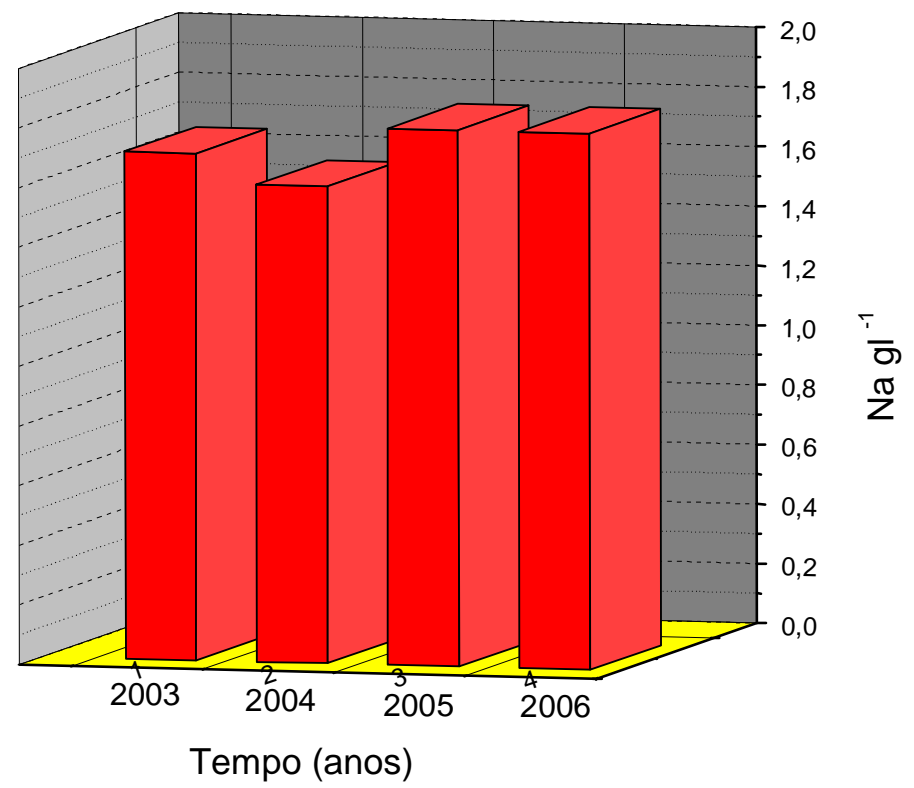

FIGURA 32 - Monitoramento do Na em sangue total em função do tempo na cidade de São Paulo.

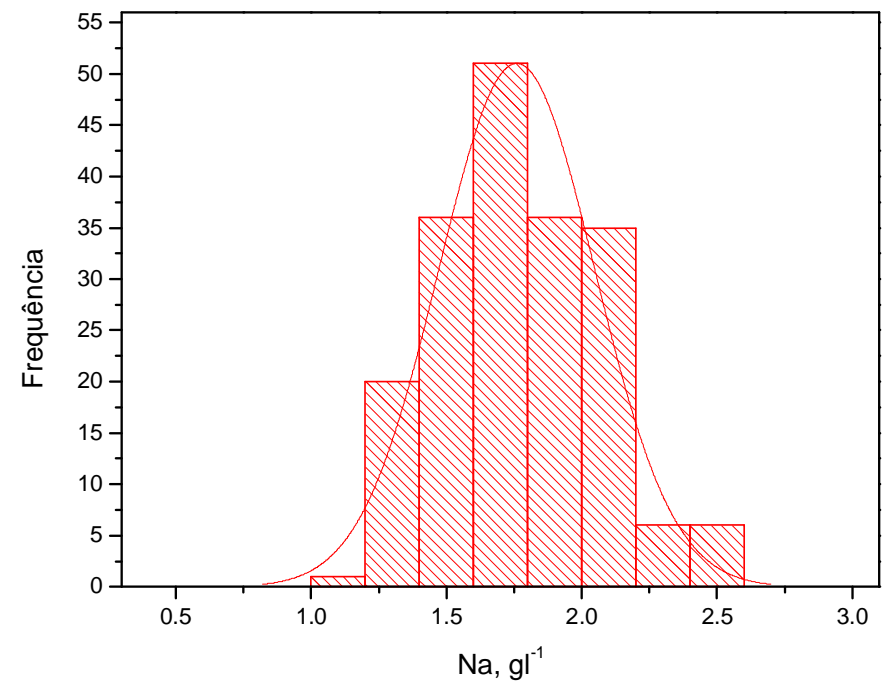

FIGURA 33 - Histograma e ajuste gaussiano da concentração de Na. 


\subsection{Comparação entre regiões e gênero}

Para realizar a comparação entre as médias das duas regiões estudadas e entre as médias dos gêneros masculino e feminino foi utilizado o Teste $t$ (Anexo 7).

O teste usado nesse trabalho é um Teste t não emparelhado, ou seja, de amostras retiradas de universos diferentes.

Nas TAB. 14 a 21 são apresentados os resultados do Teste t para os elementos $\mathrm{Br}, \mathrm{Cl}, \mathrm{K}$ e $\mathrm{Na}$ para os gêneros masculino e feminino de duas populações de diferentes regiões que foram avaliadas no presente estudo.

TABELA 14 - Resultados do Teste t para o elemento $\mathrm{Br}$ em sangue total em função do gênero.

\begin{tabular}{l|c|c|c}
\hline Br, gl ${ }^{-1}$ & Homem & Mulher & Teste t \\
\hline Total & $0,0162 \pm 0,0095$ & $0,0180 \pm 0,0110$ & $\mathrm{t}=1,48 \mathrm{P}>0,05$ \\
\hline $\begin{array}{l}\text { São Paulo } \\
\text { (região Sudeste) }\end{array}$ & $0,0091 \pm 0,0075$ & $0,0132 \pm 0,0065$ & $\mathrm{t}=3,45 \mathrm{P}<0,05$ \\
\hline $\begin{array}{l}\text { Recife } \\
\text { (região Nordeste) }\end{array}$ & $0,0180 \pm 0,0091$ & $0,0204 \pm 0,0121$ & $\mathrm{t}=1,34 \mathrm{P}>0,05$ \\
\hline
\end{tabular}


TABELA 15 - Resultados do Teste $\mathrm{t}$ para o elemento $\mathrm{Br}$ em sangue total em função da região.

\begin{tabular}{l|c|c|c}
\hline Br, gl ${ }^{-1}$ & $\begin{array}{c}\text { São Paulo } \\
\text { (região Sudeste) }\end{array}$ & $\begin{array}{c}\text { Recife } \\
\text { (região Nordeste) }\end{array}$ & Teste t \\
\hline Total & $0,0102 \pm 0,0074$ & $0,0183 \pm 0,0096$ & $\mathrm{t}=7,94 \mathrm{P}<0,05$ \\
\hline Homem & $0,0091 \pm 0,0075$ & $0,0180 \pm 0,0091$ & $\mathrm{t}=6,53 \mathrm{P}<0,05$ \\
\hline Mulher & $0,0132 \pm 0,0065$ & $0,0204 \pm 0,0121$ & $\mathrm{t}=4,28 \mathrm{P}<0,05$ \\
\hline
\end{tabular}

TABELA 16 - Resultados do Teste t para o elemento $\mathrm{Cl}$ em sangue total em função do gênero.

\begin{tabular}{l|c|c|c}
\hline Cl, gl ${ }^{-1}$ & Homem & Mulher & Teste t \\
\hline Total & $3,00 \pm 0,48$ & $3,12 \pm 0,50$ & $\mathrm{t}=2,06 \mathrm{P}<0,05$ \\
\hline $\begin{array}{l}\text { São Paulo } \\
\text { (região Sudeste) }\end{array}$ & $2,94 \pm 0,42$ & $3,12 \pm 0,49$ & $\mathrm{t}=2,35 \mathrm{P}<0,05$ \\
\hline $\begin{array}{l}\text { Recife } \\
\text { (região Nordeste) }\end{array}$ & $3,02 \pm 0,49$ & $3,12 \pm 0,53$ & $\mathrm{t}=1,17 \mathrm{P}>0,05$ \\
\hline
\end{tabular}


TABELA 17 - Resultados do Teste $\mathrm{t}$ para o elemento $\mathrm{Cl}$ em sangue total em função da região.

\begin{tabular}{l|c|c|c}
\hline $\mathrm{Cl}, \mathrm{gl}^{-1}$ & $\begin{array}{c}\text { São Paulo } \\
\text { (região Sudeste) }\end{array}$ & $\begin{array}{c}\text { Recife } \\
\text { (região Nordeste) }\end{array}$ & Teste t \\
\hline Total & $2,99 \pm 0,44$ & $3,03 \pm 0,50$ & $\mathrm{t}=0,71 \mathrm{P}>0,05$ \\
\hline Homem & $2,94 \pm 0,42$ & $3,02 \pm 0,49$ & $\mathrm{t}=1,07 \mathrm{P}>0,05$ \\
\hline Mulher & $3,12 \pm 0,49$ & $3,12 \pm 0,53$ & $\mathrm{t}=0 \mathrm{P}>0,05$ \\
\hline
\end{tabular}

TABELA 18 - Resultados do Teste t para o elemento K em sangue total em função do gênero.

\begin{tabular}{l|c|c|c}
\hline K, gl ${ }^{-1}$ & Homem & Mulher & Teste t \\
\hline Total & $1,63 \pm 0,27$ & $1,50 \pm 0,27$ & $\mathrm{t}=4,04 \mathrm{P}<0,05$ \\
\hline $\begin{array}{l}\text { São Paulo } \\
\text { (região Sudeste) }\end{array}$ & $1,64 \pm 0,27$ & $1,52 \pm 0,19$ & $\mathrm{t}=3,02 \mathrm{P}<0,05$ \\
\hline $\begin{array}{l}\text { Recife } \\
\text { (região Nordeste) }\end{array}$ & $1,63 \pm 0,28$ & $1,48 \pm 0,32$ & $\mathrm{t}=2,98 \mathrm{P}<0,05$ \\
\hline
\end{tabular}


TABELA 19 - Resultados do Teste $\mathrm{t}$ para o elemento $\mathrm{K}$ em sangue total em função da região.

\begin{tabular}{l|c|c|c}
\hline $\mathrm{K}, \mathrm{gl}^{-1}$ & $\begin{array}{c}\text { São Paulo } \\
\text { (região Sudeste) }\end{array}$ & $\begin{array}{c}\text { Recife } \\
\text { (região Nordeste) }\end{array}$ & Teste t \\
\hline Total & $1,60 \pm 0,25$ & $1,61 \pm 0,29$ & $\mathrm{t}=0,31 \mathrm{P}>0,05$ \\
\hline Homem & $1,64 \pm 0,27$ & $1,63 \pm 0,28$ & $\mathrm{t}=0,22 \mathrm{P}>0,05$ \\
\hline Mulher & $1,52 \pm 0,19$ & $1,48 \pm 0,32$ & $\mathrm{t}=0,88 \mathrm{P}>0,05$ \\
\hline
\end{tabular}

TABELA 20 - Resultados do Teste t para o elemento Na em sangue total em função do gênero.

\begin{tabular}{l|c|c|c}
\hline Na, gl & Homem & Mulher & Teste t \\
\hline Total & $1,76 \pm 0,29$ & $1,80 \pm 0,27$ & $\mathrm{t}=1,20 \mathrm{P}>0,05$ \\
\hline $\begin{array}{l}\text { São Paulo } \\
\text { (região Sudeste) }\end{array}$ & $1,67 \pm 0,22$ & $1,74 \pm 0,18$ & $\mathrm{t}=2,05 \mathrm{P}<0,05$ \\
\hline $\begin{array}{l}\text { Recife } \\
\text { (região Nordeste) }\end{array}$ & $1,79 \pm 0,30$ & $1,84 \pm 0,32$ & $\mathrm{t}=0,96 \mathrm{P}>0,05$ \\
\hline
\end{tabular}


TABELA 21 - Resultados do Teste t para o elemento Na em sangue total em função da região.

\begin{tabular}{l|c|c|c}
\hline Na, gl & $\begin{array}{c}\text { São Paulo } \\
\text { (região Sudeste) }\end{array}$ & $\begin{array}{c}\text { Recife } \\
\text { (região Nordeste) }\end{array}$ & Teste t \\
\hline Total & $1,69 \pm 0,21$ & $1,80 \pm 0,30$ & $\mathrm{t}=3,57 \mathrm{P}<0,05$ \\
\hline Homem & $1,67 \pm 0,22$ & $1,79 \pm 0,30$ & $\mathrm{t}=2,79 \mathrm{P}<0,05$ \\
\hline Mulher & $1,74 \pm 0,18$ & $1,84 \pm 0,32$ & $\mathrm{t}=2,22 \mathrm{P}<0,05$ \\
\hline
\end{tabular}

De acordo com as TAB. 14 a 21 os resultados do Teste t para os elementos $\mathrm{Br}$, $\mathrm{Cl}$, K e Na, com o nível de significância utilizado, apresentam evidências suficientes para descartar a hipótese de igualdade entre as concentrações em termos de gênero e região.

\subsection{Análise das correlações}

Por meio da análise das correlações (Anexo 8) entre os elementos medidos pode-se extrair informações a respeito das relações prioritárias que governam cada processo biológico [46].

$\mathrm{Na}$ TAB. 22 é apresentada a matriz de correlação para os elementos $\mathrm{Br}, \mathrm{Cl}, \mathrm{K} \mathrm{e}$ $\mathrm{Na}$ determinados em sangue total para toda população de estudo. 
TABELA 22 - Matriz de correlação para $\mathrm{Br}, \mathrm{Cl}, \mathrm{K}$ e $\mathrm{Na}$ em sangue total para toda população de estudo.

\begin{tabular}{l|cccc} 
& $\mathbf{B r}$ & $\mathbf{C l}$ & $\mathbf{K}$ & $\mathbf{N a}$ \\
\hline $\mathbf{B r}$ & 1 & & & \\
$\mathbf{C l}$ & 0,24 & 1 & & \\
$\mathbf{K}$ & 0,11 & 0,63 & 1 & \\
$\mathbf{N a}$ & 0,28 & 0,81 & 0,61 & 1
\end{tabular}

Através desta matriz (TAB. 22) pode-se fazer a comparação com as matrizes geradas em função de gênero e região e através das variações desses coeficientes de correlação verificar se existe o mesmo comportamento entre eles.

Nas TAB. 23 e 24 são apresentadas as matrizes de correlação para os elementos $\mathrm{Br}, \mathrm{Cl}, \mathrm{K}$ e Na determinados em sangue total de indivíduos saudáveis em função do gênero.

Nas TAB. 25 e 26 são apresentadas as matrizes de correlação para os elementos $\mathrm{Br}, \mathrm{Cl}, \mathrm{K}$ e $\mathrm{Na}$ determinados em sangue total de indivíduos saudáveis das duas regiões monitoradas nesse estudo (Sudeste - São Paulo e Nordeste - Recife).

TABELA 23 - Matriz de correlação para $\mathrm{Br}, \mathrm{Cl}, \mathrm{K}$ e $\mathrm{Na}$ em sangue total para o gênero feminino.

\begin{tabular}{l|cccc} 
& $\mathbf{B r}$ & $\mathbf{C l}$ & $\mathbf{K}$ & $\mathbf{N a}$ \\
\hline $\mathbf{B r}$ & 1 & & & \\
$\mathbf{C l}$ & 0,36 & 1 & & \\
$\mathbf{K}$ & 0,22 & 0,64 & 1 & \\
$\mathbf{N a}$ & 0,56 & 0,72 & 0,72 & 1
\end{tabular}


TABELA 24 - Matriz de correlação para $\mathrm{Br}, \mathrm{Cl}, \mathrm{K}$ e $\mathrm{Na}$ em sangue total para o gênero masculino.

\begin{tabular}{l|cccc} 
& $\mathbf{B r}$ & $\mathbf{C l}$ & $\mathbf{K}$ & $\mathbf{N a}$ \\
\hline $\mathbf{B r}$ & 1 & & & \\
$\mathbf{C l}$ & 0,21 & 1 & & \\
$\mathbf{K}$ & 0,10 & 0,67 & 1 & \\
$\mathbf{N a}$ & 0,23 & 0,86 & 0,61 & 1
\end{tabular}

TABELA 25 - Matriz de correlação para $\mathrm{Br}, \mathrm{Cl}, \mathrm{K}$ e $\mathrm{Na}$ em sangue total para a região Sudeste.

\begin{tabular}{l|cccc} 
& $\mathbf{B r}$ & $\mathbf{C l}$ & $\mathbf{K}$ & $\mathbf{N a}$ \\
\hline $\mathbf{B r}$ & 1 & & & \\
$\mathbf{C l}$ & 0,37 & 1 & & \\
$\mathbf{K}$ & $-0,08$ & 0,12 & 1 & \\
$\mathbf{N a}$ & $-0,07$ & 0,49 & 0,41 & 1
\end{tabular}

TABELA 26 - Matriz de correlação para $\mathrm{Br}, \mathrm{Cl}, \mathrm{K}$ e $\mathrm{Na}$ em sangue total para a região Nordeste.

\begin{tabular}{l|cccc} 
& $\mathbf{B r}$ & $\mathbf{C l}$ & $\mathbf{K}$ & $\mathbf{N a}$ \\
\hline $\mathbf{B r}$ & 1 & & & \\
$\mathbf{C l}$ & 0,21 & 1 & & \\
$\mathbf{K}$ & 0,14 & 0,76 & 1 & \\
$\mathbf{N a}$ & 0,29 & 0,91 & 0,65 & 1
\end{tabular}

De acordo com as matrizes geradas em função do gênero (TAB. 23 e 24) e em função da região (TAB. 25 e 26) verificam-se variações entre as correlações dos elementos medidos, em função da região, quando comparada com a matriz obtida para toda população de estudo (TAB. 22). 


\subsection{Análise dos elementos $\mathrm{Ca}$ e Fe}

Os elementos $\mathrm{Ca}(\mathrm{T} 1 / 2 \sim 8 \mathrm{~min})$ e Fe (T 1/2 $~ 45$ d) também foram medidos nesse trabalho. Entretanto, em função da pouca estatística, são apresentados dados preliminares referentes a doadores de sexo masculino, faixa etária acima de 30 anos, coletados no Banco de Sangue Paulista.

Os resultados apresentados na TAB. 27 foram obtidos pela análise das amostras em duplicata e o tratamento estatístico aplicado envolve a determinação da média aritmética (M), desvio padrão (DP), valor mínimo (Vmin) e valor máximo (Vmax).

TABELA 27 - Concentração dos elementos Ca e Fe em sangue total usando AAN.

\begin{tabular}{l|c|c|c|c}
\hline Elementos & Média & DP $(68 \%)$ & Valor Mínimo & Valor Máximo \\
\hline $\begin{array}{l}\mathrm{Ca}, \mathrm{gl}^{-1} \\
\mathrm{n}=22\end{array}$ & 0,233 & 0,083 & 0,090 & 0,390 \\
\hline $\mathrm{Fe}, \mathrm{gl}^{-1}$ & 0,395 & 0,059 & 0,315 & 0,475 \\
$\mathrm{n}=20$ & & & & \\
\hline
\end{tabular}

n: número de amostras analisadas

Um aspecto positivo, extraído do estudo realizado por Lins [31], relaciona-se ao uso da estimava de $\mathrm{Fe}$ em sangue total como parâmetro para avaliação de disfunções associadas ao seu acúmulo ou déficit no organismo. Entretanto, é necessário um maior número de análises para estabelecer seu valor de referência em sangue total. 


\section{CAPÍTULO 5. DISCUSSÃO}

\subsection{Vantagens do uso da AAN em bioquímica clínica}

Com relação ao uso do método semi-paramétrico de AAN, para realização de análises bioquímicas em sangue, algumas vantagens podem ser apontadas quando comparada com outras técnicas convencionais [2,3]: uso de sangue total; utilização de pequena quantidade material biológico $(100 \mu \mathrm{l})$ para a análise de vários elementos simultaneamente; simplificação no mecanismo de coleta do material biológico, ou seja, não há necessidade do processamento pré-analítico da amostra, pois o processo não necessita da separação soro/plasma e armazenamento sem a necessidade de refrigeração. Além disso, por ser um método não destrutivo as análises podem ser refeitas ao término de sua atividade residual ( $72 \mathrm{hs}$ ) ou armazenadas por longos períodos (até anos, pois depende da durabilidade do papel).

Considerando o tempo empregado para realização dessas análises, isto é, tempo de irradiação de 3 minutos; tempo de contagem de 15 segundos para cada detetor de ativação (e respectiva medida de radiação fundo) e 10 minutos para amostra biológica (e respectiva medida de radiação de fundo), pode-se concluir a análise da amostra em aproximadamente 30 minutos.

Da mesma forma, para avaliação do Ferro (irradiação de $500 \mu \mathrm{l}$ ) não há necessidade do processamento pré-analítico da amostra e também não necessita de refrigeração. As análises podem ser refeitas ao término de sua atividade residual $(\sim 3$ meses) ou armazenadas por longos períodos (até anos, pois depende da durabilidade do invólucro de plástico).

As vantagens apontadas fazem desse procedimento um método rápido e eficaz, dado seu caráter simultâneo de análise o que nem sempre é possível nos procedimentos convencionais em bioquímica clínica [2-3]. 


\subsection{Estudo do comportamento dos elementos medidos via AAN em sangue total}

Para a realização de um estudo comparativo é fundamental que o tratamento estatístico seja uniformizado e contenha o maior número de dados possíveis, tais como: média aritmética, desvio padrão, mediana, moda e intervalo de referência, de modo que seja possível avaliar o comportamento dos elementos medidos em brasileiros que vivem em regiões distintas, neste estudo Sudeste e Nordeste, bem como realizar comparações entre essas regiões em função da idade e do sexo.

\subsubsection{Comportamento do elemento bromo em função do gênero, idade e localização geográfica}

Os resultados para o $\mathrm{Br}$ apresentados nas FIG. 15 e 16 sugerem algumas variações quando se faz uma comparação em função da idade, do sexo e da localização geográfica. Especificamente, com relação à faixa etária os resultados apresentados na FIG. 15 mostram que a concentração de bromo varia com a idade. Já, na FIG. 16 é possível observar que sua concentração é ligeiramente maior nas mulheres do que nos homens.

Com relação à localização geográfica a FIG. 16 mostra um aumento na concentração de bromo na população de Recife, quando comparada à população de São Paulo, o que pode estar relacionado ao fato que Recife é uma cidade litorânea conseqüentemente a população local tem uma ingestão maior de frutos do mar, alimentos ricos em bromo. Porém, estudos complementares relacionados à nutrição devem ser feitos a fim subsidiar esta discussão.

Com relação ao monitoramento do $\mathrm{Br}$ em sangue total em função do tempo na cidade de São Paulo, nenhuma mudança significativa foi observada nesses 3 anos, de acordo com a FIG. 17. 


\subsubsection{Comportamento do elemento cloro em função de gênero, idade e localização geográfica}

Os resultados para o $\mathrm{Cl}$ apresentados nas FIG. 20 e 21 não sugerem variações nesse elemento quando se faz uma comparação em função da idade, do sexo e da distribuição geográfica.

Com relação ao monitoramento do $\mathrm{Cl}$ em sangue total em função do tempo na cidade de São Paulo, nenhuma mudança significativa foi observada nesses 4 anos, de acordo com a FIG. 22.

\subsubsection{Comportamento do elemento potássio em função de gênero, idade e localização geográfica}

Os resultados para o $\mathrm{K}$ apresentados nas FIG. 25 e 26 sugerem algumas variações quando se faz uma comparação em função da idade, do sexo e da localização geográfica. Especificamente, com relação à faixa etária os resultados apresentados na FIG. 25 mostram que a concentração de potássio varia com a idade. Já, na FIG. 26 é possível observar que sua concentração é ligeiramente menor nas mulheres do que nos homens. Esse comportamento é sistemático para as duas regiões analisadas.

Com relação ao monitoramento do $\mathrm{K}$ em sangue total em função do tempo na cidade de São Paulo, nenhuma mudança significativa foi observada nesses 4 anos, de acordo com a FIG. 27.

\subsubsection{Comportamento do elemento sódio em função de gênero, idade e localização geográfica}

Os resultados para o $\mathrm{Na}$ apresentados nas FIG. 30 e 31 sugerem algumas variações quando se faz uma comparação em função da idade, do sexo e da distribuição geográfica. Especificamente, com relação à faixa etária os resultados apresentados na FIG. 30 mostram que a concentração de sódio varia com a idade. Já, na FIG. 31 é possível observar que sua concentração é ligeiramente maior nas mulheres do 
que nos homens; isso pode estar relacionado ao fato de que as mulheres retêm mais líquidos corporais do que os homens e como os íons de sódio no organismo estão intimamente ligados ao equilíbrio hídrico do corpo, pode haver um aumento em sua concentração.

Com relação à localização geográfica, a FIG. 31 também mostra um aumento na concentração de sódio na população de Recife, quando comparada à população de São Paulo; isto pode estar relacionado ao fato que Recife é uma cidade litorânea e conseqüentemente a população local tem uma ingestão maior de frutos do mar que são alimentos ricos em sódio. Porém, estudos complementares relacionados à nutrição devem ser feitos a fim subsidiar esta discussão.

Com relação ao monitoramento do $\mathrm{Na}$ em sangue total em função do tempo na cidade de São Paulo, nenhuma mudança significativa foi observada nesses quatro anos, de acordo com a FIG. 32.

\subsection{Comparação com outras estimativas}

Em função do tratamento estatístico aplicado, foi possível também confrontar os resultados obtidos dos elementos medidos em sangue total com outras estimativas da literatura (dados de outros países) obtidas por diferentes métodos. Na TAB. 28 é apresentado um sumário com dados estabelecidos para $\mathrm{Br}, \mathrm{Ca}, \mathrm{Cl}, \mathrm{Fe}, \mathrm{K}$ e $\mathrm{Na}$ e o que se observa é uma compatibilidade entre os dados para dois Desvios Padrão. 
TABELA 28 - Sumário dos dados relacionados ao valor de referência em sangue total.

\begin{tabular}{|c|c|c|}
\hline Elemento $\left(\mathrm{gl}^{-1}\right)$ & Média (DP) & Técnica, ano \\
\hline \multirow[t]{2}{*}{$\mathrm{Cl}$} & $3,02 \pm 0,48$ & pe \\
\hline & $1,72 \pm 0,69$ & PIXE [14], 1984 \\
\hline \multirow[t]{3}{*}{$K$} & $1,61 \pm 0,28$ & pe \\
\hline & $1,66 \pm 0,12$ & CMP-AES [47], 1999 \\
\hline & $0,806 \pm 0,312$ & PIXE [14], 1984 \\
\hline \multirow[t]{2}{*}{$\mathrm{Na}$} & $1,77 \pm 0,29$ & pe \\
\hline & $1,20 \pm 0,60$ & CMP-AES [47], 1999 \\
\hline \multirow[t]{4}{*}{$B r$} & $0,0165 \pm 0,0098$ & pe \\
\hline & $0,0079 \pm 0,0027$ & PIXE [14], 1984 \\
\hline & $0,014 \pm 0,001$ & ICP-MS [48], 2000 \\
\hline & $0,0079 \pm 0,0046$ & ICP-SMS [49], 1999 \\
\hline \multirow[t]{2}{*}{$\mathrm{Ca}$} & $0,233 \pm 0,083$ & pe \\
\hline & $0,181 \pm 0,065$ & PIXE [14], 1984 \\
\hline \multirow[t]{4}{*}{$F e$} & $0,395 \pm 0,059$ & pe \\
\hline & $0,295 \pm 0,106$ & PIXE [14], 1984 \\
\hline & $0,445 \pm 0,071$ & {$[50], 1988$} \\
\hline & $0,476 \pm 0,068$ & ICP-SMS [49], 1999 \\
\hline
\end{tabular}

* Compilação de dados obtidos com diferentes técnicas pe: presente estudo

PIXE: Proton Induced X-Ray Emission

CMP-AES: Capacitively Coupled Microwave Plasma Atomic Emission Spectrometer

ICP-MS: Inductively Coupled Plasma Mass Spectrometry

ICP-SMS: High resolution inductively coupled plasma mass spectrometry

\subsection{Comparação sangue e soro}

Os dados referentes às analises nos materiais de referência de sangue total (TAB. 4) e soro (TAB. 3) permitem uma comparação entre as concentrações de $\mathrm{Cl}, \mathrm{K}$ e $\mathrm{Na}$ obtidas via AAN apresentadas no diagrama da FIG. 34. 


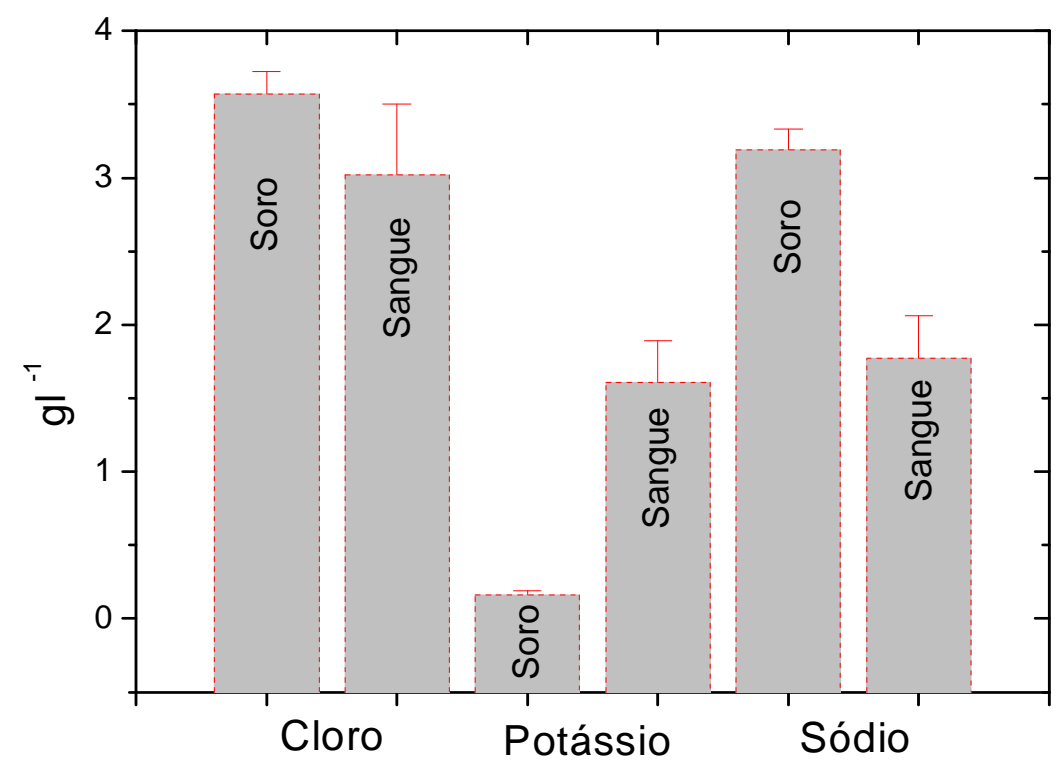

FIGURA 34 - Comparação sangue total - soro para os elementos $\mathrm{Cl}$, K e Na.

De acordo com os resultados apresentados na FIG. 34 observamos que as concentrações de $\mathrm{Cl}$ em sangue e soro são praticamente constantes, enquanto as concentrações de K e Na são maiores em sangue total e soro, respectivamente.

Da mesma forma, esse comportamento pode ser também observado para o conjunto de medidas realizados em sangue total no presente estudo (sintetizados na TAB. 5) quando comparado com os dados de AAN em soro, para população brasileira, extraídos do estudo recente realizado por Kovacs [51]. Na TAB. 29 é apresentada a síntese desses dados. 
TABELA 29 - Comparação dos resultados das análises bioquímicas em soro e sangue para a população brasileira pela técnica de AAN.

\begin{tabular}{l|c|c}
\hline Elemento & $\begin{array}{c}\text { Média } \pm \mathrm{DP} \\
\text { Soro }\left(\mathrm{gl}^{-1}\right)\end{array}$ & $\begin{array}{c}\text { Média } \pm \mathrm{DP} \\
\text { Sangue total }\left(\mathrm{gl}^{-1}\right)\end{array}$ \\
\hline $\mathrm{Cl}$ & $3,50 \pm 0,15$ & $3,02 \pm 0,48$ \\
$\mathrm{~K}$ & $0,16 \pm 0,03$ & $1,61 \pm 0,28$ \\
\hline $\mathrm{Na}$ & $3,19 \pm 0,14$ & $1,77 \pm 0,29$ \\
\hline
\end{tabular}

A baixa concentração de $\mathrm{K}$ em soro deve-se ao fato de que o potássio é o principal cátion do meio intracelular e, conseqüentemente, encontra-se em maior concentração em células de tecidos e nas hemácias enquanto que o $\mathrm{Na}$, por ser o principal cátion do meio extracelular, encontra-se em maior concentração no soro [52]. 


\section{CAPÍTULO 6. CONCLUSÕES}

O procedimento semi-paramétrico de Análise por Ativação com Nêutrons foi utilizado com sucesso para obtenção dos valores de referência (VR) em padrão de soro humano, permitindo a validação do método e seu emprego na análise de sangue total.

Foram obtidos dados neste estudo para o valor de referência dos elementos $\mathrm{Br}$, $\mathrm{Cl}$, K e Na em sangue total e seus coeficientes de correlação, sendo estes os primeiros índices estabelecidos para a população brasileira.

O tratamento estatístico aplicado, isto é, sua padronização contendo o maior número de estimadores possíveis (média, desvio padrão, moda, mediana e valor de referência) tornou possível a comparação dos dados entre as diferentes regiões brasileiras, em função da idade e do sexo, além de permitir a comparação com estimativas da literatura (dados de outros países) obtidas por diferentes métodos.

As análises das correlações mostram que os elementos $\mathrm{Br}, \mathrm{Cl}, \mathrm{K}$ e $\mathrm{Na}$ seguem o mesmo comportamento independentemente da região, mas os coeficientes das correlações sugerem que os limites de normalidade sejam avaliados em termos regionais.

Este procedimento de análise pode se estender para os demais elementos, passíveis de ativação em sangue total, para obtenção de seus valores de referência e implementação da matriz de correlação.

Uma conseqüência importante deste estudo está relacionada à viabilidade de uso do método nuclear em questão como alternativa para realização de análises bioquímicas em sangue total, uma vez que os limites de normalidade para a população brasileira foram estabelecidos no presente estudo. 
ANEXO 1

\section{TERMO DE CONSENTIMENTO LIVRE E ESCLARECIDO}

Acredito ter sido suficientemente informado da pesquisa que será realizada com minha amostra de sangue, ficando claro que minha participação é isenta de despesas e de quaisquer riscos, com garantia de confidencialidade e esclarecimentos permanentes.

Concordo voluntariamente a participar deste estudo sem prejuízo de qualquer benefício que eu tenha adquirido.

Assinatura do doador

Testemunha

São Paulo, de de 20 


\section{ANEXO 2}

\section{Programa IDF usado para o cálculo da área}

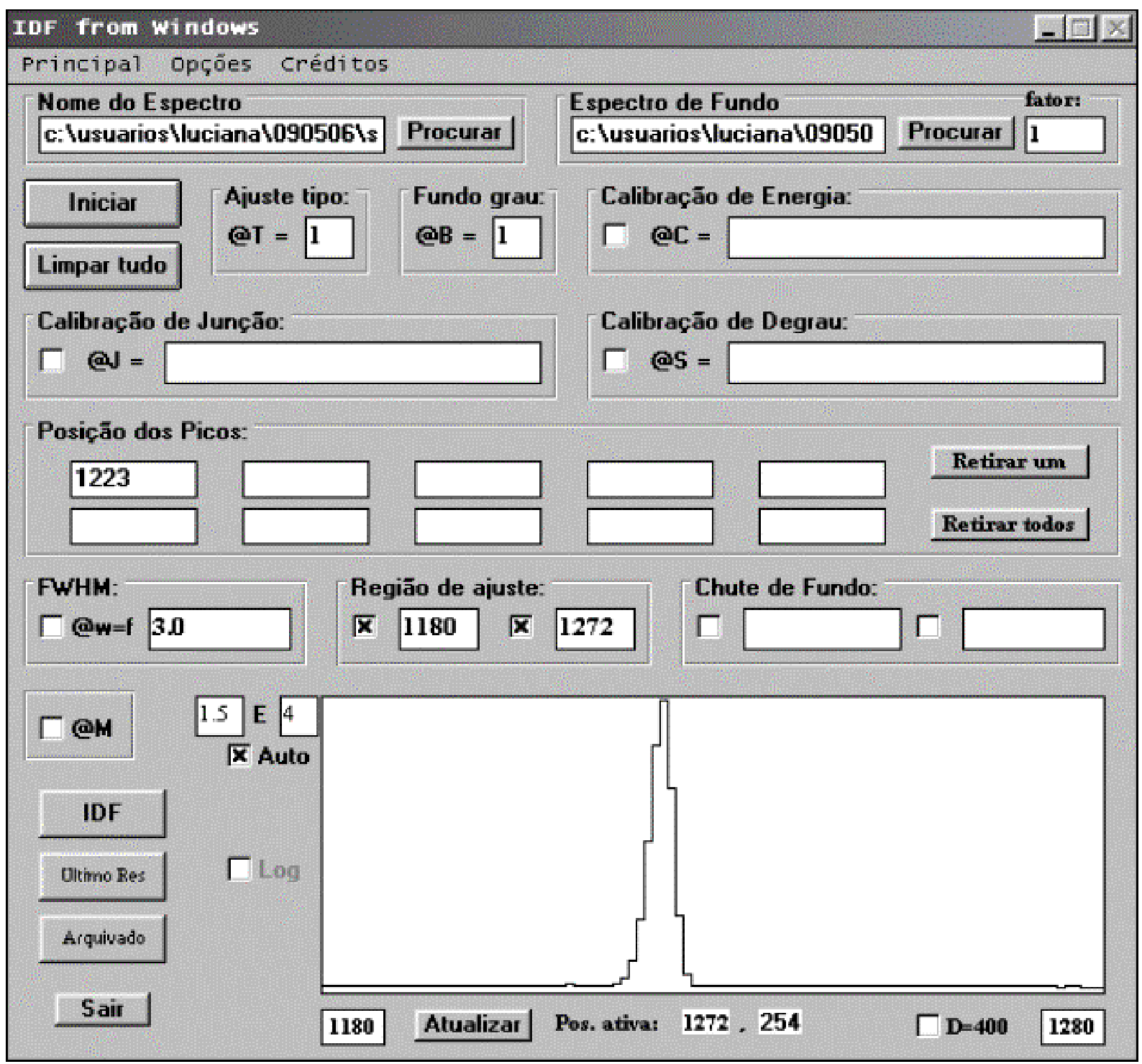




\section{ANEXO 3}

\section{Resultado da área calculada pelo programa IDF}

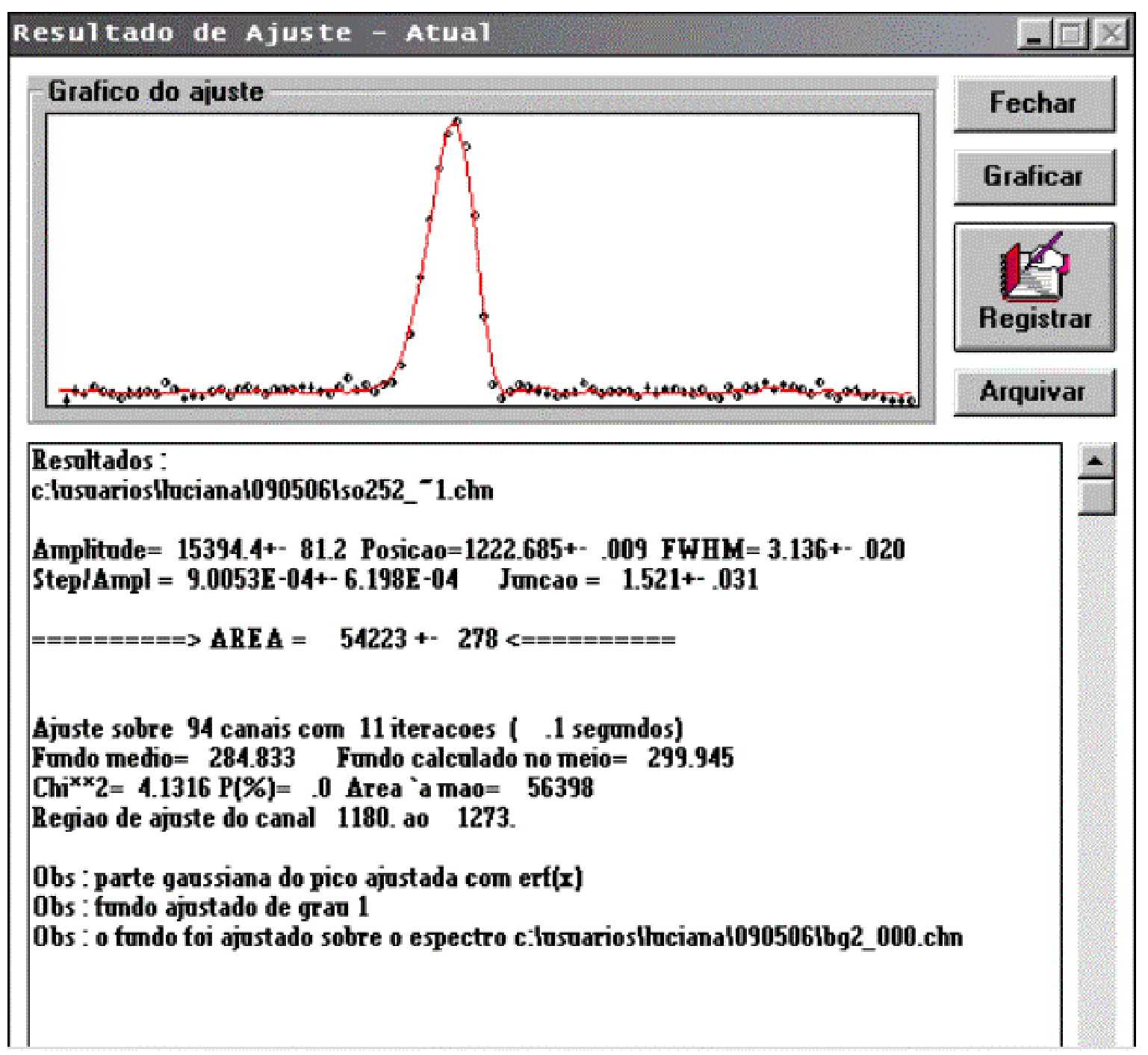




\section{ANEXO 4}

\section{Tela principal do programa ATIVAÇÃO}

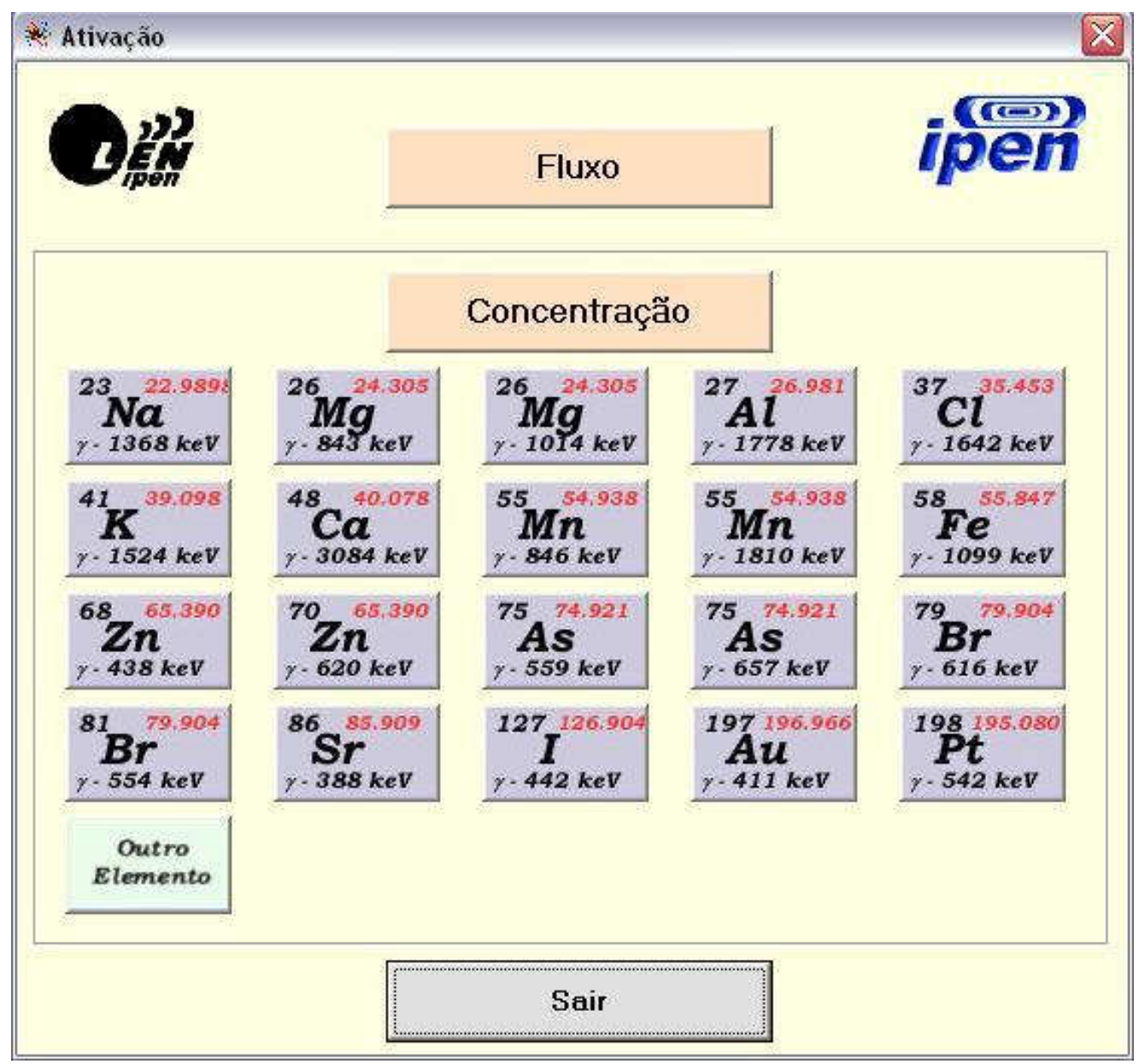

A partir desta tela (tela de entrada) é feita a seleção do procedimento Cálculo do Fluxo (Anexo 5); retorna-se a essa tela para seleção do elemento que permite o cálculo de sua concentração (Anexo 6). Os parâmetros a serem fornecidos dizem respeito a área da transição $\gamma$, tempo de irradiação (Ti), tempo de contagem (Tc) e massa (do Au para cálculo do fluxo e da amostra biológica para obtenção da concentração). 


\section{ANEXO 5}

\section{Tela do cálculo do fluxo do programa ATIVAÇÃO}

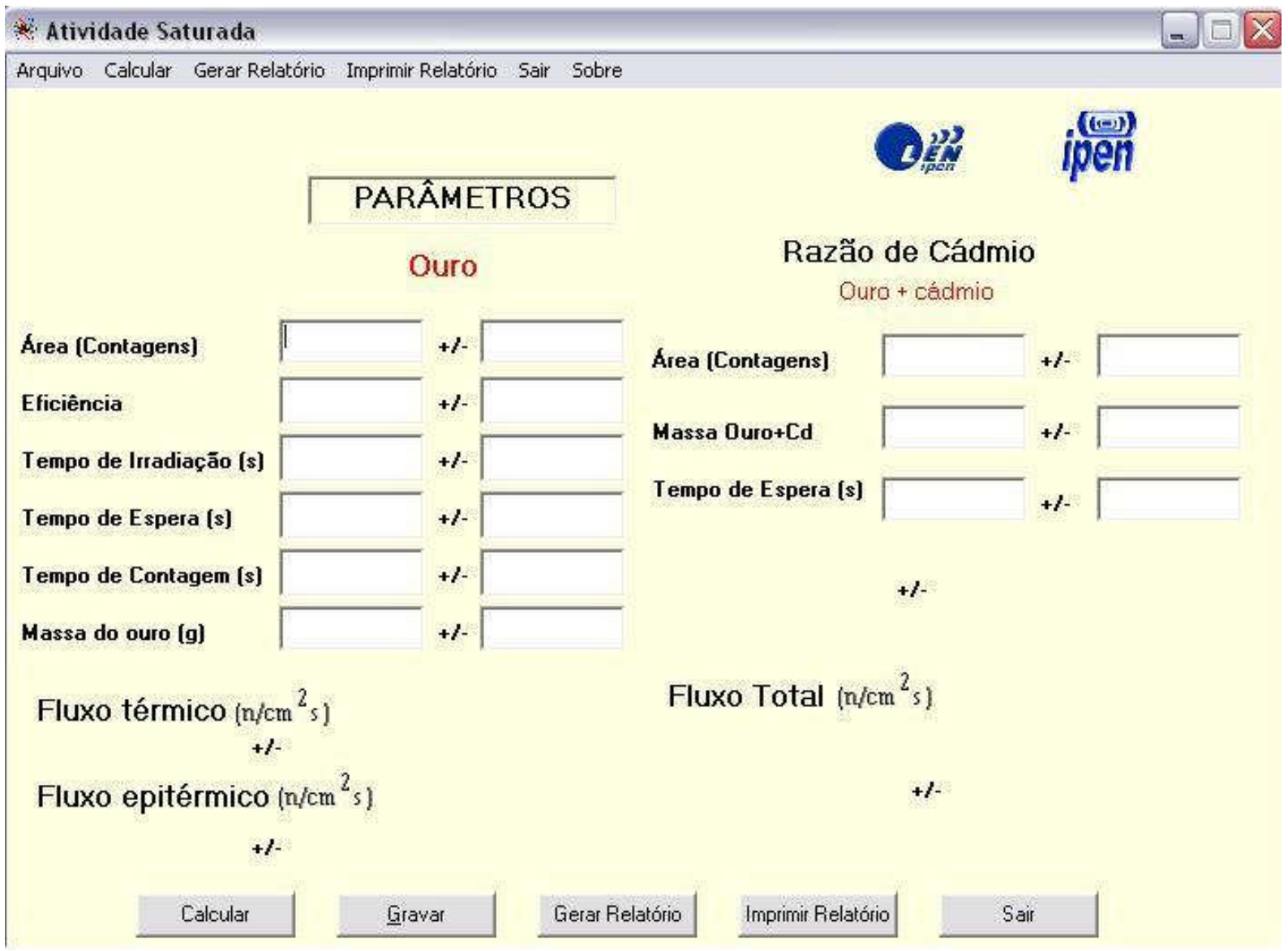




\section{ANEXO 6}

\section{Tela do cálculo da concentração do programa ATIVAÇÃO}

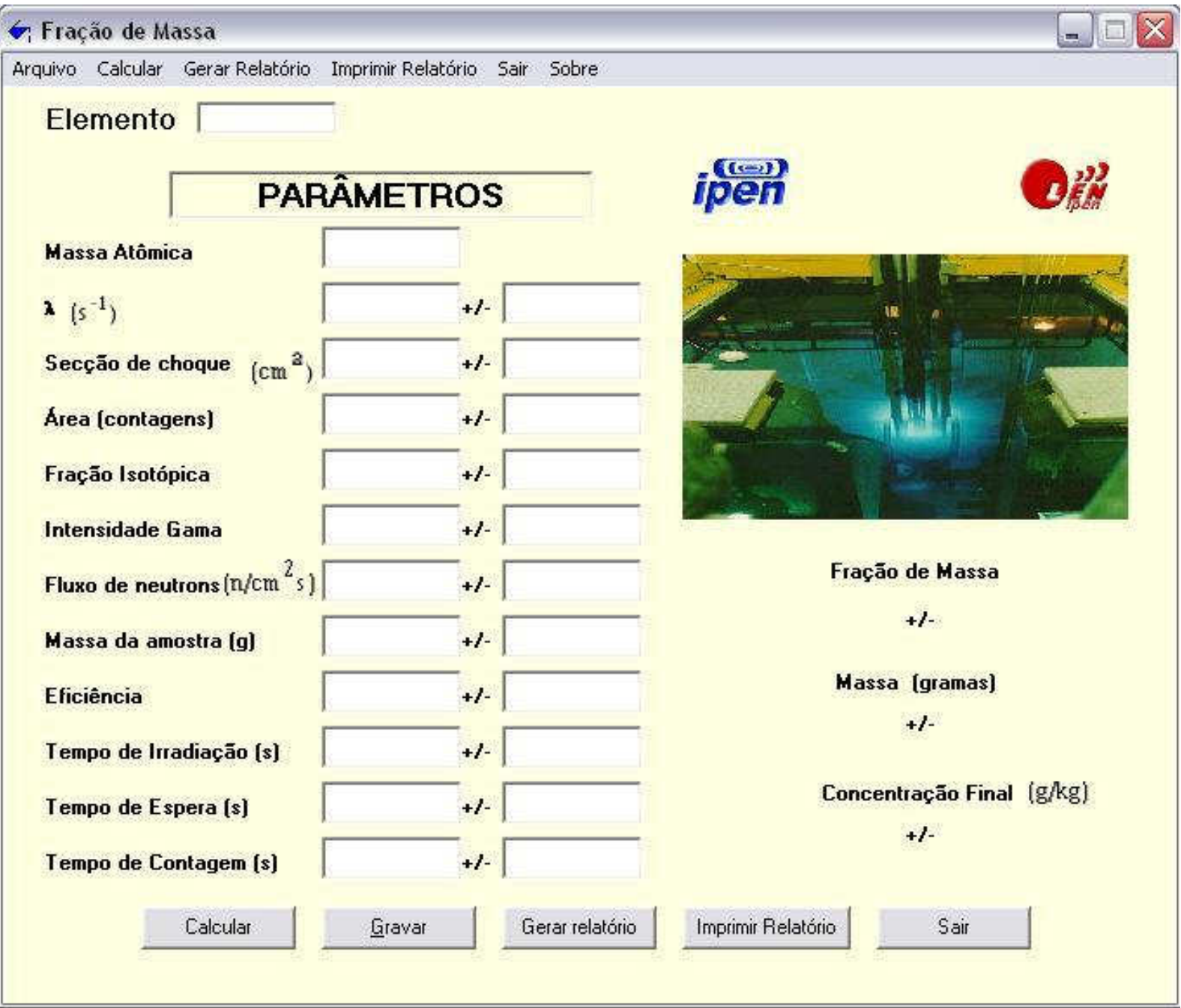

De posse dos dados referentes ao fluxo de nêutrons $(\mathrm{fn})$, área $(\mathrm{Cg})$, massa da amostra, eficiência e dos tempos envolvidos ( $\mathrm{Ti}, \mathrm{Te}, \mathrm{Tc}$ ), obtém-se a concentração do elemento selecionado. 


\section{ANEXO 7}

\section{TESTE T}

\section{Teste de hipótese da diferença entre as médias de duas populações: amostras independentes}

Considerando que o tamanho da amostra é grande $\left(n_{1} \geq 30, n_{2} \geq 30\right)$ e as amostras independentes, em geral as hipóteses utilizadas são escritas como:

$$
\begin{aligned}
& H_{0}: \mu_{1}-\mu_{2}=0 \\
& H_{1}: \mu_{1}-\mu_{2} \neq 0
\end{aligned}
$$

Usando a diferença entre as médias da amostra como a estimativa pontual da diferença entre as médias da população, para o caso da grande amostra, a distribuição de $x_{1}-x_{2}$ pode ser aproximada por uma distribuição normal de probabilidade, utilizando o teste estatístico:

$$
z=\frac{\left(\bar{x}_{1}-\bar{x}_{2}\right)-\left(\mu_{1}-\mu_{2}\right)}{\sqrt{\frac{\sigma_{1}^{2}}{n_{1}}+\frac{\sigma_{2}^{2}}{n_{2}}}}
$$




\section{ANEXO 8}

\section{Análise das correlações}

Para esta análise considera-se o valor de cada variável $X_{j i}(j=1, \ldots, m$ elementos) em cada amostra analisada ( $\mathrm{i}=1, \ldots ., \mathrm{N}$ amostras), sendo a correlação entre os elementos medidos, por exemplo $\mathrm{X}_{1}$ e $\mathrm{X}_{2}$, expressa por:

$$
\begin{aligned}
& \rho_{12}=\operatorname{cov}\left(\mathrm{X}_{1} \mathrm{X}_{2}\right) / \sigma_{\mathrm{x} 1} \cdot \sigma_{\mathrm{x} 2} \\
& \quad \text { onde } \\
& \operatorname{cov}\left(\mathrm{X}_{1} \mathrm{X}_{2}\right)=\sum\left(\mathrm{X}_{11}-\mathrm{X}_{1}^{\mathrm{m}}\right)\left(\mathrm{X}_{21}-\mathrm{X}_{2}^{\mathrm{m}}\right) / \mathrm{N}-1
\end{aligned}
$$

sendo:

$\mathbf{X}_{\mathbf{j}}^{\mathbf{m}}$ é o valor médio da variável j nas $\mathrm{N}$ amostras medidas e o desvio padrão da variável $X_{j}$ expresso por $\sigma_{x j}$. 


\section{ANEXO 9}

Sumário dos valores de referência obtidos pela técnica AAN em sangue total

\begin{tabular}{|c|c|c|c|}
\hline Elementos & M & DP & Intervalo de referência \\
\hline $\begin{array}{l}\mathrm{Br} \\
\mathrm{n}=283\end{array}$ & 0,0165 & 0,0098 & $\begin{array}{r}0,0067-0,0263 \mathrm{gl}^{-1} \\
0,08-0,3 \mathrm{mEq} / 1\end{array}$ \\
\hline $\begin{array}{l}\mathrm{Cl} \\
\mathrm{n}=283\end{array}$ & 3,02 & 0,48 & $\begin{array}{c}2,54-3,50 \mathrm{gl}^{-1} \\
71,5-98,5 \mathrm{mEq} / 1\end{array}$ \\
\hline $\begin{array}{l}K \\
n=283\end{array}$ & 1,61 & 0,28 & $\begin{array}{l}1,33-1,89 \mathrm{gl}^{-1} \\
33-47 \mathrm{mEq} / 1\end{array}$ \\
\hline $\begin{array}{l}\mathrm{Na} \\
\mathrm{n}=283\end{array}$ & 1,77 & 0,29 & $\begin{array}{c}1,48-2,06 \mathrm{gl}^{-1} \\
64-89,5 \mathrm{mEq} / 1\end{array}$ \\
\hline $\begin{array}{l}\mathrm{Ca} \\
\mathrm{n}=22\end{array}$ & 0,233 & 0,083 & - \\
\hline $\begin{array}{l}\mathrm{Fe} \\
\mathrm{n}=20\end{array}$ & 0,395 & 0,059 & - \\
\hline
\end{tabular}

n: número de amostras analisadas 


\section{REFERÊNCIAS BIBLIOGRÁFICAS}

[1] HENRY, J.B. Diagnósticos Clínicos e Conduta Terapêutica por exames Laboratoriais. 10 ed. Vol. 1, 1982.

[2] LABORATÓRIO FLEURY. Manual de exames do laboratório Fleury. São Paulo, 1996.

[3] FRÉJAVILLE, J.P. AND KAMOUN, P. (eds). Guide des examens de laboratoire, Paris, Flammarion, 1981.

[4] OLIVEIRA, L.C.; ZAMBONI, C.B.; ZAHN, G.S.; MASCHIO, M.A.; FIGUEIREDO, A.M.G.; ZEVALLOS-CHÁVEZ, J.Y.; CRUZ, M.T.F.; CESTARI, A.C. The Cadmium Ratio Technique for studying biological functions of mammalian submitted to Uranium ingestion. In: REUNIÃO DE TRABALHO SOBRE FÍSICA NUCLEAR NO BRASIL, 53, 31-4 agosto/setembro, 2002, São Pedro. Resumos... São Paulo.

[5] COMENS, P. Metal-binding in Medicine, Ed. M.J. Server and L. A. Johnson, 1960.

[6] GOODEN, D.S. Non destructive NAA for the determination of $\mathrm{Mg}$ and $\mathrm{Zn}$ in Human skin biopsoies. Physics Medicine and Biology, v. 17, n.1, p. 26-31, 1972.

[7] LEVRI, E.A.; RUNYAN, T.E.; BASS, B.G.; MAHIN, D.T. Diagnostic applications of neutrons activation analysis in medicine. In: SECOND INTERNATIONAL CONFERENCE ON MEDICAL PHYSICS, 155, 10-14 August , 1969, Boston, EUA.

[8] CATA-DANIEL, I.; MORO, R.; GIALANELLA, G. Nuclear Techiniques for trace element analysis. PIXE and its applications to biomedical samples. Romaniam Report Physics. v. 48, p. 105, 1996.

[9] ABBOUD, S.; SCHLESINGER, T.; LAVI, N.; DAVID, M.; FEUERMAN, E.J. Investigation of a possible correlation between the level of Se in blood and skin disease by NAA. In: JOINT ANNUAL MEETING OF THE ISRAEL NUCLEAR SOCIETIES BEM GURION UNIVERSITY OF THE NEGEV, 781, 28 December, 1978, Beersheba, Israel.

[10] PANAYI, A.E.; SPYROU, N.M.; PART, P. Differences in trace element concentrations between Alzheimer and normal human brain tissue using Instrumental Neutron Activation Analysis. Journal Rad Nucl Chem, v. 249 (2), p. 437, 2001. 
[11] ELIIS, K.J.; SHYPAILO, R.J.; HERGENROEDER, A.C.; PEREZ, M.D.; ABRAMS, S.A. Total body calcium by Neutron Activation Analysis: References data for chidren. Journal Rad Nucl Chem, v. 249 (2), p. 461, 2001.

[12] MIHAI, M.; POPESCU, I.V. The correlation's matrix determined among trace elements present in human fluid. Romanian Journal Physics, v. 45, p. 157, 2000.

[13] POPESCU, I.V.; MIHAI, M. Mathematical model for the distribution of trace elements in biological tissues. Romanian Journal Physics, v. 44, p. 655, 1999.

[14] MOUSAVI-YEGANEH, S.; EBRAHIMY-FAKHAR, F.; ENAYATI, F. Analysis of addicted and normal blood samples from humans by Proton Induced X-ray Emission. Nuclear Instruments and Methods in Physics Research B3, p. 364, 1984.

[15] HASEGAWA, T.; INAGAKI, K.; HARAGUCHI, H. Multielement Correlation Analysis of Major-to-Trace Elements in Human Blood Serum for Medical Diagnosis as Studied by ICP-AES and ICP-MS, Analytical Sciences, v. 17 supplent, p. 979, 2001.

[16] ARRUDA-NETO, J.D.T.; VANIN, V.R.; DEPPMAN, A.; LIKHACHEV, V.P.; MESA, J.; HELENE, O.A.M.; MARTINS, M.N.; CESTARI, A.C.; NOGUEIRA, G.P.; FONSECA, L.E.C.; ZAMBONI, C.B.; SAIKI, M.; GOUVEIA, A.N.; JORGE, S.A.C.; RODRIGUEZ, O.; GUZMÁN, F.; GARCIA, F. The role played by phytase and metabolism in the accumulation of Uranium in the poultry bones. In: ENCONTRO NACIONAL DE APLICAÇÕES NUCLEARES - ENAN, 11 -16 agosto, 2002, Rio de Janeiro, Proceedings... CD-ROM.

[17] OLIVEIRA, L.C.; ZAMBONI, C.B.; CESTARI, A.C.; DALAQUA JUNIOR, L.; MANSO, M.V.G.; FIGUEIREDO, A.M.G.; ARRUDA-NETO, J.D.T. Nuclear Methodology for Studying Biological Functions of Mammalians Submitted to Uranium Ingestion. Revista Brasileira de Pesquisa e Desenvolvimento, v. 4, n. 3, p. 1035-1039, 2002.

[18] ARRUDA-NETO, J.D.T.; CESTARI, A.C.; NOGUEIRA, G.P.; FONSECA, L.E.C.; ZAMBONI, C.B.; SAIKI, M.; MANSO, M.V.; MESA, J.; VANIN, V.R.; HELENE, O.A.M.; DEPPMAN, A.; LIKHACHEV, V.P.; GOUVEIA, A.N.; JORGE, S.A.C.; MARTINS, M.N. Observação de interferência metabólica acentuada na biocinética de urânio em ossos de frangos de corte. In: ENCONTRO NACIONAL DE APLICAÇÕES NUCLEARES - ENAN, 11 -16 agosto, 2002, Rio de Janeiro, Proceedings... CD-ROM.

[19] MANSO, M.V.; GOUVEIA, A.N.; DEPPMAN, A.; LIKHACHEV, V.P.; HELENE, O.A.M.; VANIN, V.R.; MESA, J.; ARRUDA-NETO, J.D.T.; ZAMBONI, C.B.; SAIKI, M.; NOGUEIRA, G.P.; CESTARI, A.C.; CAMARGO, S.P.; RODRIGUEZ, O.; GUZMAN, F.; GARCIA, F. Microdistribution and localized dosimetry of 238U in beagle bones. In: REUNIÃO DE TRABALHO SOBRE FÍSICA NUCLEAR NO BRASIL, 47, 1 5 setembro, 2001, Águas de Lindóia. Resumos... São Paulo. 
[20] FIGUEIREDO, A.M.G.; SAIKI, M.; ZAMBONI, C.B.; GENEZINI, F.A. Determination of Trace Elements in Wistar Rats Bone by Neutron Activation Analysis. In: REUNIÃO DE TRABALHO SOBRE FÍSICA NUCLEAR NO BRASIL, 52, 1-5 setembro, 2001, Águas de Lindóia. Resumos... São Paulo.

[21] OLIVEIRA, L.C., ZAMBONI, C.B.; FIGUEIREDO, A.M.G.; CESTARI, A.C.; ARRUDA-NETO, J.D.T. Nuclear Methodology to Perform Clinical Examination of Urine. ALASBIMN Journal (Online), v. 14, p. 4.13, 2002.

[22] ZAMBONI, C.B.; FIGUEIREDO, A.M.G.; SAIKI, M.; CESTARI, A.C.; GUEVARA, M.V.M.; ARRUDA NETO, J.D.T. Uranium incorporation investigation in Wistar rats bone. In: ENCONTRO NACIONAL DE APLICAÇÕES NUCLEARES - ENAN, outubro 15-20, 2000, Rio de Janeiro. Proceedings... Rio de Janeiro. CD-ROM.

[23] ZAMBONI, C.B.; MEDEIROS, I.M.M.A.; GENEZINI, F.A.; CESTARI, A.C.; ARRUDA NETO, J.D.T. Nuclear methodology to study kidney anomalies. ENCONTRO NACIONAL DE APLICAÇÕES NUCLEARES - ENAN, outubro 15-20, 2000, Rio de Janeiro. Proceedings... Rio de Janeiro. CD-ROM.

[24] ZAMBONI, C.B.; ZAHN, G.S.; SANT'ANNA, O.A. Trace elements at whole blood of distinct mouse lines by using NAA. AIP. v. 884, p. 507-509, 2007.

[25] ZAMBONI, C.B.; OLIVEIRA, L.C.; DALAQUA JR, L.; MESA, J. An application of Absolute Neutron Activation Analysis to bone samples. J. Radioanal. Nucl. Chem., v. 269, n. 2, p. 331-334, 2006.

[26] OLIVEIRA, L.C.; ZAMBONI, C.B.; GENEZINI, F.A.; FIGUEIREDO, A.M.G.; ZAHN, G.S. Use of Thermal Neutrons to Perform Clinical Analyses in Blood and Urine Samples. J. Radioanal. Nucl. Chem., v. 263, n. 3, p. 783-786, 2005.

[27] OLIVEIRA, L.C.; ZAMBONI, C.B.; ZAHN, G.S.; RAELE, M.P.; MASCHIO, M.A. Use of Thermal Neutrons to Perform Analyses in Body Organs of Small Sized Animals. Braz. J. Phys., v. 34, n. 3A, p. 811-813, 2004.

[28] SANTOS, N.F.; VILELA, E.C.; ZAMBONI, C.B.; KOVACS, L. Quantification of calcium and phosphorus in whole blood of pacients submitted to dialysis using nuclear methodology. Fisioterapia Brasil, supl. SPQV, p. 42-42, 2006.

[29] OLIVEIRA, L.C.; ZAMBONI, C.B.; LINS, P.S.; AZEVEDO, M.R.A. The Chlorine Reference Value in Blood using ANAA. Braz. J. Phys., v. 35, n. 3B, p. 793-796, 2005.

[30] OLIVEIRA, L.C.; ZAMBONI, C.B.; MESA, J. Quantitative estimation of Br, Cl, K and $\mathrm{Na}$ in sample blood by NAA. J. Radioanal. Nucl. Chem., v. 269, n. 3, p. 541-545, 2006. 
[31] LINS, P.S. Padronização de metodologia nuclear para determinação da concentração de ferro em amostras de sangue total. 2004. Dissertação (Mestrado) - Universidade de Santo Amaro, São Paulo.

[32] ZAMBONI, C.B.; KOVACS, L.; AZEVEDO, M.R.A.; LINS, P.S.; SANTOS, N.F. Avaliação bioquímica de ferro usando procedimento nuclear: novo enfoque para o estudo de anemias. Revista Brasileira de Hematologia e Hemoterapia, v. 28, supl. 2, p. 3-3, 2006.

[33] KOVACS, L. Utilização de metodologia nuclear para quantificação de Cloro, Potássio e Sódio em soro humano. 2007. Dissertação (Mestrado) - Universidade de Santo Amaro, São Paulo.

[34] SCHMIDT-NIELSEN, K. Fisiologia animal: adaptação e meio ambiente. Ed.Santos, São Paulo, 1996.

[35] FIRESTONE, R.B. Table of Isotopes. 8 Ed. New York, N.Y., Wiley, 1996.

[36] REUS, U.; WESTMEIER, W. Catalog of gamma rays from radioactive decay Part 1. Atomic Data and Nuclear Data Tables. Germany, v. 29, p. 1-192, 1983.

[37] KNOLL, G.F. Radiation detection and measurements. New York, N.Y.: Wiley, 1979.

[38] ZAMBONI, C.B. Fundamentos da Física de Neutrons, $1^{\text {a }}$ Ed., Ed. Livraria da Física, São Paulo, 2007.

[39] YORIYAZ, H.; FANARO, L.C.C.B.; DINIZ, R.; JEREZ, R. Methodology for evaluation and experimental measurements of parameters of the core of research reactor IEA-R1 using the Monte Carlo method. IAEA Report, Progress Report 2, 2000.

[40] MUECK, K.; BENSCH, F. Cadmium correction factors of several thermal neutron foil detectors. J. Nucl. Engl. Áustria, v. 27, p. 677-688, 1973.

[41] MUGHABGHAB, S.F; DIVADEENAM, M.; AND HOLDEN, N.E. Neutron Cross Sections from Neutron Resonance Parameters and Thermal Cross Sections. Academic Press, London, 1981.

[42] MESTNIK FILHO, J. A distribuição espacial de fluxo de nêutrons no núcleo do reator IEA-R1, obtida por meio da ativação de folhas. São Paulo, 1978. Dissertação (Mestrado em Ciência e Tecnologias Nucleares). Escola Politécnica da Universidade de São Paulo.

[43] GOUFFON, P. Manual do programa Idefix. Universidade de São Paulo, Instituto de Física, Laboratório do Acelerador Linear, São Paulo, 1987. 
[44] INTERNATIONNAL ATOMIC ENERGY AGENCY. X-Ray and Gamma-Ray Standards for detector calibration. (IAEA - TECDOC - 619), Viena, 1991.

[45] MEDEIROS, J.A.G.; ZAMBONI, C.B.; ZAHN, G.S.; OLIVEIRA, L.C.; DALAQUA JR., L. Software para realização de análises hematológicas utilizando processo radioanalítico. In: $39^{\circ}$ Congresso Brasileiro de Patologia Clinica / Medicina Laboratorial, 2005, São Paulo. Anais... São Paulo: 39 CBPC/ML, 2005.

[46] JOHNSON, R.A.; WICHERN, D.W. Applied Multivariate Statistical Analysis. Fifth Edition, Prentice Hall, 2001.

[47] BESTEMAN, A.D.; BRYAN, G.K.; LAU, N.; WINEFORDNER, J.D. Multielement Analysis of Whole Blood Using a Capacitively Coupled Microwave Plasma Atomic Emission Spectrometer. Microchemical Journal, v. 61, n. 3, p. 240-246, 1999.

[48] RODUSHKIN, I.; ODMAN, F.; OLOFSSON, R.; AXELSSON, M.D. Determination of 60 elements in whole blood by sector field inductively coupled plasma mass spectrometry. J. Anal. At. Spectrom., v. 15, p. 937-944, 2000.

[49] RODUSHKIN, I.; ODMAN, F.; BRANTH, S. Multielement analysis of whole blood by high resolution inductively coupled plasma mass spectrometry. Fresenius J. Anal. Chem., v. 364, p. 338-346, 1999.

[50] IYENGAR V.; WOITTIEZ, J. Trace elements in human clinical specimens: evaluation of literature data to identify reference values. Clin. Chem., v. 34, n. 3, p. 474481, 1988.

[51] KOVACS, L.; ZAMBONI, C.B.; OLIVEIRA, L.C.; SALVADOR, L.R.; SATO, I.M.; AZEVEDO, M.R.A. Analysis of serum and whole blood using NAA and EDXRF techniques for clinical investigation. In: Modern Trends of Activation Analysis MTAA12, 16 - 21 setembro, 2007, Japão. Proceedings...

[52] BURTIS, C.A.; ASHWOOD, E.R. Tietz - Fundamentos de Química Clínica, $4^{\mathrm{a}}$ ed., Rio de Janeiro: Guanabara Koogan, 1998. 